INSTITUTO DE PESQUISAS ENERGÉTICAS E NUCLEARES

Autarquia associada à Universidade de São Paulo

INCORPORAÇÃO E LIBERAÇÃO DE RESVERATROL EM HIDROGÉIS POLIMÉRICOS

ROBERTA GRAZZIELLI RAMOS ALVES PASSARELLI MOMESSO

Dissertação apresentada como parte dos requisitos para obtenção do Grau de Mestre em Ciências na Área de Tecnologia Nuclear - Materiais.

Orientador:

Dr. Ademar Benévolo Lugão

SÃO PAULO 
Dedico este trabalho aos meus pais, Miriam e José Antonio. 


\section{AGRADECIMENTOS}

A Deus.

Ao Dr. Ademar Benévolo Lugão por dividir seus conhecimentos e seu precioso tempo. Obrigada por todo apoio e suporte em todos os momentos que precisei.

Ao Dr. José Roberto Rogero pela grande contribuição a este trabalho, sugestões e apoio.

Ao Dr. Patrick J. Spencer, obrigada por me ajudar e ensinar em todos os momentos que precisei, pela confiança, suporte e orientação na parte cromatográfica do trabalho.

À Msc. Sizue Ota Rogero por toda ajuda, apoio, carinho e incentivo desde que entrei no IPEN.

À Elizabeth S. R. Somessari e Carlos G. da Silveira do Centro de Tecnologia das Radiações (CTR-IPEN), obrigada pela irradiação das amostras, pelo carinho e atenção.

Ao Instituto Adolfo Lutz e Dra. Áurea S. Cruz pelo fornecimento das microplacas.

À querida Dra. Nilce Ortiz por estar sempre disposta a me ajudar e ensinar. Obrigada pela confiança, carinho e atenção.

À querida Dra. Luci Diva Machado, obrigada pelo apoio, carinho, atenção e disposição em me ajudar.

À Dra. Célia Marina Napolitano pela gentileza em disponibilizar seu tempo para me ensinar. 
Ao Johny e José Maria do Centro de Biotecnologia (CB-IPEN), obrigada pelo enorme apoio e atenção.

À Jacinete e Dra. Maria Claudia pela ajuda na fase inicial deste trabalho.

Aos queridos amigos Renata, Lígia, Mara e Sousa que estiveram ao meu lado desde que entrei no IPEN, obrigada pela amizade, apoio, ajuda e incentivo em todos os momentos.

Às queridas amigas Carol e Mari pelo companheirismo, por toda ajuda, apoio e principalmente pelo carinho e amizade.

Aos queridos colegas do IPEN: Raquel, Sirlene, Gislaine, Juliane, Sandra, Maria José e Beth pelo carinho, incentivo e apoio.

Ao Daniel T. Lebre do Centro de Espectrometria de Massa Aplicada (CEMSA) pela gentileza em disponibilizar seu tempo para me ajudar na interpretação de dados.

Aos amigos do Centro de Biotecnologia (CB-IPEN): Karina, Rodrigo e Rosa por toda ajuda e amizade durante todo o tempo que passei no CB.

Às queridas Gislene Madeira e Ilze Puglia pelo enorme apoio e suporte em todos os momentos que precisei. Obrigada pela disposição em me ajudar, pelo carinho, atenção e amizade.

Aos meus pais que além da vida me deram todo o carinho, amor, base e estrutura. Enfim, sempre me deram muito mais do que precisei. Obrigada por todo incentivo, apoio, amor e dedicação!

Aos meus queridos irmãos: Mairim, Junior e Alemão que me apoiaram e entenderam minha ausência em muitos momentos. 
Ao Frê que é a minha maior felicidade e que me proporciona grandes alegrias.

Ao Gerson que esteve ao meu lado em todos os momentos, obrigada por seu amor, carinho, paciência e companheirismo.

Às queridas amigas do CPC (IIEP-Einstein) que me proporcionaram momentos de muita alegria e que sempre me deram força, apoio e torceram pelo meu crescimento profissional. 


\title{
INCORPORAÇÃO E LIBERAÇÃO DE RESVERATROL EM HIDROGÉIS POLIMÉRICOS
}

\author{
Roberta Grazzielli Ramos Alves Passarelli Momesso
}

RESUMO

Resveratrol (3, 4', 5-trihidroxiestilbeno) é um polifenol produzido por uma grande variedade de plantas em resposta ao estresse e encontrado predominantemente em cascas de uvas. Este princípio ativo apresenta vários benefícios à saúde, como a capacidade antioxidante, relacionada à prevenção de diversos tipos de câncer e do envelhecimento precoce da pele. No entanto, apresenta baixa biodisponibilidade quando administrado por via oral, o que torna interessante sua aplicação tópica. O principal objetivo deste trabalho foi a incorporação de resveratrol em hidrogéis poliméricos para obtenção de um sistema de liberação utilizado topicamente contra o desenvolvimento de desordens cutâneas, como o envelhecimento cutâneo e o câncer de pele. As matrizes poliméricas compostas por poli( $N$-vinil-2-pirrolidona) (PVP), poli(etileno glicol) (PEG) e ágar ou PVP e propano-1,2,3-triol (glicerina) e irradiadas a 20 kGy foram caracterizadas pelos ensaios de fração gel e intumescimento; sua biocompatibilidade preliminar foi avaliada in vitro por meio do ensaio de citotoxicidade utilizando o método de incorporação do vermelho neutro. Devido à baixa solubilidade do resveratrol em água, verificou-se o efeito da adição de $2 \%$ de etanol às matrizes. Todas as matrizes estudadas, contendo ou não álcool, apresentaram alto grau de reticulação, capacidade de intumescimento e não apresentaram toxicidade em ensaio preliminar de biocompatibilidade. Os dispositivos foram obtidos pela incorporação de resveratrol nas matrizes poliméricas, realizada de forma direta e indireta, ou seja, antes e após irradiação, respectivamente. Os dispositivos obtidos pelo método direto foram submetidos aos ensaios de fração gel, intumescimento e citotoxicidade e apresentaram-se semelhantes às respectivas matrizes. Os dispositivos contendo $0,05 \%$ de resveratrol obtidos pelo método direto e os dispositivos contendo $0,1 \%$ de resveratrol obtidos pelo método indireto foram submetidos ao ensaio de cinética de liberação durante $24 \mathrm{~h}$. A quantificação do resveratrol liberado foi realizada por cromatografia líquida de alta eficiência (HPLC). Apenas os dispositivos obtidos pelo método indireto apresentaram capacidade de liberar o resveratrol incorporado, que apresentou capacidade antioxidante após liberação. 


\title{
RESVERATROL IMMOBILIZATION AND RELEASE IN POLYMERIC HYDROGELS
}

\author{
Roberta Grazzielli Ramos Alves Passarelli Momesso
}

\begin{abstract}
Resveratrol (3, 4', 5-trihydroxystilbene) is a polyphenolic produced by a wide variety of plants in response to injury and found predominantly in grape skins. This active ingredient has been shown to possess benefits for the health, such as the antioxidant capacity which is related to the prevention of several types of cancer and skin aging. However, the oral bioavailability of resveratrol is poor and makes its topical application interesting. The purpose of this study was to immobilize resveratrol in polymeric hydrogels to obtain a release device for topical use. The polymeric matrices composed of poli( $N$-vinyl-2-pyrrolidone) (PVP), poly(ethyleneglycol) (PEG) and agar or PVP and glycerol irradiated at 20 kGy dose were physical-chemically characterized by gel fraction and swelling tests and its preliminary biocompatibility by in vitro test of cytotoxicity using the technique of neutral red uptake. Due to low solubility of resveratrol in water, the addition of $2 \%$ ethanol to the matrices was verified. All matrices showed a high crosslinking degree, capacity of swelling and the preliminary cytotoxicity test showed nontoxicity effect. The devices were obtained by resveratrol immobilizaton in polymeric matrices, carried out in a one-or-two-steps process, that is, before or after irradiation, respectively. The one step resveratrol devices were characterized by gel fraction, swelling tests and preliminary biocompatibility, and their properties were maintained even after the resveratrol incorporation. The devices containing $0,05 \%$ of resveratrol obtained by one-step process and $0,1 \%$ of resveratrol obtained by two-steps process were submitted to the release test during $24 \mathrm{~h}$. Resveratrol quantification was done by high performance liquid chromatography (HPLC). The results obtained in the kinetics of release showed that only the devices obtained by two-step process release the resveratrol, which demonstrate antioxidant capacity after the release.
\end{abstract}




\section{SUMÁRIO}

Página

1 INTRODUÇÃO

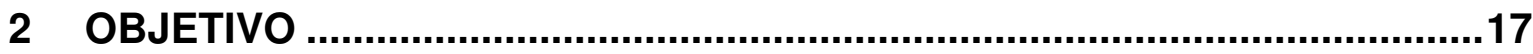

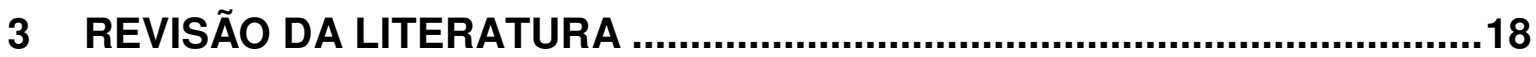

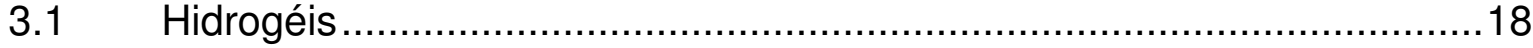

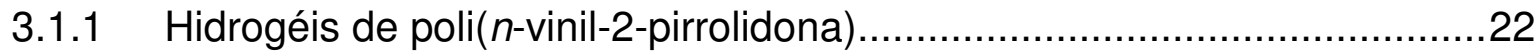

3.2 Interação da radiação ionizante com a matéria e a ação sobre polímeros ..

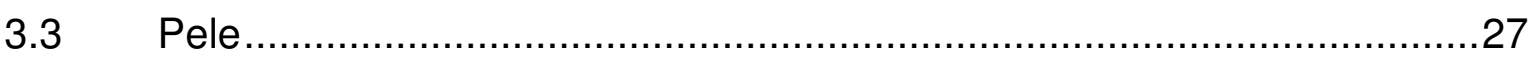

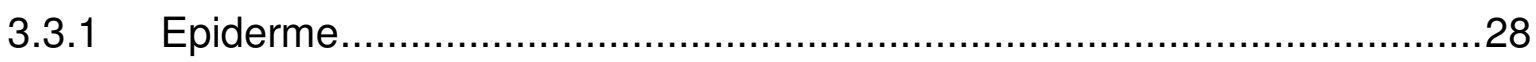

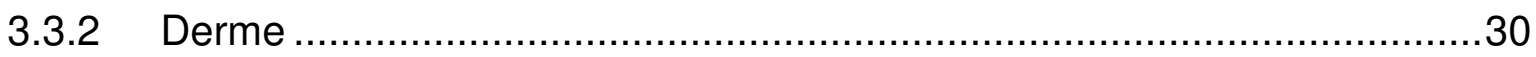

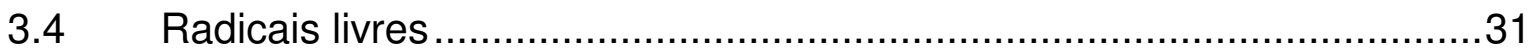

3.4.1 Espécies reativas de oxigênio........................................................33

3.4.2 Desordens cutâneas provenientes da ação de radicais livres: o envelhecimento cutâneo precoce e o câncer de pele ..........................................34

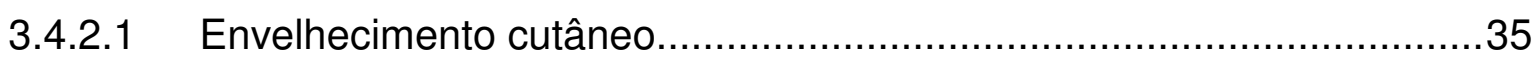

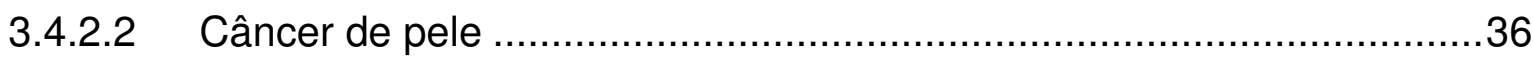

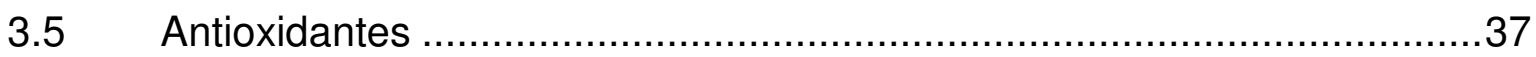

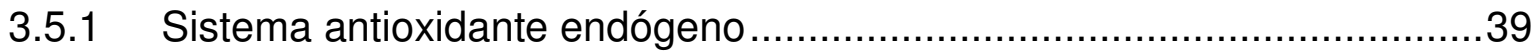

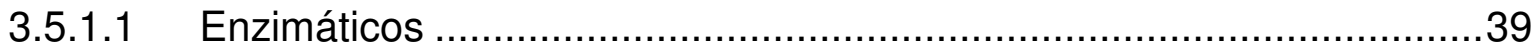

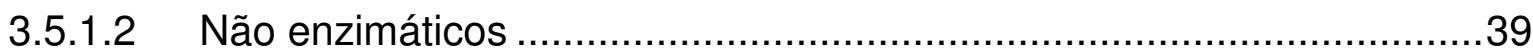

3.5.2 Sistemas antioxidantes exógenos .................................................... 40

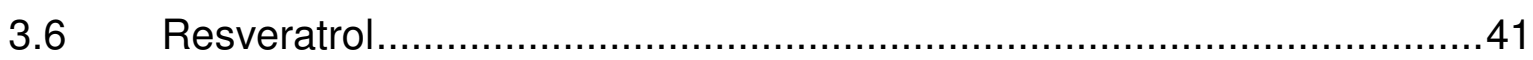

3.6.1 Propriedades e aplicações do resveratrol ............................................4

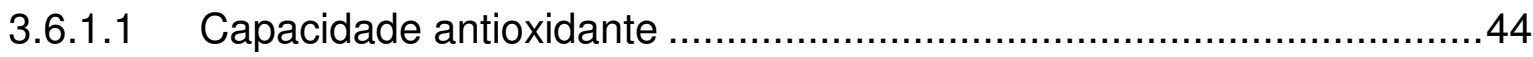

3.6.1.2 Capacidade anticancerígena …………........................................... 45

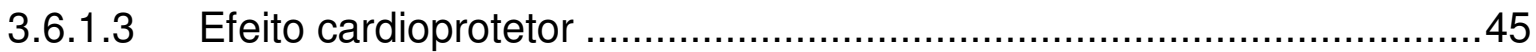

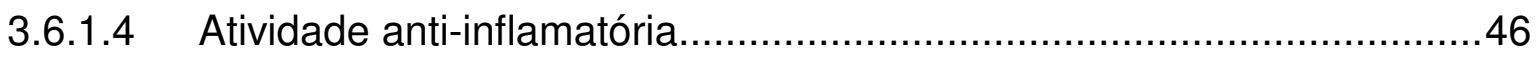

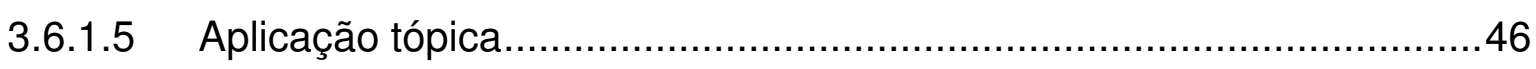

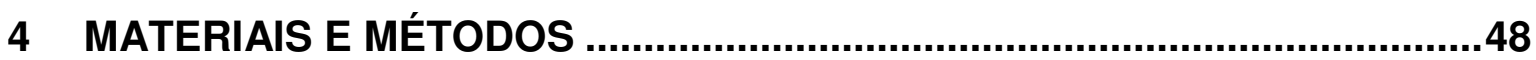

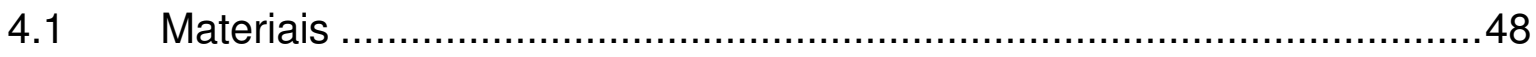

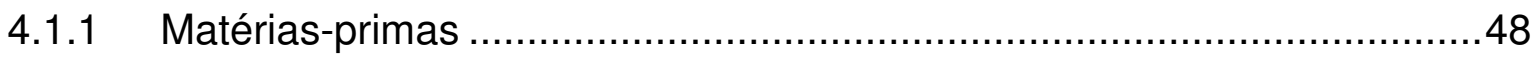




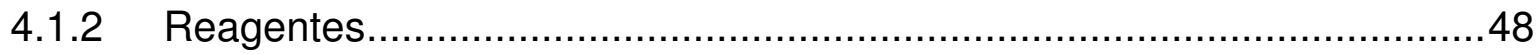

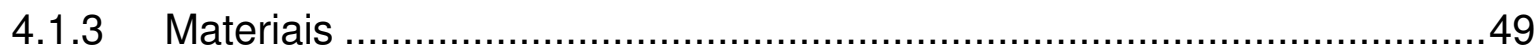

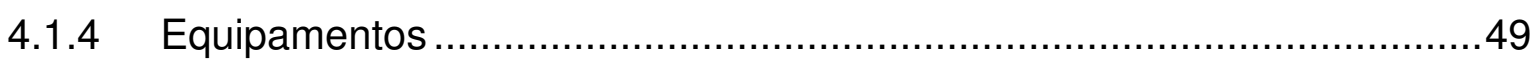

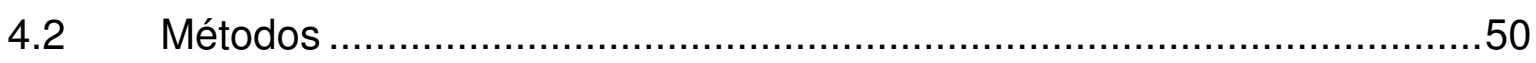

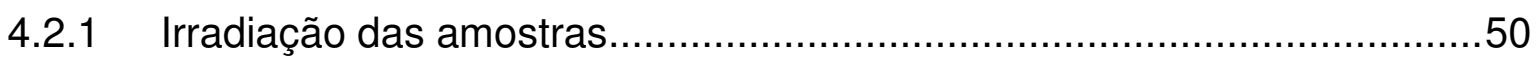

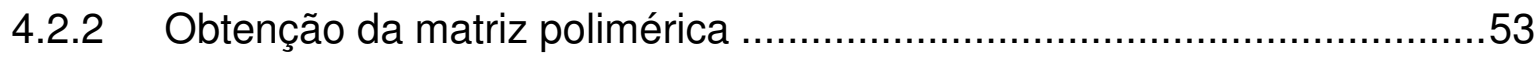

4.2.3 Caracterização da matriz de hidrogel..................................................55

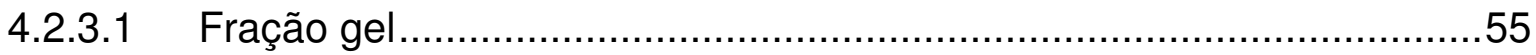

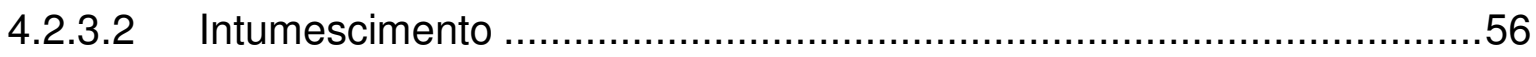

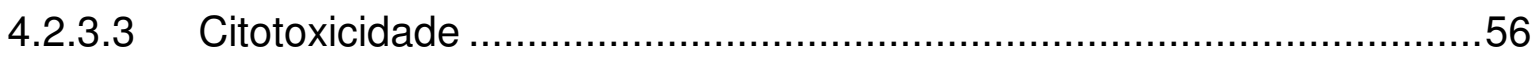

4.2.4 Quantificação do resveratrol por cromatografia líquida de alta eficiência

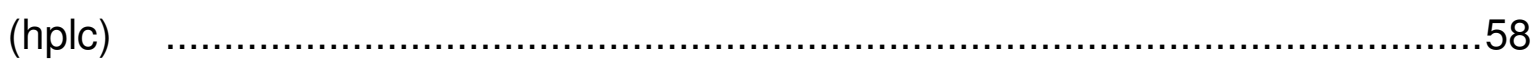

4.2.5 Estudo do efeito da radiação no resveratrol...........................................60

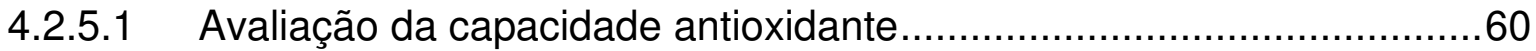

4.2.6 Avaliação do comportamento do resveratrol frente à luz ultravioleta........62

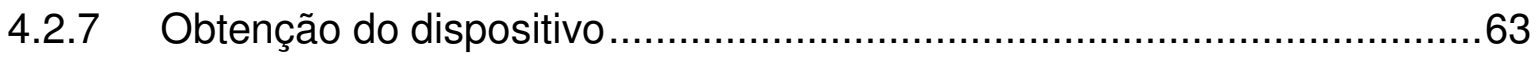

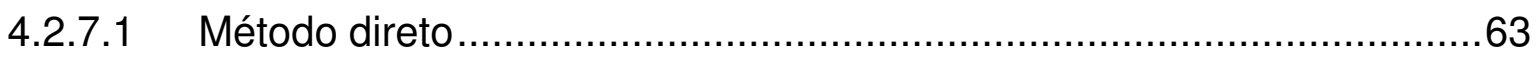

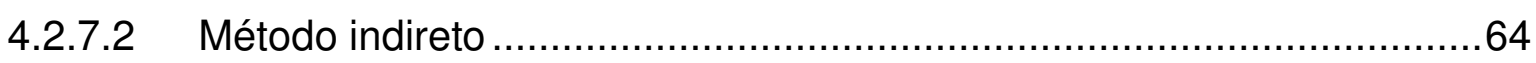

4.2.8 Cinética de liberação e doseamento do resveratrol ..................................66

4.2.8.1 Intumescimento dos dispositivos em pbs ........................................66

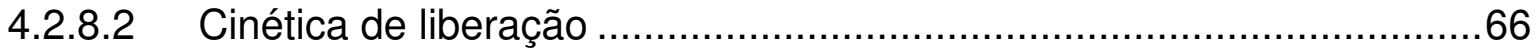

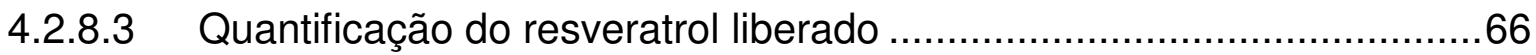

4.2.9 Avaliação da capacidade antioxidante do resveratrol liberado pelo

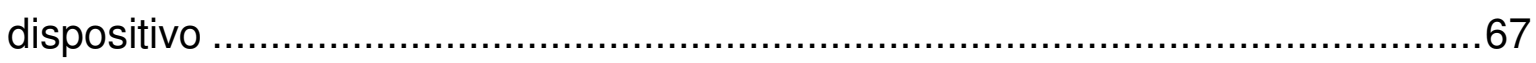

4.2.10 Análise dos dispositivos obtidos por método direto ...........................67

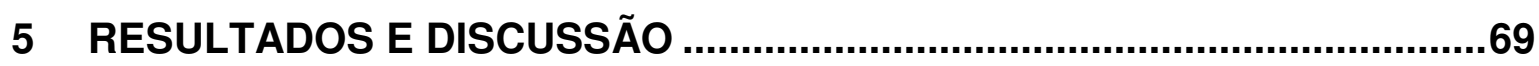

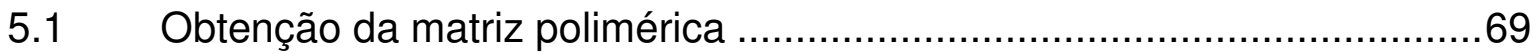

5.2 Caracterização da matriz de hidrogel...................................................69

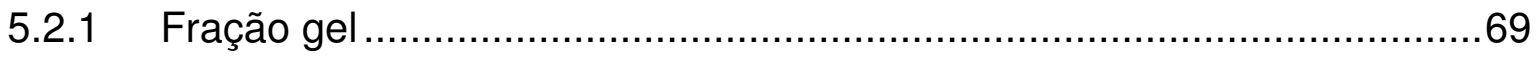

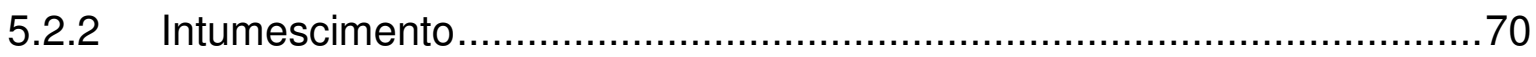

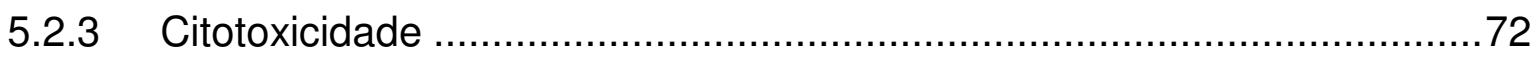

5.3 Estudo do efeito da radiação no resveratrol.........................................74

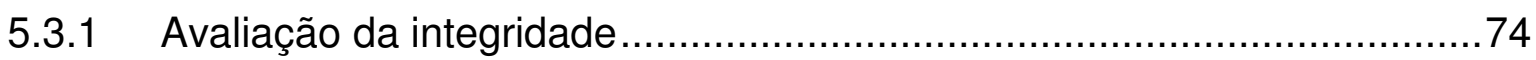

5.3.2 Avaliação da capacidade antioxidante ...............................................78 
5.4 Avaliação do comportamento do resveratrol frente à luz ultravioleta .......81

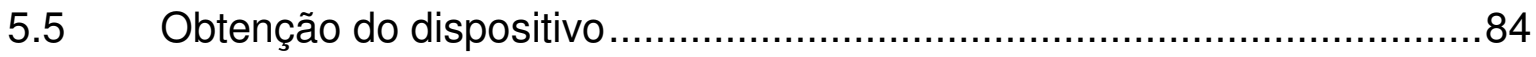

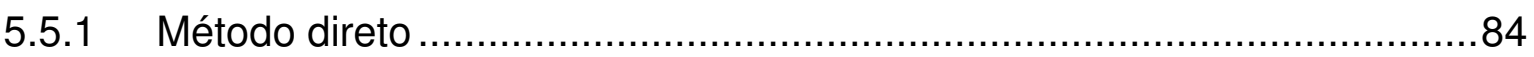

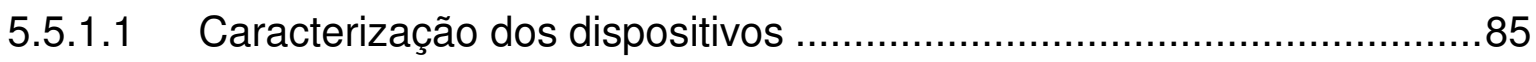

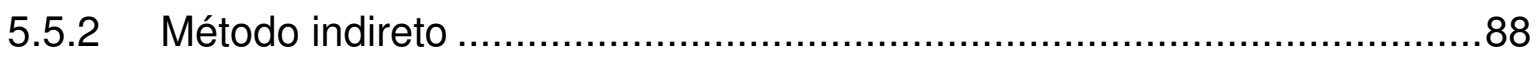

5.6 Cinética de liberação e doseamento do ativo ……………......................90

5.6.1 Intumescimento dos dispositivos em pbs............................................90

5.6.2 Quantificação do resveratrol liberado......................................................

5.6.3 Capacidade antioxidante do resveratrol liberado .....................................96

5.7 Análise dos dispositivos obtidos por método direto ...............................98

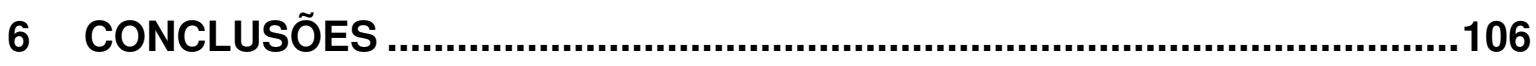

REFERÊNCIAS BIBLIOGRÁFICAS..............................................................107 


\section{LISTA DE FIGURAS}

Página

FIGURA 1 - Formação do radical polimérico 19

FIGURA 2 - Variações de concentração de princípios ativos administrados por (a) métodos tradicionais e (b) sistemas de liberação controlada. .21

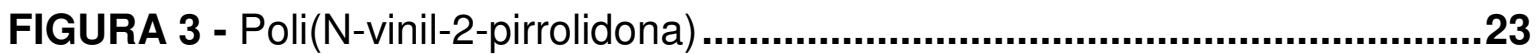

FIGURA 4 - Cisão da cadeia molecular ............................................................26

FIGURA 5 - Formação de ligações cruzadas entre as cadeias poliméricas .........27

FIGURA 6 - Camadas da pele .........................................................................28

FIGURA 7 - Produtos formados pela da radiólise da água e seus respectivos

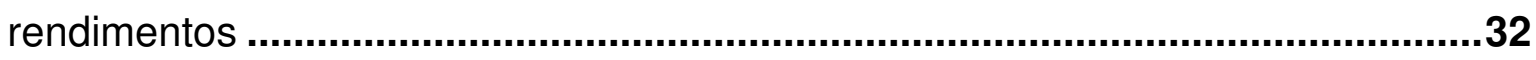

FIGURA 8 - Formação de ERO ..........................................................................33

FIGURA 9 - Biosíntese do resveratrol.............................................................41

FIGURA 10 - Estrutura química da forma glicosídica de resveratrol......................42

FIGURA 11 - Metabólitos de resveratrol: (a) sulfato e (b) glicuronídeo .................43

FIGURA 12 - Irradiador de Cobalto-60 do tipo gammacell ...................................51

FIGURA 13 - Suporte contendo fontes de Cobalto-60 ..........................................51

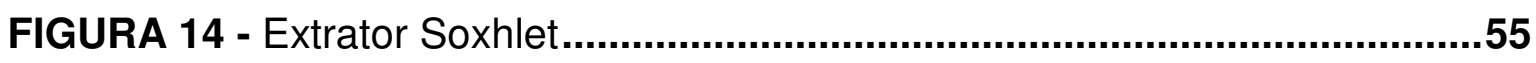

FIGURA 15 - Esquema da distribuição dos extratos das amostras e controle na

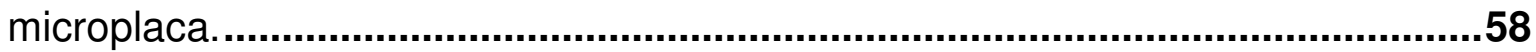

FIGURA 16 - Sistema de cromatografia líquida de alta eficiência .........................59

FIGURA 17 - Matrizes poliméricas: (a) PVP-PEG-OH e (b) PVP-GLI-OH.............69

FIGURA 18 - Curvas de intumescimento dos hidrogéis.......................................72

FIGURA 19 - Curvas de viabilidade celular dos hidrogéis de PVP-PEG e PVP-GLI no ensaio de citotoxicidade ......................................................................74

FIGURA 20 - Cromatograma da solução de resveratrol não irradiada ...................75

FIGURA 21 - Cromatograma da solução de resveratrol irradiada a 20 kGy ..........76

FIGURA 22 - Espectro de massas da solução de resveratrol não irradiada .........77

FIGURA 23 - Espectros de massas da solução de resveratrol irradiada a 20 kGy

FIGURA 24 - Curva de degradação do DPPH exposto a luz do espectrofotômetro 
FIGURA 25 - Cinética de DPPH das soluções de resveratrol não irradiadas ou irradiada a 20 kGy

FIGURA 26 - Cromatograma do resveratrol não exposto à luz ultravioleta 82

FIGURA 27 - Cromatograma do resveratrol exposto à luz ultravioleta 82

FIGURA 28 - Espectro de absorção da solução de resveratrol antes (trans) e após (cis) exposição à luz ultravioleta .83

FIGURA 29 - Dispositivo PVP-RES 0,05 .84

FIGURA 30 - Dispositivo GLI-RES 0,05. .85

FIGURA 31 - Dispositivo PVP-RES 0,1 .85

FIGURA 32 - Perfil de intumescimento dos dispositivos GLI-RES 0,05 e PVP-RES 0,05

FIGURA 33 - Curvas de viabilidade celular dos dispositivos PVP-RES 0,05 e GLIRES 0,05 no ensaio de citotoxicidade.

FIGURA 34 - Perfil de intumescimento em álcool etílico dos hidrogéis de PVPPEG e PVP-GLI

FIGURA 35 - Perfil de intumescimento dos dispositivos de GLI-RES 0,05 e PVPRES 0,05 em PBS.

FIGURA 36 - Cromatograma da liberação da membrana controle PVP-GLI após 1 hora.

FIGURA 37 - Cromatograma da liberação da membrana controle PVP-PEG após 1 hora. .92

FIGURA 38 - Cromatograma da liberação de resveratrol do dispositivo PVP-PEGRES após 24 horas

FIGURA 39 - Cromatograma da liberação de resveratrol do dispositivo PVP-GLIRES após 24 horas .94

FIGURA 40 - Perfil de liberação do resveratrol do dispositivo PVP-PEG-RES .....95

FIGURA 41 - Perfil de liberação do resveratrol do dispositivo PVP-GLI-RES.......96 FIGURA 42 - Micrografia obtida por MEV: Presença de resveratrol no dispositivo GLI-RES 0,05 antes de ser submetido ao ensaio de liberação. 98

FIGURA 43 - Micrografia obtida por MEV: Presença de resveratrol no dispositivo PVP-RES 0,05 antes de ser submetido ao ensaio de liberação

FIGURA 44 - Micrografia obtida por MEV: Dispositivo GLI-RES 0,05 após ser submetido ao ensaio de liberação. 
FIGURA 45 - Micrografia obtida por MEV: Dispositivo PVP-RES 0,05 após ser submetido ao ensaio de liberação. 100

FIGURA 46 - Micrografia obtida por MEV: Presença de cavidade no dispositivo GLI-RES 0,05 após ser submetido ao ensaio de liberação. 101

FIGURA 47 - Micrografia obtida por MEV: Presença de cavidade no dispositivo PVP-RES 0,05 após ser submetido ao ensaio de liberação 101

FIGURA 48 - Espectros de massas da alíquota coletada do dispositivo GLI-RES 0,05 102

FIGURA 49 - Espectros de massas da alíquota coletada do dispositivo PVP-RES 0,05 103

FIGURA 50 - Espectro de massas da solução de resveratrol irradiada a 600 Gy .104 


\section{LISTA DE TABELAS}

Página

TABELA 1 - Composição das matrizes poliméricas ……………..........................54

TABELA 2 - Concentrações de DPPH• para construção da curva padrão............61

TABELA 3 - Composição do dispositivo obtido pelo método direto........................64

TABELA 4 - Resultados dos ensaios de fração gel das matrizes de hidrogel......70

TABELA 5 - Resultados de intumescimento das matrizes de hidrogel..................71

TABELA 6 - Resultados da viabilidade celular do ensaio de citotoxicidade dos hidrogéis PVP-PEG e PVP-GLI......................................................................73

TABELA 7 - Tempos de retenção e áreas dos picos das soluções de resveratrol não irradiada e irradiada a $20 \mathrm{kGy}$ .75

TABELA 8 - Valores de absorbância da solução padrão de DPPH exposta à luz do espectrofotômetro .79

TABELA 9 - Resultados de porcentagem de DPPH remanescente para as soluções de resveratrol a 0 e $20 \mathrm{kGy}$

TABELA 10 - Resultados dos ensaios de fração gel dos dispositivos.....................86

TABELA 11 - Resultados de intumescimento dos dispositivos 86

TABELA 12 - Resultados da viabilidade celular do ensaio de citotoxicidade dos dispositivos

TABELA 13 - Resultados de intumescimento das matrizes de hidrogel em álcool etílico.

TABELA 14 - Resultados de intumescimento dos dispositivos GLI-RES 0,05 e PVP-RES 0,05 em PBS

TABELA 15 - Resultados do ensaio da cinética de liberação do resveratrol dos dispositivos obtidos por método indireto

TABELA 16 - Resultados de DPPH remanescente para o resveratrol liberado dos dispositivos PVP-PEG-RES e PVP-GLI-RES. 


\section{INTRODUÇÃO}

Resveratrol (3, 4', 5'-trihidroxiestilbeno) é um polifenol presente em mais de 70 espécies de plantas e sintetizado em resposta ao estresse causado por estímulos exógenos, como a radiação ultravioleta, dano mecânico e ataque por fungos patogênicos (Frémont, 2000).

A atividade ant-iinflamatória, antioxidante e a inibição da agregação plaquetária são alguns dos efeitos biológicos benéficos apresentados pelo resveratrol. A capacidade antioxidante recebe destaque por estar relacionada a uma série de propriedades farmacológicas, medicinais e terapêuticas, como a prevenção e diminuição da progressão de doenças cardiovasculares, diversos tipos de câncer e do envelhecimento precoce da pele (Frémont, 2000).

Apesar de diversos estudos demonstrarem a potente eficácia de resveratrol in vitro, tendo em vista sua baixa biodisponibilidade por via oral, a aplicação tópica aparece como uma alternativa e tem sido muito estudada, pois a base escolhida para incorporação do princípio ativo e formação do sistema de liberação deve proporcionar velocidade de liberação, propriedades de adesão após aplicação e textura ideais (Walle et al., 2004; Boocock et al., 2007; Allen Junior et al., 2007).

Os hidrogéis poliméricos são materiais formados por redes de polímeros hidrofílicos, que possuem configuração tridimensional e capacidade de absorver elevada quantidade de água sem se dissolver ou perder sua forma. $\mathrm{O}$ interesse pelos hidrogéis na composição de sistemas de liberação de fármacos para aplicação tópica se baseia em suas características que, entre outras, podem ser destacadas a biocompatibilidade, elevado conteúdo de água, consistência macia e elástica, boa adesão à pele e capacidade de incorporação e liberação de diversos princípios ativos (Hamidi et al., 2008; Rosiak, 1991).

Rosiak e colaboradores (1989) desenvolveram um curativo de hidrogel para área de queimados comercializado na Europa como Aqua-Ge ${ }^{\circledast}$, composto por poli( $N$-vinil-2-pirrolidona) (PVP), poli(etileno glicol) (PEG) e ágar e reticulado a partir da irradiação da solução aquosa do polímero. No início de 1990, esta tecnologia foi transferida ao Instituto de Pesquisas Energéticas e Nucleares (IPEN) pelo Prof. Dr. Janus A. Rosiak como colaborador da Agência Internacional de Energia Atômica (AIEA) e resultou no desenvolvimento do Bandgel ${ }^{\circledR}$ para área 
de queimados. No entanto, por apresentar características adequadas para aplicação tópica como boa adesão à pele e facilidade de aplicação e por possibilitar a incorporação de diferentes princípios ativos este hidrogel começou a ser utilizado como matriz polimérica para compor sistemas de liberação de fármacos para aplicação tópica.

A capacidade antioxidante e a baixa biodisponibilidade por via oral apresentada pelo resveratrol, associadas às boas características do Bandgel ${ }^{\circledR}$ para aplicação tópica, tornaram relevante o estudo da incorporação e liberação do resveratrol nesse tipo de hidrogel para obtenção de um sistema de liberação utilizado topicamente contra o desenvolvimento de desordens cutâneas como o envelhecimento precoce e o câncer de pele. 


\section{OBJETIVO}

O objetivo deste trabalho foi incorporar resveratrol em matrizes de hidrogel de poli( $N$-vinil-pirrolidona) (PVP) esterilizadas e reticuladas por radiação, obtendo dispositivos para liberação de resveratrol. Para que o objetivo proposto fosse alcançado, foram realizadas as metas seguintes:

- Desenvolvimento de matriz polimérica de hidrogel de PVP para incorporação de resveratrol a partir da tecnologia Bandgel $^{\circledR}$, desenvolvida no IPEN;

- Caracterização físico-química do hidrogel e dispositivo;

- Avaliação da biocompatibildade do hidrogel e dispositivo;

- Estudo do comportamento do resveratrol frente à radiação e sua capacidade antioxidante antes e após irradiação;

- Avaliação da incorporação do resveratrol na matriz polimérica;

- Estudo in vitro da cinética de liberação do princípio ativo e capacidade antioxidante após liberação. 


\section{REVISÃO DA LITERATURA}

\subsection{Hidrogéis}

Hidrogéis poliméricos são materiais formados por redes de polímeros hidrofílicos, que possuem configuração tridimensional e capacidade de absorver elevada quantidade de água sem se dissolver ou perder sua forma (Hamidi et al., 2008; Rosiak, 1991).

A habilidade em absorver água pode ser atribuída à presença de grupos hidrofílicos como $-\mathrm{OH},-\mathrm{COOH},-\mathrm{CONH}$ (Satish et al., 2006). A insolubilidade e estabilidade de sua forma em água ocorrem pela presença de ligações cruzadas entre as moléculas do polímero, formando a rede tridimensional (Rosiak, 1991).

De maneira geral, os hidrogéis podem ser divididos em físicos ou químicos (Hamidi et al., 2008; Rosiak \& Ulansli, 1999).

Os hidrogéis físicos, também conhecidos como pseudogéis, são formados por interações físicas entre as cadeias poliméricas, por meio de forças eletrostáticas, formação de ligações de hidrogênio e entrelaçamento das cadeias. Estes hidrogéis podem ser convertidos em soluções poliméricas quando submetidos ao aquecimento (Rosiak \& Ulansli, 1999).

Os hidrogéis químicos ou permanentes são formados por ligações covalentes entre as cadeias, que podem ser obtidas por irradiação ou reações químicas com grupos complementares como aldeídos (Hamidi et al., 2008).

A obtenção de hidrogéis por processos químicos requer a utilização de substâncias, em sua maioria, tóxicas, tais como, monômeros, iniciadores ou aditivos. Estas substâncias precisam ser extraídas do produto final quando o mesmo destina-se a aplicações biomédicas ou farmacêuticas, uma vez que os requisitos específicos para que um material seja utilizado em contato com organismos vivos são funcionalidade, capacidade de ser esterilizado e biocompatibilidade (Rosiak et al., 1995).

Desta forma, a utilização da radiação para obtenção de hidrogéis apresenta vantagens (Rosiak et al., 1995; Satish et al., 2006):

- Reticulação e esterilização simultâneas; 
- Ausência de aditivos: obtenção de hidrogéis não contaminados com resíduos de iniciadores tóxicos;

- Facilidade no controle do processo e possibilidade de adequar propriedades físicas e químicas.

A interação direta da radiação com o polímero resulta na formação de radicais poliméricos, como apresentado na FIG. 1. Quando a irradiação acontece em solução aquosa, a radiólise do solvente produz espécies reativas, como radicais hidroxila, que abstraem átomos de hidrogênio das moléculas poliméricas, também formando macrorradicais (FIG. 1) (Rosiak \& Ulanski, 1999).

A reticulação de hidrogéis por meio da radiação ionizante é resultado da recombinação mútua destes macrorradicais formados na cadeia polimérica, resultando na formação de ligações covalentes inter e intramoleculares, originando a rede polimérica (Rosiak \& Ulanski, 1999; Satish et al., 2006).

\section{Direto}

$$
\begin{aligned}
& \gamma, e^{-} \\
& P \underset{P}{P} P^{*} \\
& \mathrm{P}^{*}+\mathrm{P}^{\bullet} \rightarrow \mathrm{P}-\mathrm{P} \\
& \text { (formação do radical) } \\
& \text { (reticulação) } \\
& \mathrm{H}_{2} \mathrm{O} \quad \frac{\gamma, e^{-}}{} \cdot \mathrm{OH}+\mathrm{H}^{*} \\
& \cdot \mathrm{OH}+\mathrm{P} \rightarrow \mathrm{P}^{\cdot}+\mathrm{H}_{2} \mathrm{O} \\
& \mathrm{P}^{*}+\mathrm{P}^{*} \rightarrow \mathrm{P}-\mathrm{P} \\
& \text { (formação do radical) } \\
& \text { (abstração do } \mathrm{H} \text { do polímero) }
\end{aligned}
$$

FIGURA 1 - Formação do radical polimérico 
Em 1960, Wichterle e Lim sintetizaram o poli(metacrilato de 2hidroxietila), conhecido como PHEMA. O hidrogel que obtiveram deste polímero é inerte ao organismo, resistente à degradação e não é absorvido pelo corpo, o que permite sua ampla utilização biológica (Hoffman, 2002; Peppas, 1996; Rosiak, 1991).

A partir desse trabalho pioneiro, a potencialidade dos hidrogéis vem sendo muito explorada e muitos trabalhos envolvendo esses materiais publicados. Esse grande interesse pelos hidrogéis deve-se às importantes propriedades apresentadas por esses materiais (Peppas et al., 2000; Rosiak, 1991; Satish et al., 2006):

- Habilidade em absorver grandes quantidades de água sem perder sua forma;

- Biocompatibilidade quando em contato com sangue, fluidos corpóreos e tecidos biológicos;

- Facilidade de obtenção em diferentes formas;

- Consistência macia, elástica e flexibilidade, que minimiza o atrito quando em contato com tecidos;

- Permeabilidade, permitindo o fluxo de fluidos corpóreos pelo material;

- Possibilidade de incorporação e liberação de princípios ativos.

Atualmente, mais de quarenta anos de pesquisa nesta área, resultou em um grande número de produtos comerciais e na ampla utilização e aplicabilidade dos hidrogéis (Rosiak \& Ulanski, 1999). O desenvolvimento de hidrogéis como curativos ou sistemas de liberação de drogas para aplicação tópica na prevenção e tratamento de desordens da pele são exemplos de aplicações biológicas dos hidrogéis.

Neste tipo de dispositivo, o ingrediente ativo é liberado de forma controlada e contínua mantendo a concentração em níveis desejáveis por longos 
períodos, sem alcançar níveis tóxicos ou ficar abaixo do nível mínimo efetivo, diferente do que acontece em métodos tradicionais, onde os níveis plasmáticos do ingrediente ativo podem estar acima do máximo desejado e abaixo do terapêutico, como pode ser observado na FIG. 2 (Allen Junior et al., 2007; Heller, 1996).

Além de proporcionar liberação controlada e contínua do princípio ativo, os sistemas de liberação controlada apresentam outras vantagens como redução da freqüência de administração, proporcionando maior conveniência e adesão e redução nos efeitos colaterais em virtude da redução do aparecimento de picos de concentração sanguínea acima dos níveis terapêuticos (Allen Junior et al., 2007). A base mais adequada para incorporação do princípio ativo e formação do sistema de liberação deve ser determinada de forma individual, de modo a fornecer velocidade de liberação, propriedades de adesão após aplicação e textura ideais (Allen Junior et al., 2007).
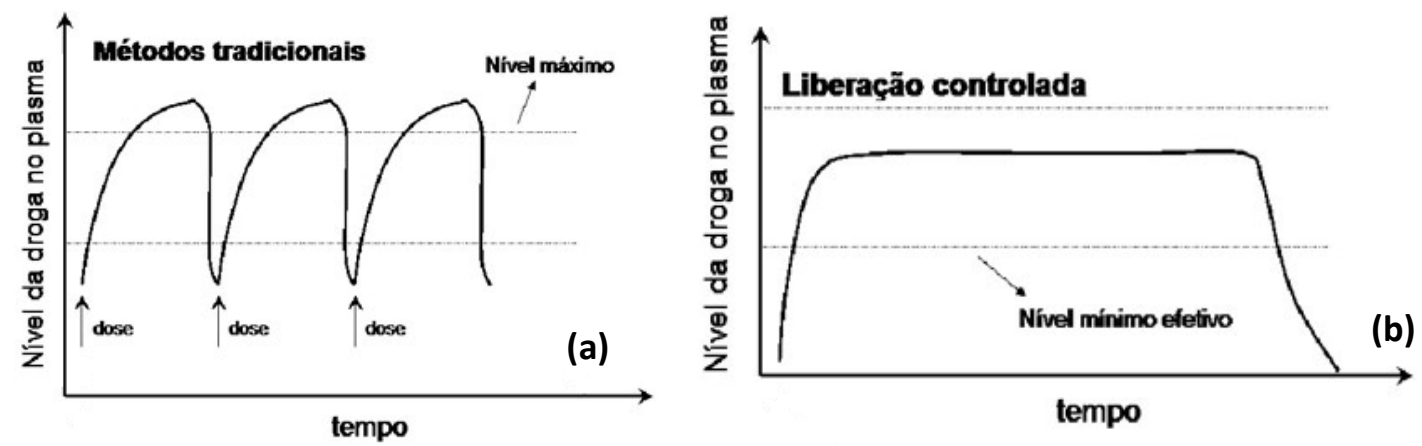

FIGURA 2 - Variações de concentração de princípios ativos administrados por (a) métodos tradicionais e (b) sistemas de liberação controlada

Os sistemas poliméricos de liberação controlada podem ser classificados de acordo com o mecanismo que controla a liberação do princípio ativo incorporado: por difusão (sistema monolítico ou controlado por membrana), pela penetração de água (sistema osmótico ou por intumescimento) e quimicamente (sistema monolítico ou de cadeia pendente) (Heller, 1996; Peppas et al., 2000).

No sistema monolítico, o princípio ativo é disperso em uma matriz polimérica e a liberação é controlada por difusão pela matriz. Esta difusão 
depende da solubilidade do ativo no polímero, que poderá estar abaixo do seu limite de solubilidade e dissolvido no polímero ou acima do seu limite de solubilidade e disperso no polímero. Em dispositivos controlados por membrana (dispositivos reservatórios), o princípio ativo está contido em um compartimento que é envolto por uma fina membrana polimérica, que controla a difusão do fármaco para o meio externo (Heller, 1996).

Quimicamente, a liberação do fármaco ocorre por degradação do polímero; por meio de reações químicas, enzimáticas ou pela presença de água. No sistema monolítico a liberação é controlada pela difusão do fármaco ou pela degradação do polímero e nos sistemas de cadeias pendentes ocorre com o rompimento das ligações entre o polímero e o fármaco (Heller, 1996).

Nos dispositivos controlados pela penetração de água, a liberação do fármaco é controlada pela penetração de água no dispositivo. Por intumescimento, o princípio ativo é disperso em um polímero hidrofílico, quando em contato com meio aquoso, a água penetra na matriz e como consequência do intumescimento, o princípio ativo se difunde pelo polímero (Heller, 1996).

Em dispositivos do tipo bomba osmótica, o agente osmótico está contido em um compartimento rígido, que possui uma membrana semipermeável e é separado do princípio ativo por uma partição móvel. Quando colocado em meio aquoso a água penetra no compartimento osmótico, que ao aumentar de volume, exerce pressão sobre a parte móvel resultando em liberação do princípio ativo por meio de um orifício (Heller, 1996).

\subsubsection{Hidrogéis de poli( $N$-vinil-2-pirrolidona)}

O poli(N-vinil-2-pirrolidona) (PVP) (FIG. 3) é um polímero altamente polar obtido por meio da polimerização do N-vinil-pirrolidona.

Solubilidade em água, baixa toxicidade e boas características para formar filmes são propriedades que tornam o PVP interessante para formação de hidrogéis. 


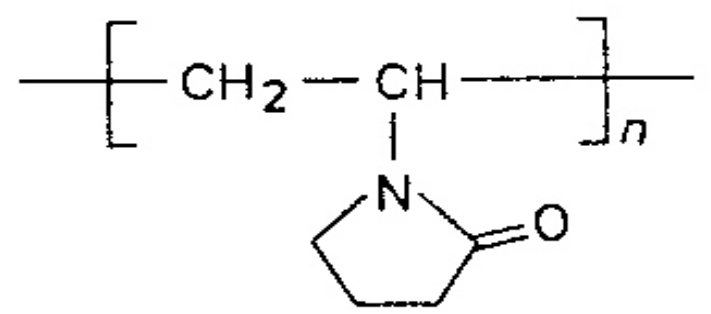

FIGURA 3 - Poli(N-vinil-2-pirrolidona)

Rosiak e colaboradores (1989) desenvolveram um hidrogel composto por PVP, PEG e ágar, reticulado a partir da irradiação da solução aquosa do polímero. Produzido para ser utilizado como curativo na área de queimados, esse hidrogel é comercializado na Europa desde 1990 como Aqua-Gel ${ }^{\circledR}$.

As vantagens apresentadas pelos hidrogéis de PVP para aplicação tópica são:

-Formação de uma barreira na pele que evita a contaminação de microorganismos e a perda excessiva de fluidos biológicos, mas que permite a passagem de oxigênio;

- Absorção de exsudato, quando utilizados como curativos;

-Consistência macia, elástica e flexível, apresentando propriedades mecânicas adequadas à manipulação;

- Facilidade de aplicação;

- Boa adesão à pele e baixa adesão a feridas ou cicatrizes;

- Transparência, permitindo a monitoração da pele sem a necessidade de remoção do hidrogel, o que facilita a observação de uma possível reação adversa;

- Incorporação e liberação de diversos princípios ativos. 
Com o objetivo de melhorar estas propriedades e ampliar a aplicabilidade dos hidrogéis de PVP, muitos estudos têm sido realizados avaliando a utilização de diferentes doses e tipos de radiação, adição de componentes e incorporação de diversos princípios ativos.

Lopérgolo e colaboradores (2003) utilizaram radiação ultravioleta como alternativa à radiação de alta energia na preparação de hidrogéis de PVP. Os hidrogéis obtidos foram considerados adequados para utilização como curativos e para liberação de drogas, apresentando propriedades semelhantes aos obtidos por radiação y ou aceleradores de elétrons.

Miranda e colaboradores (1999) estudaram o efeito da dose de radiação e concentração de $P V P$ em hidrogéis contendo $P E G$ e ágar. $A$ concentração ideal de PVP estudada foi 5\% e a dose de radiação entre 20 a 30 kGy, possibilitando uma maior reticulação dos hidrogéis.

As propriedades mecânicas do hidrogel de PVP foram melhoradas com a adição do poli (álcool vinílico) (PVA), obtendo hidrogel de blenda de PVP-PVA com propriedades adequadas e mostrando ser uma boa barreira contra microorganismos (Razzak et al., 2001).

A adição de PEG aumentou a flexibilidade dos hidrogéis de maneira dependente da concentração. No entanto, verificou-se que o PEG não funciona apenas como um plastificante, diminuindo a porcentagem de fração gel dos hidrogéis (Ajii et al., 2005; El-Mohdy \& Hegazy, 2008).

D’Errico e colaboradores (2008) avaliaram a interferência da adição de 1 a $10 \%$ de glicerol em hidrogéis de PVP reticulados por radiação UV. A presença de glicerol aumentou a fração solúvel do polímero e modificou as propriedades mecânicas do hidrogel de forma dependente da concentração.

Esta alteração nas propriedades mecânicas também foi observada em filmes de quitosana, que apresentaram menor resistência e maior elasticidade após adição de glicerol (Ziani et al., 2008).

Concentrações de até 3\% de glicerol foram consideradas satisfatórias, pois aumentaram a permeabilidade do hidrogel, favorecendo a liberação de princípios ativos (D’Errico et al., 2008).

Geever e colaboradores (2008) avaliaram a incorporação de diclofenaco de sódio e procaína em hidrogéis de PVP e poli(isopropilacrilamida), responsivos à temperatura. A incorporação foi realizada antes da exposição à 
radiação ultravioleta, e os resultados obtidos mostraram capacidade de incorporação e liberação dos fármacos estudados.

\subsection{Interação da radiação ionizante com a matéria e a ação sobre polímeros}

A química das radiações é o campo da ciência que estuda os efeitos químicos e físicos produzidos quando materiais são expostos às radiações de alta energia, também denominadas ionizantes. Os tipos de radiações mais conhecidos são as emitidas por núcleos radioativos $(\alpha, \beta$ e $\gamma)$, partículas de alta energia (elétrons, pósitrons, etc.) e radiação eletromagnética de onda curta (raios $\mathrm{x}$ ) (Spinks \& Woods, 1990).

A absorção da radiação de alta energia pela matéria ocorre por meio de interações com o núcleo dos átomos e com a nuvem eletrônica ao seu redor. Os três principais processos de interação são o efeito fotoelétrico, efeito Compton e a produção de pares (Bovey, 1958; Farhataziz \& Rodgers, 1987).

No efeito fotoelétrico, toda energia do fóton é transferida para um elétron atômico, que é ejetado (Bovey, 1958). A energia cinética do elétron ejetado é igual à diferença entre a energia do fóton e a energia de ligação do elétron ao átomo (Farhataziz \& Rodgers, 1987). O elétron expelido pode perder a energia recebida do fóton, produzindo ionizações (Bovey, 1958).

No efeito Compton, apenas uma parte da energia do fóton incidente é transmitida ao elétron. Como resultado desta interação o fóton incidente desaparece e um segundo fóton é criado com energia menor e direção diferente da incidente (Farhataziz \& Rodgers, 1987).

Ao contrário do observado nos efeitos fotoelétrico e Compton, a produção de pares eletrônicos envolve a interação do fóton com o núcleo atômico. Essa interação ocorre somente com fótons de energia igual ou superior a 1,02 $\mathrm{MeV}$ e resulta no desaparecimento do fóton incidente e no aparecimento de duas partículas, um pósitron e um elétron (Farhataziz \& Rodgers, 1987).

A importância relativa dos três processos depende da energia do fóton incidente. Neste trabalho, as irradiações foram realizadas utilizando fontes do tipo Cobalto-60, cujos fótons possuem energia média de 1,2 MeV e interagem com a matéria preferencialmente pelo efeito Compton. Neste caso, a contribuição do efeito fotoelétrico é pequena e pode ser desconsiderada, pois o mesmo é 
resultado da interação da matéria com fótons de baixa energia, ou seja, menores que $1 \mathrm{MeV}$. A probabilidade da ocorrência da produção de pares também é muito pequena, pois a mesma é energeticamente possível para fótons com energia igual ou superior a 1,02 MeV, o que possibilita a formação do par elétron-pósitron. Além disso, em água, a produção de pares torna-se significante para fótons com energia de $3 \mathrm{MeV}$.

A irradiação de polímeros tem o propósito de modificar algumas propriedades do material, como solubilidade, condutividade e propriedades mecânicas, ampliando as áreas de aplicações destes materiais (Bovey, 1958; Farhataziz \& Rodgers, 1987).

A interação da radiação ionizante com um polímero induz a ionização e excitação da molécula, formando espécies reativas, disponíveis para reagir quimicamente (Reichmanis \& O’Donnel, 1989).

Esta interação da radiação com polímeros tem como efeitos principais (Bovey, 1958):

- Cisão das cadeias moleculares com diminuição do peso molecular (degradação polimérica) (FIG. 4).

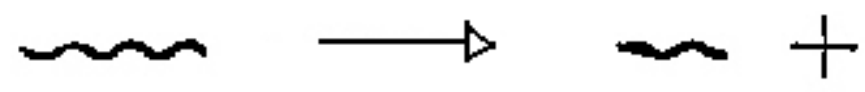

FIGURA 4 - Cisão da cadeia molecular

- Formação de ligações cruzadas entre as cadeias poliméricas (reticulação), que podem ser suficientes para formação de uma rede insolúvel (FIG. 5). Neste caso, há um aumento do peso molecular. 

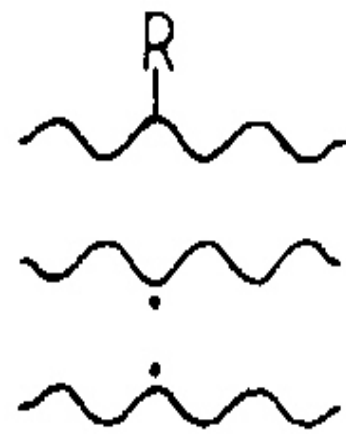
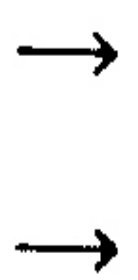
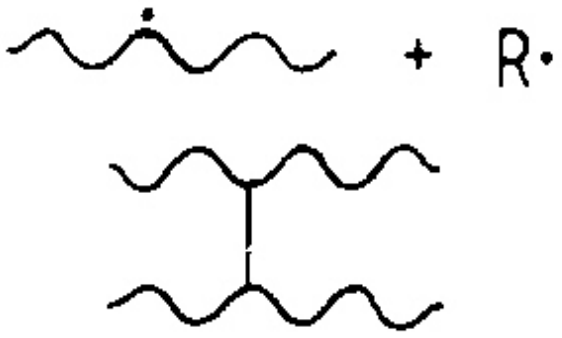

FIGURA 5 - Formação de ligações cruzadas entre as cadeias poliméricas

O mecanismo de reticulação mais aceito propõe que a ação da radiação ionizante resulta em quebra de uma ligação $\mathrm{C}-\mathrm{H}$ da cadeia polimérica, expulsando um átomo de hidrogênio e formando um radical polimérico. Esse átomo de hidrogênio pode retirar outro hidrogênio do polímero, formando um radical polimérico adicional. Os dois radicais poliméricos se recombinam formando a ligação cruzada (Schnabel, 1981).

A formação de ligações cruzadas e a cisão das cadeias podem acontecer simultaneamente. No entanto, a predominância de um dos processos dependerá da estrutura química do polímero e de fatores externos, como por exemplo, a presença de oxigênio que pode favorecer a cisão das cadeias moleculares (Bovey, 1958; Farhataziz \& Rodgers, 1987).

\subsection{Pele}

A pele é um dos maiores órgãos do corpo humano, atingindo até $16 \%$ do peso corporal. Além da proteção física a órgãos internos, a pele constitui uma barreira eficiente contra agentes ambientais deletérios de natureza química ou biológica. Este órgão sensorial possui importante papel na defesa imunológica do organismo e é responsável pela excreção de eletrólitos e controle da perda de água por evaporação, colaborando para a termorregulação corpórea (Junqueira \& Carneiro, 1999; Sousa \& Vargas, 2004).

Conforme ilustrado na FIG. 6, a pele é constituída por uma porção epitelial, a epiderme e uma porção conjuntiva, a derme. Embora a hipoderme tenha a mesma origem que a derme, esta não é considerada por muitos autores 
como parte integrante da pele, servindo apenas de suporte e união com os órgãos subjacentes (Junqueira \& Carneiro, 1999).

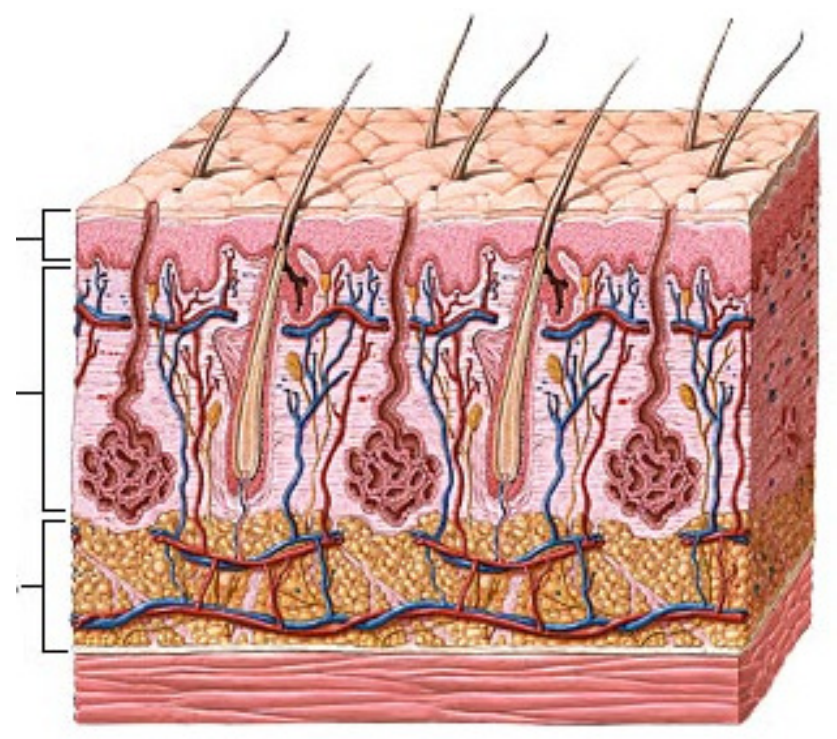

\subsubsection{Epiderme}

A epiderme é a camada mais superficial da pele e divide-se em subcamadas, da porção mais interna à superfície, sendo: camada basal ou estrato germinativo, estrato espinhoso, granuloso, lúcido e córneo. É constituída por epitélio estratificado pavimentoso queratinizado e apresenta como principal função a produção de queratina, proteína responsável pela impermeabilidade da pele e prevenção da evaporação de água pela superfície corporal (Baumann, 2004; Junqueira \& Carneiro, 1999).

A espessura e a estrutura da epiderme são variáveis, apresentando-se mais espessa e complexa na palma da mão e planta do pé, atingindo espessura de até 1,5 mm nestas regiões (Junqueira \& Carneiro, 1999). Em outras regiões do corpo a epiderme é mais fina e simples, caracterizada pela ausência das camadas granulosa e lúcida e apresentando uma camada córnea muito reduzida.

O estrato germinativo ou camada basal apresenta intensa atividade mitótica, sendo responsável pela constante renovação da epiderme, por meio de um deslocamento celular permanente e repetido, que ocorre a cada 20 a 30 dias. 
As células produzidas nesta camada se diferenciam à medida que avançam para a superfície, apresentando um acúmulo gradual de filamentos intermediários de queratina. Em média um queratinócito basal leva duas semanas para se tornar um queratinócito córneo; o mesmo período de tempo é utilizado para que o mesmo se desprenda da pele em um processo de descamação (Junqueira \& Carneiro, 1999; Sousa \& Vargas, 2004).

A camada espinhosa é constituída por células poligonais cuboides ou ligeiramente achatadas que apresentam expansões citoplasmáticas. Estes prolongamentos citoplasmáticos se aproximam e mantêm as células unidas por meio de desmossomos, estruturas com função importante na manutenção da coesão das células da epiderme e na sua resistência ao atrito (Junqueira \& Carneiro, 1999).

O estrato granuloso é caracterizado pela presença de células poligonais achatadas, que produzem grânulos de querato-hialina e grânulos envolvidos por membrana de substância fosfolipídica associada à glicosaminoglicanas, o que confere à camada granulosa impermeabilidade à água e outras substâncias, prevenindo a desidratação das camadas subjacentes da epiderme (Baumann, 2004).

O estrato lúcido está localizado acima da camada granulosa e é encontrado apenas na palma das mãos e plantas dos pés, conferindo um maior espessamento da pele nestas regiões (Junqueira \& Carneiro, 1999).

A camada mais superficial da epiderme é o estrato córneo, constituído por uma matriz lipídica e várias camadas de células mortas, achatadas, sem núcleo e ricas em queratina, resultado do processo de queratinização iniciado na camada basal (Baumann, 2004).

A principal função do estrato córneo é prevenir a perda de água transepidérmica, regulando o equilíbrio hídrico na pele (Sousa \& Vargas, 2004). Em virtude da presença de células compactadas e ricas em queratina, esta camada é capaz de absorver e refletir raios ultravioleta, atuando como uma barreira fotoprotetora (Puizina-Ivic, 2008).

Ainda na epiderme são encontrados outros dois mecanismos fotoprotetores da pele: a melanina, um pigmento de cor marrom-escura, produzido pelos melanócitos e encontrada geralmente nas camadas basal e espinhosa da epiderme e o ácido urocânico presente no estrato córneo. Ambos refletem e 
absorvem grande quantidade de radiação ultravioleta, prevenindo os danos decorrentes da exposição crônica a este tipo de radiação (Junqueira \& Carneiro, 1999; Puizina-Ivic, 2008).

\subsubsection{Derme}

A derme é o tecido conjuntivo situado entre a epiderme e a hipoderme, constituído principalmente por colágeno e elastina. A presença de colágeno proporciona características de durabilidade e elasticidade à pele e as fibras de elastina conferem propriedades de recuo elástico. Além disso, também estão presentes nervos, anexos cutâneos como pelos e glândulas sudoríparas e uma rede vascular, que permite a nutrição da pele, uma vez que a epiderme não é vascularizada (Baumann, 2004; Sousa \& Vargas, 2004).

Assim como a epiderme, a derme também apresenta espessura variável de acordo com a região observada, atingindo um máximo de $3 \mathrm{~mm}$ na planta do pé (Junqueira \& Carneiro, 1999). Com o envelhecimento, essa camada diminui em espessura e hidratação (Baumann, 2004).

$\mathrm{Na}$ derme podem ser observadas duas camadas de limites pouco distintos, a papilar (superficial) e a reticular (mais profunda). Ambas possuem muitas fibras elásticas, responsáveis em parte, pela elasticidade da pele (Junqueira \& Carneiro, 1999).

A derme papilar é caracterizada por menores feixes colágenos, maior celularidade, alta densidade nos seus elementos vasculares e possui fibrilas especiais de colágeno que se inserem na membrana basal e penetram na epiderme, prendendo-a a derme (Junqueira \& Carneiro, 1999; Baumann, 2004).

Já a camada reticular é mais espessa e caracterizada por fibras colágenas mais espessas e abundantes, em comparação com a derme papilar.

Estas fibras colágenas presentes na derme papilar e reticular são permeadas por um sistema elástico, que é responsável pela capacidade da pele voltar á posição original quando submetida à força de estiramento (Sousa \& Vargas, 2004). 


\subsection{Radicais Livres}

Radicais livres são espécies químicas que contém um ou mais elétrons desemparelhados disponíveis para formação de ligações químicas (Spinks \& Woods, 1990). O não emparelhamento confere grande capacidade de reação a estas moléculas, comportando-se como receptores ou doadores de elétrons e sua configuração instável confere propriedades específicas, como a alta reatividade e curto tempo de meia-vida (Young \& Woodside, 2001).

Estas espécies são importantes para manutenção de muitas funções fisiológicas, atuando como ativadores do sistema imunológico e receptores de cátions para o controle da acidose celular (Valko et al., 2007). Quimicamente também participam de diversos processos como polimerização, reticulação e degradação de polímeros (Lazár et al., 1989).

A formação de radicais livres pode ocorrer de diferentes maneiras, dentre elas podemos citar os processos de óxido-redução e a dissociação molecular, resultado de uma transferência de energia suficiente para que haja rompimento de ligações químicas, gerando uma divisão de elétrons para os radicais formados como acontece na fotólise e radiólise (Lazár et al., 1989; Spinks \& Woods, 1990).

A óxido-redução envolve a transferência de um elétron entre duas espécies químicas podendo produzir radicais livres (Lazár et al., 1989; Spinks \& Woods, 1990).

$\mathrm{Na}$ fotólise as moléculas são excitadas pela absorção de luz e se dissociam formando os radicais livres (Spinks \& Woods, 1990).

A radiólise é um método importante de formação de radicais livres em meio aquoso e consequentemente em organismos vivos. A interação da radiação de alta energia com a água, leva à formação de espécies reativas primárias $(\mathrm{OH} \bullet$, $\mathrm{e}_{\mathrm{aq}}^{-}, \mathrm{H}_{3} \mathrm{O}^{+}$e $\left.\mathrm{H}^{+}\right)$e produtos moleculares $\left(\mathrm{H}_{2}\right.$ e $\left.\mathrm{H}_{2} \mathrm{O}_{2}\right)$ denominados "produtos primários da radiólise da água", que podem causar danos ao organismo ao interagir com moléculas biológicas (Lazár et al., 1989; LaVerne, 2000; Singh, 1989).

O processo de radiólise da água é usualmente dividido em três estágios: físico, físico-químico e químico. O estágio físico tem duração de $10^{-15}$ segundos ou menos e consiste na transferência de energia, ocasionando 
ionização e excitação das moléculas de água, conforme apresentado nas reações (1) e (2) (Draganic \& Draganic, 1971):

$$
\begin{aligned}
& \mathrm{H}_{2} \mathrm{O}------\longrightarrow \mathrm{e}^{-}+\mathrm{H}_{2} \mathrm{O}^{+} \text {(ionização) } \\
& \mathrm{H}_{2} \mathrm{O} \text {------ } \rightarrow \mathrm{H}_{2} \mathrm{O}^{*} \text { (excitação) }
\end{aligned}
$$

No estágio físico-químico, os elétrons removidos com a ionização tornam-se hidratados, originando o elétron aquoso $\left(\mathrm{e}_{\mathrm{aq}}^{-}\right)$, um agente redutor que apresenta alta reatividade e capacidade de causar danos em macromoléculas. Os íons $\mathrm{H}_{2} \mathrm{O}^{+}$formados reagem com moléculas de água originando $\mathrm{H}_{3} \mathrm{O}^{+}$e radicais hidroxila $(\mathrm{OH} \bullet)$, conforme reação (3) (Draganic \& Draganic, 1971):

$$
\mathrm{H}_{2} \mathrm{O}^{+}+\mathrm{H}_{2} \mathrm{O}-----\longrightarrow \mathrm{H}_{3} \mathrm{O}^{+}+\mathrm{OH}
$$

Ainda no estágio físico-químico, ocorre a dissociação da molécula de água excitada $\left(\mathrm{H}_{2} \mathrm{O}^{*}\right)$ (reação 4 ), originando como principais produtos átomos de hidrogênio e radicais hidroxila. No entanto, a contribuição na formação de espécies reativas primárias decorrente do processo de excitação tem menor importância quando comparada à dos processos de ionização (Draganic \& Draganic, 1971).

$$
\mathrm{H}_{2} \mathrm{O}^{*}------\mathrm{H} \bullet+\mathrm{OH} \bullet
$$

$\mathrm{Na}$ etapa química, as reações das espécies formadas continuam acontecendo e produtos estáveis começam a ser formados. Os "produtos primários da radiólise da água" e seus respectivos rendimentos para $100 \mathrm{eV}$ de energia absorvida estão apresentados na FIG. 7 (Draganic \& Draganic, 1971).

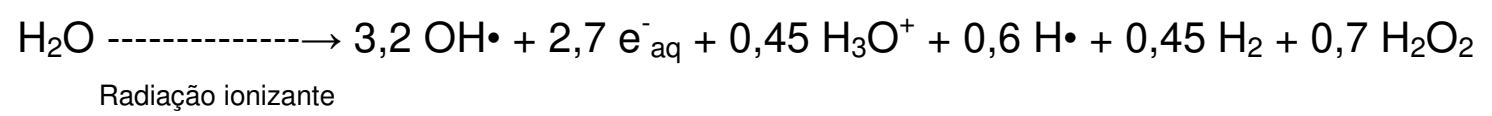

FIGURA 7 - Produtos formados pela da radiólise da água e seus respectivos rendimentos 
Dentre as espécies reativas formadas, o radical hidroxila $(\mathrm{OH} \bullet)$ e 0 elétron aquoso $\left(\mathrm{e}_{\mathrm{aq}}^{-}\right)$apresentam maior reatividade e são os principais causadores de danos em macromoléculas, como proteínas. As reações que envolvem o $\mathrm{e}_{\text {aq }}^{-}$ ocorrem por transferência de elétrons e no caso do $\mathrm{OH} \cdot$ as reações são variadas e podem acontecer por abstração de hidrogênio, quebra de anel aromático e também por transferência de elétrons (Draganic \& Draganic, 1971; Lazár et al., 1989).

\subsubsection{Espécies Reativas de Oxigênio}

Espécies reativas de oxigênio (ERO) estão envolvidas em uma série de processos degenerativos, devido à propriedade de serem ou gerarem radicais livres e à habilidade de reagir rapidamente com várias moléculas, interferindo na função celular. Processos de transferência de elétrons ou a absorção de energia podem levar o oxigênio a gerar espécies reativas, sendo o radical ânion superóxido $\left(\mathrm{O}_{2}{ }^{-}\right)$, o radical hidroxila $(\mathrm{OH} \bullet)$ e o peróxido de hidrogênio $\left(\mathrm{H}_{2} \mathrm{O}_{2}\right)$ as principais ERO (Lazár et al., 1989; Valko et al., 2007).

A principal via de metabolismo do oxigênio no organismo envolve a sua completa redução à água, incorporando quatro elétrons ao final da cadeia respiratória (FIG. 8). Durante o metabolismo aeróbico, aproximadamente 2 a 5\% do oxigênio que respiramos não é completamente reduzido à água, resultando na produção de ERO (Halliwell \& Gutteridge, 1999).

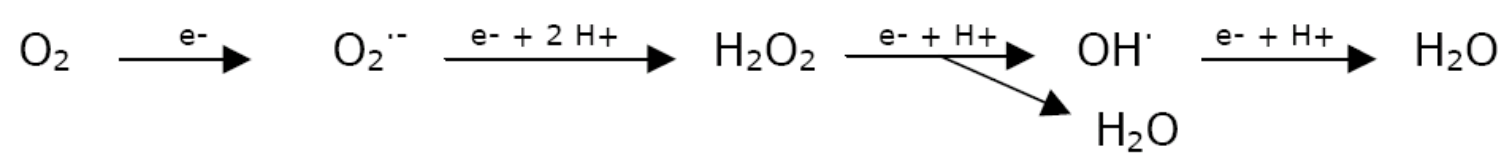

FIGURA 8 - Formação de ERO

O ânion superóxido é produzido pela adição de um elétron ao oxigênio, sendo formado a partir dele as demais ERO (Young \& Woodside, 2001). Isoladamente esse radical é pouco reativo e de vida curta, porém possui grande capacidade de gerar peróxido de hidrogênio e, consequentemente, radicais secundários, como o $\mathrm{OH} \bullet$. 
O peróxido de hidrogênio não é um radical livre por definição; é um oxidante fraco e relativamente estável, porém é importante porque na presença de metais de transição pode ser convertido em radicais hidroxila, por meio da Reação de Fenton (reação 5) (Betteridge, 2000). Além disso, possui vida longa e grande capacidade de se difundir através das membranas celulares, formando radicais $\mathrm{OH} \bullet$ no interior das células.

$$
\mathrm{Fe}^{2+}+\mathrm{H}_{2} \mathrm{O}_{2} \rightarrow \mathrm{Fe}^{3+}+\mathrm{OH} \bullet+\mathrm{OH}^{-}
$$

O radical hidroxila é um dos mais potentes oxidantes e apresenta capacidade de atravessar membranas e reagir com moléculas como ácidos graxos poli-insaturados, iniciando a peroxidação lipídica e alterando a fluidez, permeabilidade e função celular (Singh, 1989).

O oxigênio singlete $\left(\mathrm{O}_{2}^{1}\right)$ é uma espécie excitada de oxigênio, altamente reativa e formada pela excitação eletrônica do oxigênio molecular através da luz (Halliwell, 2006).

A geração de radicais livres in vivo ocorre naturalmente por meio de processos endógenos, durante a execução de processos metabólicos e exógenos como a exposição à radiação e pesticidas (Gaté et al., 1999; Lazár et al., 1989). Esses radicais livres formados são importantes para manutenção de muitas funções fisiológicas. No entanto, biomoléculas de DNA, lipídios, proteínas e outros componentes celulares tornam-se alvos potenciais para danos oxidativos provenientes da ação dessas espécies. Alterações na estrutura de qualquer uma destas biomoléculas podem interferir nas funções normais executadas pelas mesmas, induzindo a processos patológicos como câncer, cardiopatias e envelhecimento precoce (Ames et al., 1993; Betteridge, 2000; Kohen, 1999; Steenvoorden \& Henegouwen, 1997; Sies, 1993).

\subsubsection{Desordens cutâneas provenientes da ação de radicais livres: 0 envelhecimento cutâneo precoce e o câncer de pele}

Mais do que qualquer outro tecido, a pele é exposta a inúmeros agentes químicos, físicos e microbiológicos, muitos dos quais induzem a formação de radicais livres, os contribuintes mais importantes para o aparecimento de desordens cutâneas. Dentre os fatores de risco, a exposição à 
radiação ultravioleta solar é considerada um dos fatores mais importantes, pois além do aspecto do envelhecimento, está associada a um risco aumentado no aparecimento de câncer de pele (Cochran et al., 2001; González et al., 2008; Machado-Pinto, 1996).

Estudos epidemiológicos demonstraram que trabalhadores sob exposição solar apresentam maior incidência no aparecimento dessas desordens cutâneas. A provável causa do aparecimento dessas alterações é atribuída à diminuição dos sistemas antioxidantes cutâneos e à formação de ERO na epiderme, que ocorrem durante a exposição solar (Harris, 2003; Miyachi, 1995; Puizina-Ivic, 2008).

\subsubsection{Envelhecimento Cutâneo}

Existem dois tipos de envelhecimento: o envelhecimento intrínseco, que ocorre por fatores genéticos e cronológicos, e o extrínseco, que é causado por fatores externos como tabagismo, poluentes e principalmente exposição solar, e neste caso é conhecido como fotoenvelhecimento ou envelhecimento actínico (Baumann, 2004; Puizina-lvic, 2008). Diferentemente do intrínseco, o envelhecimento extrínseco pode ser prevenido e regulado (Miyachi, 1995).

Em 1956, Denhan Harman relacionou as mudanças decorrentes do envelhecimento às reações causadas pela presença de radicais livres e propôs a teoria de que o envelhecimento é resultado de danos causados por estas espécies. Muitas teorias envolvendo fatores genéticos e ambientais já foram propostas para tentar explicar os fenômenos que ocorrem durante 0 envelhecimento, mas até o momento não foi possível elucidar de forma isolada o processo complexo de envelhecer (Adelman \& Roter, 1982).

Atualmente, a teoria dos radicais livres é reconhecida como uma das principais causas do envelhecimento e das doenças degenerativas associadas à idade, em virtude das alterações moleculares e lesões celulares desencadeadas pelas ERO (Adelman \& Roter, 1982; Miyachi, 1995).

$\mathrm{Na}$ pele, os principais efeitos das ERO estão relacionados à perda de elasticidade e a capacidade de retenção de água, o que gera aumento na rugosidade e perda de maciez e viço, característicos da pele fotoenvelhecida (Harris, 2003). Estes efeitos são resultados das alterações promovidas pelas ERO na estrutura e função de proteínas cutâneas como colágeno, elastina e 
glicosaminoglicanos e em vias de expressão de genes que levam à degradação do colágeno e ao acúmulo de elastina (Baumann, 2004; Makrantonaki \& Zouboulis, 2008; Puizina-Ivic, 2008).

Assim como todo organismo, a pele sofre alterações com 0 envelhecimento, perdendo suas características estruturais e morfológicas em toda a extensão da epiderme, derme e tecido subcutâneo (Makrantonaki \& Zouboulis, 2008). Histologicamente a pele envelhecida é caracterizada principalmente pela diminuição do colágeno e glicosaminoglicanos, aumento da elastose e redução da vascularidade, diminuindo o fluxo sanguíneo e a troca de nutrientes (Baumann, 2004; Makrantonaki \& Zouboulis, 2008; Puizina-Ivic, 2008).

Aparentemente são observadas alterações na textura e no aspecto da superfície da pele, que se torna mais seca em virtude do aumento da perda de água transepidérmica e apresenta-se mais fina, com menor elasticidade e com presença de rugas e lesões pigmentadas, como sardas e áreas de hiperpigmentação (Baumann, 2004; Makrantonaki \& Zouboulis, 2008).

\subsubsection{Câncer de Pele}

O câncer é uma patologia caracterizada pela multiplicação e propagação descontrolada de células anormais, que possuem características especiais como perda da capacidade de diferenciação e função, poder de invasão e metástases.

O câncer de pele é a neoplasia maligna mais comum e o fator predisponente mais importante para seu aparecimento é a exposição crônica à radiação ultravioleta (Machado-Pinto, 1996; Marsillac \& Rezende, 1996). Essa patologia apresenta incidência crescente mundialmente, sendo que apenas nos Estados Unidos, mais de um milhão de novos casos de câncer de pele são registrados por ano (Baliga \& Katiyar, 2006).

Existem três tipos de câncer de pele: o carcinoma basocelular, carcinoma epidermoide ou espinocelular e o melanoma (Machado-Pinto, 1996; Marsillac \& Rezende, 1996).

O carcinoma basocelular é originário da epiderme e dos apêndices cutâneos, e histologicamente é caracterizado pela presença de células tumorais muito semelhantes às células presentes na camada basal da epiderme. É o tipo de câncer de pele mais frequente, representando cerca de $75 \%$ dos casos. 
Raramente são observadas metástases originadas pelo carcinoma basocelular, no entanto sua propagação é local e arrastada, podendo invadir estruturas locais adjacentes (Machado-Pinto, 1996; Wolfe, 2000; Marsillac \& Rezende, 1996).

O carcinoma epidermoide é um tumor derivado de queratinócitos da epiderme, responsável por 15 a 20\% dos cânceres cutâneos. Apresenta-se inicialmente como uma placa avermelhada, endurecida, acompanhada de infecção e metastatiza-se mais frequentemente que o carcinoma basocelular, propagando-se inicialmente para linfonodos (Machado-Pinto, 1996; Marsillac \& Rezende, 1996; Wolfe, 2000).

O melanoma corresponde há apenas 4\% dos tumores cutâneos, no entanto, apresenta maior letalidade e sua incidência tem aumentado mais rapidamente que outras neoplasias, duplicando a freqüência de aparecimento a cada 10-15 anos (Cunha, 1996; Marsillac \& Rezende, 1996; Cochran et al., 2001). Além disso, o melanoma é o único tumor que apresenta capacidade de evoluir para metástase em qualquer órgão, incluindo localizações pouco comuns como o intestino, baço e coração (Marsillac \& Rezende, 1996).

No Brasil, o câncer de pele é o tipo de câncer mais incidente, correspondendo a cerca de $25 \%$ de todos os tumores malignos registrados. Segundo o Instituto Nacional de Câncer em 2010 o câncer de pele do tipo não melanoma continuará sendo o mais incidente na população brasileira, seguido pelos tumores de próstata e mama feminina. O número de novos casos de câncer de pele não melanoma estimado será de 53.410 entre homens e de 60.440 nas mulheres, correspondendo a um risco estimado de 56 novos casos a cada 100 mil homens e 61 para cada 100 mil mulheres (INCA, 2009).

Desta forma, apesar de a pele apresentar mecanismos de fotoproteção, a exposição repetida à radiação ultravioleta associada à presença descontrolada de radicais livres pode levar ao aparecimento de desordens cutâneas. A presença de antioxidantes no estrato córneo é conhecida por apresentar um papel importante na proteção da pele e prevenção contra os danos decorrentes desta exposição (Puizina-Ivic, 2008).

\subsection{Antioxidantes}

Em resposta à frequente e variada exposição a metabólitos reativos, o organismo desenvolveu uma série de mecanismos de defesa com o objetivo de 
limitar os níveis de oxidantes, prevenindo a indução de danos pelos mesmos (Ames et al., 1993). No entanto, o mecanismo de defesa mais importante é o sistema antioxidante (Kohen, 1999).

Antioxidantes são um dos elementos que retardam in vivo as reações de oxidação induzidas por radicais livres, reduzindo os danos causados pelos mesmos, por meio de processos que desacelerem ou bloqueiem estas reações (Ames et al., 1993; Thomas, 2000; Ratnam et al., 2006; Halliwell \& Gutteridge, 1999).

Dependendo de seu mecanismo de ação, os antioxidantes podem ser divididos em duas classes: antioxidantes de quebra de cadeia ou antioxidantes preventivos (Larson, 1997).

Os antioxidantes de quebra de cadeia são moléculas que podem receber ou doar um elétron de um radical com a formação de bioprodutos estáveis (Young \& Woodside, 2001). Essas moléculas interagem diretamente com o radical livre, capturando-o, prevenindo sua propagação e bloqueando as reações de oxidação induzidas pelos mesmos (Ames et al., 1993; Thomas, 2000; Miquel et al., 1989).

Antioxidantes preventivos evitam o acúmulo de moléculas que possam promover a formação de radicais livres, reduzindo a iniciação de novas reações em cadeia por meio de processos distintos. Dentre esses processos, podemos citar a redução de peróxidos por meio da catálise enzimática e a captura de íons metálicos de transição, prevenindo a peroxidação lipídica de ácidos graxos (Ames et al., 1993; Thomas, 2000; Miquel et al., 1989; Larson, 1997).

Durante todo o processo evolutivo, o sistema antioxidante funcionou como resposta às concentrações aumentadas de oxigênio e foi desenvolvido para interagir diretamente com as ERO, a fim de impedir o ataque a sítios biológicos (Kohen, 1999; Halliwell \& Gutteridge, 1999).

Nos últimos anos, os antioxidantes têm ganhado muita importância em virtude de seu potencial como agente profilático e terapêutico em muitas doenças, sendo extensivamente utilizados no tratamento de patologias, na prevenção do envelhecimento cutâneo e das consequências causadas pela radiação ultravioleta a curto e longo prazo, como o câncer de pele (Kaur et al., 2007; Kohen, 1999).

Estudos epidemiológicos têm mostrado uma significante variação na incidência de diversas doenças entre grupos étnicos que possuem hábitos e 
exposição a fatores ambientais diferentes. O paradoxo francês é um exemplo desta evidência epidemiológica, que mostra a eficiência dos antioxidantes na prevenção de doenças (Ratnam et al., 2006).

O estilo de vida francês é caracterizado por hábitos que aumentam o risco de doenças cardiovasculares, como uma dieta rica em gorduras saturadas, alto índice de fumantes e pouca atividade física. No entanto, a taxa de mortalidade por doenças cardiovasculares é menor do que a esperada, devido aos hábitos da população. A explicação para esse paradoxo são os antioxidantes provenientes do alto consumo de vinho por essa população (Sun et al., 2002; Ratnam et al., 2006; Opie \& Lecour, 2007).

\subsubsection{Sistema antioxidante endógeno}

\subsubsection{Enzimáticos}

Dentre os antioxidantes enzimáticos, destacam-se as enzimas superóxido dismutase, catalase e glutationa peroxidase (Blokhina et al., 2003, Valko et al., 2007, Sies, 1993), sendo a superóxido dismutase e a catalase os mais potentes antioxidantes conhecidos no organismo (Ratnam et al., 2006; Gaté et al., 1999).

A superóxido dismutase é a primeira linha de defesa da célula contra o estresse oxidativo. Esta enzima converte o ânion superóxido em peróxido de hidrogênio e oxigênio (Ratnam et al., 2006; Gaté et al., 1999).

A catalase é a segunda enzima que age na desintoxicação celular. Presente nos peroxissomas, esta enzima catalisa a decomposição de peróxido de hidrogênio em água e oxigênio (Ratnam et al., 2006; Gaté et al., 1999; Pinnell, 2003).

Assim como a catalase, a enzima glutationa peroxidase tem como função bioquímica converter peróxido de hidrogénio a água, oxidando a glutationa (GSH) ao seu correspondente dissulfeto (GSSG).

\subsubsection{Não Enzimáticos}

A glutationa (GSH) é um tripeptídeo formado pelos aminoácidos glicina, cisteína e ácido glutâmico e encontrado no organismo em concentrações milimolares. Além de envolvido na conversão de peróxido de hidrogênio em água, também funciona como um doador de hidrogênio para muitos antioxidantes 
endógenos, como o ascorbato que é importante na regenaração do a-tocoferol (Steenvoorden \& Henegouwen,1997; Gaté et al., 1999).

\subsubsection{Sistemas Antioxidantes Exógenos}

A presença de antioxidantes permite que os níveis de radicais livres mantenham-se baixos, possibilitando que os mesmos executem suas funções biológicas sem causar danos ao organismo (Halliwell, 2006).

O perfeito equilíbrio entre a quantidade de moléculas antioxidantes e oxidantes é importante para que a integridade do organismo seja mantida. No entanto, apenas as defesas antioxidantes endógenas não são suficientes para manter esse equilíbrio, podendo ocasionar um distúrbio favorável às moléculas oxidantes, denominado estresse oxidativo (Ratnam et al.,2006; Betteridge, 2000; Halliwell \& Gutteridge, 1999). Esse distúrbio é uma das grandes causas do aparecimento de algumas patologias como envelhecimento cutâneo precoce e o câncer de pele (Ratnam et al.,2006; Betteridge, 2000).

Em pessoas mais idosas, o nível de lipoproteínas oxidadas ou a susceptibilidade para a oxidação das mesmas estão aumentados e a quantidade de moléculas antioxidantes presentes naturalmente no organismo são incapazes de contrabalancear o ataque oxidativo (Kaur et al., 2007). Por estas razões, a reposição de antioxidantes por meio da dieta e suplementos orais ou por aplicação tópica representa uma estratégia interessante de proteção cutânea contra o estresse oxidativo. Além da reposição utilizando moléculas endógenas, buscam-se novas substâncias com ação antioxidante, bem como substâncias com capacidade de aumentar direta ou indiretamente os níveis endógenos (Kaur et al., 2007).

No entanto, fatores como dose, solubilidade, permeabilidade e estabilidade do antioxidante e parâmetros farmacocinéticos como absorção e distribuição podem afetar a biodisponibilidade de antioxidantes provenientes de fonte oral, limitando a quantidade entregue à pele (Ratnam et al., 2006).

O desenvolvimento de novos sistemas de liberação contendo antioxidantes aparece como uma alternativa à utilização de alimentos ou suplementos orais, pois possibilitam uma liberação controlada no local de ação e a superação de problemas farmacocinéticos, proporcionando um aumento da biodisponibilidade e eficácia do antioxidante. 


\subsection{Resveratrol}

Resveratrol (3,4',5'-trihidroxiestilbeno) é um polifenol, que faz parte do conjunto das fitoalexinas, substâncias produzidas em resposta ao estresse causado por estímulos exógenos, como a radiação ultravioleta, dano mecânico e ataque por fungos patogênicos (Frémont, 2000).

Esse princípio ativo é sintetizado na planta sob duas formas isômeras: trans-resveratrol (trans-3, 4', 5-trihidróxiestilbeno) e cis-resveratrol (cis-3, 4', 5trihidróxiestilbeno) a partir de derivados de cumaril-CoA e malonil-CoA em uma reação catalisada pela enzima estilbeno sintetase (FIG. 9). Em presença de luz visível o isômero trans é convertido em cis-resveratrol (Udenigwe et al., 2008).

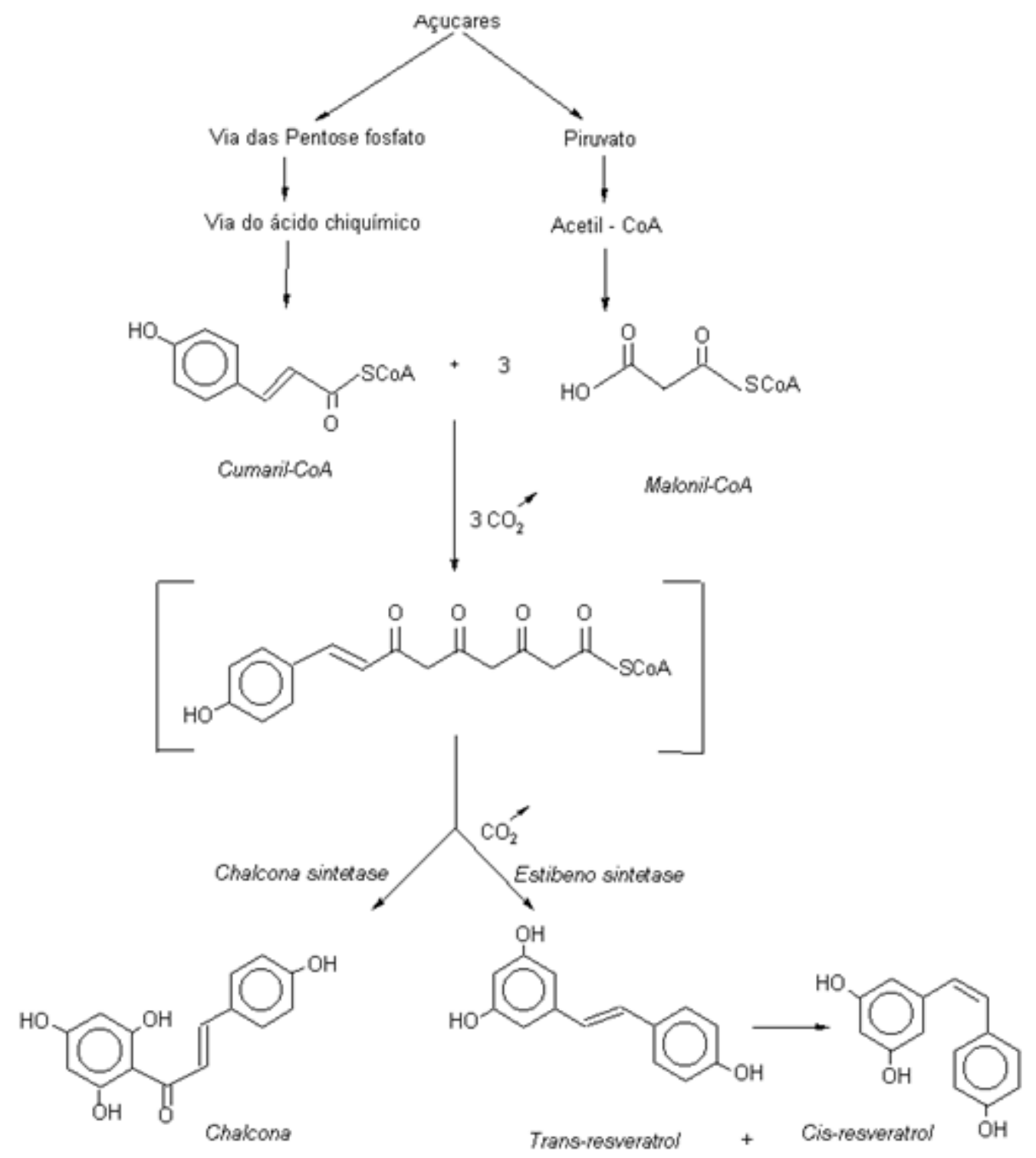

FIGURA 9 - Biosíntese do resveratrol

FONTE - Adaptada de Alves, 2006, p.35. 
Os isômeros também são encontrados sob a forma glicosídica (FIG. 10), conhecida por proteger o resveratrol da degradação oxidativa (Athar et al., 2007).

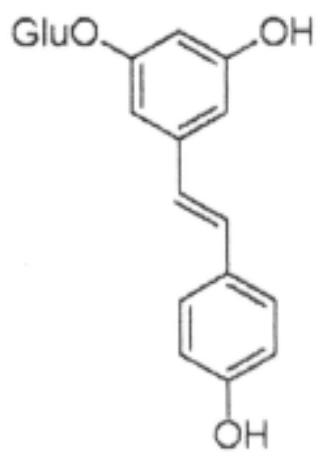

FIGURA 10 - Estrutura química da forma glicosídica de resveratrol

A molécula de resveratrol foi isolada pela primeira vez em 1940 em raízes de Veratrum grandiflorum O. Loes (Takaoka apud Baur \& Sinclair, 2006) e posteriormente, em 1963, detectada em raízes de Polygonum cuspidatum, planta de ampla utilização na medicina oriental (Takaoka apud Baur \& Sinclair, 2006).

Em 1976, Langcake e Pryce detectaram a presença de transresveratrol em tecidos da uva (Vitis vinifera) e em 1992, Siemann e Creasy reportaram a presença da molécula em vinhos (Frémont, 2000).

Atualmente, sabe-se que o resveratrol está presente naturalmente em mais de 70 espécies de plantas, como amendoim e algumas frutas silvestres, entretanto é encontrado predominantemente em cascas de uvas, que contém aproximadamente 50 a $100 \mu \mathrm{g}$ de resveratrol por grama (Soleas et al., 2002; Udenigwe et al., 2008; Sgambato et al., 2001; Baliga \& Katiyar, 2006).

Nos vinhos, o resveratrol é encontrado em concentrações relativamente altas, particularmente em vinhos tintos, cujos valores observados variam entre 0.1 a $6 \mathrm{mg} / \mathrm{L}$ (Souto et al., 2001). Por outro lado, vinhos brancos apresentam concentrações menores, em razão do processo de produção, em que a fermentação é realizada após a remoção da casca da uva.

O tipo de cultivo das uvas, origem geográfica, infecção por fungos patogênicos e práticas enológicas também podem interferir na quantidade de 
resveratrol presente nos diferentes tipos de vinhos (Meng et al., 2004; Frémont, 2000).

A presença de resveratrol em uma grande variedade de espécies de plantas e alimentos facilita seu consumo. No entanto, observou-se que embora a absorção de resveratrol seja elevada, sua biodisponibilidade por via oral é muito baixa, haja vista sua rápida metabolização no fígado. Os principais metabólitos detectados no plasma e urina foram glicuronídeos e sulfato de resveratrol (FIG. 11) (Walle et al., 2004; Boocock et al., 2007; Juan et al., 2002; Goldberg et al., 2003).

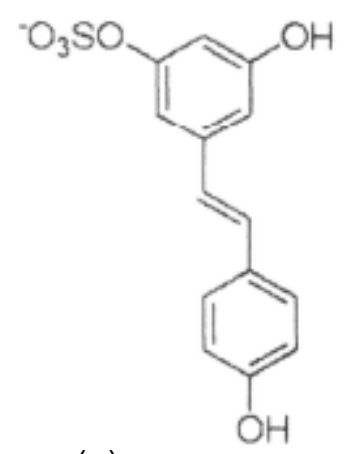

(a)

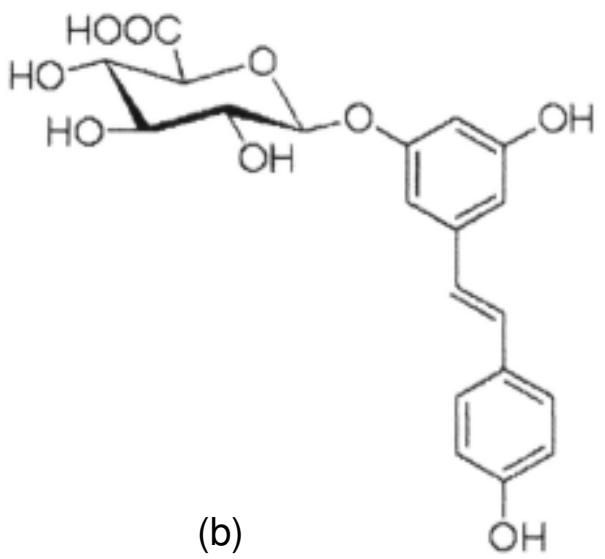

FIGURA 11 - Metabólitos de resveratrol: (a) sulfato e (b) glicuronídeo

Walle e colaboradores (2004) observaram níveis plasmáticos de transresveratrol e seus metabólitos de $491 \pm 90 \mathrm{ng} / \mathrm{mL}$ após 1 hora da administração oral de $25 \mathrm{mg}$.

Em ensaio preliminar de segurança, voluntários sadios que receberam doses de até $5 \mathrm{~g}$ de resveratrol não apresentaram eventos adversos sérios (Boocock et al., 2007). A administração oral de $20 \mathrm{mg} / \mathrm{kg}$ de trans-resveratrol durante 28 dias também se mostrou segura, não ocasionando eventos adversos ou morte em roedores (Juan et al., 2002).

A utilização de radiomarcadores possibilitou a avaliação da biodistribuição de resveratrol após administração oral. Resveratrol foi detectado em maiores concentrações em órgãos relacionados à absorção e eliminação 
como estômago, intestino, fígado e rins e, em menores quantidades, no cólon, duodeno, pulmão, coração e cérebro (Vitrac et al., 2003).

Em roedores, a diminuição dos níveis de resveratrol nos rins e as baixas concentrações encontradas no cólon indicaram que a excreção é realizada preferencialmente por via urinária e em menores quantidades pela rota fecal (Vitrac et al., 2003). Estes resultados foram semelhantes aos apresentados por Walle e colaboradores (2004), que observaram em humanos maior excreção pela urina após administração oral ou intravenosa de ${ }^{14} \mathrm{C}$-resveratrol.

\subsubsection{Propriedades e aplicações do resveratrol}

Após conhecimento do paradoxo francês, que mostrou os benefícios proporcionados pelos antioxidantes provenientes do alto consumo de vinho observou-se um aumento significativo no número de estudos envolvendo o resveratrol. Dentre os efeitos benéficos apresentados por esta molécula, podemos citar a atividade anti-inflamatória, antioxidante e a inibição da agregação plaquetária.

As atividades biológicas estão relacionadas especialmente à forma isômera trans. Entretanto, os efeitos biológicos decorrentes da utilização do cisresveratrol estão sendo estudados e os resultados obtidos indicam que este isômero também apresenta propriedades biológicas.

\subsubsection{Capacidade antioxidante}

A capacidade antioxidante recebe destaque por estar relacionada a uma série de propriedades farmacológicas, medicinais e terapêuticas apresentadas pelo resveratrol, como a prevenção e diminuição da progressão de doenças cardiovasculares, diversos tipos de câncer e do envelhecimento precoce da pele. A estrutura formada por dois anéis aromáticos ligados por uma ponte de etileno, e três grupos hidroxila é determinante para sua atividade como captador de radicais livres (Udenigwe et al., 2008).

Trans-resveratrol e trans-4-hidroxiestilbeno apresentaram capacidade semelhante em capturar radicais livres e superioridade quando comparados ao trans-3,5-di-hidroxiestilbeno, sugerindo que o grupo hidroxil presente na posição 4 apresenta dominância quando comparado ao mesmo grupo presente na posição 3 e 5 (Stojanovic et al., 2001; Stivala et al., 2001). 
A prevenção de danos oxidativos pelo trans-resveratrol foi atribuída à capacidade de captar e prevenir a formação de ERO (Rhayem et al., 2008; Sgambato et al., 2001), demonstrando efeito inibitório na formação de radicais superóxido e peróxido de hidrogênio (Martinez \& Moreno, 2000).

Leiro e colaboradores (2004) demonstraram que trans e cis-resveratrol inibiram a formação de ERO produzidos por macrófagos de forma dependente da concentração.

Stojanovic e colaboradores (2001) observaram que trans-resveratrol foi capaz de inibir a peroxidação lipídica de forma mais eficiente que a vitamina $\mathrm{C}$ e E, mostrando ser um melhor captador de radicais livres.

\subsubsection{Capacidade anticancerígena}

Em 1997, Jang e colaboradores demonstraram uma grande atividade anticancerígena do resveratrol como conseqüência de sua capacidade de inibir os estágios de iniciação, promoção e progressão da carcinogênese.

Udenigwe e colaboradores (2008) publicaram uma revisão sobre estudos que avaliaram a capacidade anticancerígena do trans-resveratrol in vitro. O mesmo apresentou capacidade quimiopreventiva em diferentes tipos de câncer, como câncer de próstata, mama, intestino, pâncreas e leucemias por diferentes mecanismos de ação. Essa atividade foi confirmada por estudos pré-clínicos realizados com resveratrol, que também mostrou in vivo ser um efetivo agente quimiopreventivo em vários tipos de câncer (Athar et al., 2007).

Além da capacidade antioxidante, outro mecanismo anticancerígeno muito publicado refere-se à habilidade do trans-resveratrol em induzir apoptose em células cancerígenas por diversos caminhos relacionados à regulação da morte e sobrevida celular (Udenigwe et al., 2008). Resveratrol foi capaz de induzir apoptose em células de epiderme de camundongo, células de leucemia promielocíticas de humanos, diversas linhagens de células de câncer de cólon e próstata e células mamárias (Dong, 2003).

\subsubsection{Efeito cardioprotetor}

O efeito cardioprotetor do resveratrol está relacionado à sua capacidade de diminuir a agregação plaquetária, regulação da produção de 
vasodilatadores e vasoconstritores, inibição da peroxidação lipídica e consequentemente prevenção da aterosclerose.

O trans-resveratrol inibe a peroxidação lipídica tanto pela captação de radicais livres quanto pela quelação de cobre, diminuindo a oxidação de lipoproteínas de baixa densidade (LDL) (Frémont, 2000; Baur \& Sinclair, 2006).

Coelhos que receberam dieta rica em colesterol apresentaram diminuição da agregação plaquetária após adminstração sistêmica de resveratrol. O resultado observado sugere uma inibição preferencial da enzima ciclooxigenase 1 (COX1) pelo resveratrol, envolvida na síntese de substâncias indutoras de agregação plaquetária e vasoconstritoras (Wang et al., 2002; Baur \& Sinclair, 2006).

\subsubsection{Atividade anti-inflamatória}

A atividade anti-inflamatória de trans-resveratrol deve-se à inibição da ciclo-oxigenase, enzima muito importante na formação de moléculas próinflamatórias, como a prostaglandina (Baur \& Sinclair, 2006; Bhat \& Pezzuto, 2002).

Martinez e Moreno (2000) observaram capacidade do trans-resveratrol em diminuir a liberação do ácido araquidônico e a formação de prostaglandinas, ambos envolvidos em processos inflamatórios.

Resveratrol também apresentou capacidade de prevenir a rejeição alogênica e reduzir significantemente processos inflamatórios como edemas agudos e crônicos induzidos quimicamente, inflamação de vias aéreas induzida por lipopolissacarídeos e osteoartrite (Baur \& Sinclair, 2006).

\subsubsection{Aplicação tópica}

Apesar de diversos estudos demonstrarem a potente eficácia de resveratrol in vitro, tendo em vista sua baixa biodisponibilidade por via oral a aplicação tópica tem sido testada contra o desenvolvimento de desordens cutâneas como o envelhecimento precoce e o câncer de pele.

A aplicação tópica de resveratrol $(25 \mu \mathrm{mol})$ em ratos resultou em uma significante inibição de edema de pele induzido pela radiação ultravioleta-B (UVB) (Afaq et al., 2003). 
Reagan-Shaw e colaboradores (2004) também estudaram os efeitos da utilização tópica de resveratrol em ratos expostos à radiação ultravioleta. A aplicação tópica de $10 \mu \mathrm{mol}$ de resveratrol 30 minutos antes da exposição (sete exposições em dias alternados) resultou em diminuição de edema de pele e de processo inflamatório ocasionados pela exposição à radiação ultravioleta.

Soleas e colaboradores (2002) observaram uma redução de 60\% em papilomas após aplicação tópica de resveratrol.

Hung e colaboradores (2008) estudaram a incorporação de resveratrol em hidrogéis e a solubilidade em diferentes veículos para o desenvolvimento de sistemas de liberação para aplicação tópica de resveratrol.

A permeação e a deposição na pele foram avaliadas in vitro e os resultados obtidos demonstraram alta permeabilidade do resveratrol de maneira dependente do $\mathrm{pH}$ das soluções aquosas. Em hidrogéis, a permeabilidade foi controlada pela viscosidade do hidrogel e os mesmos apresentaram eficácia para serem utilizados na aplicação tópica de resveratrol (Hung et al., 2008). 


\section{MATERIAIS E MÉTODOS}

\subsection{Materiais}

\subsubsection{Matérias-primas}

- 3,5,4'-trihidróxido-trans-estilbeno (trans-resveratrol), Resvetrolß Attivos Magisttrais

Aparência: pó branco

Solubilidade: solúvel em metanol e insolúvel em água

A presença de $100 \%$ de resveratrol na forma trans é garantida pela empresa Attivos magisttrais - Grupo Pharmacopéia, que comercializa o produto como Resvetrolß. Segundo certificado de análise fornecido pela empresa, o teor de trans-resveratrol determinado por cromatografia líquida de alta eficiência (HPLC) foi igual a $101,56 \%$, valor que está dentro da especificação do produto $(99,00 \%)$.

O resveratrol adquirido da empresa Attivos Magisttrais armazenado nas condições indicadas pelo fornecedor e sem exposição à luz foi considerado o padrão para as análises efetuadas.

- Poli(N-vinil-2-pirrolidona) (PVP) K 90, Kollidon® 90F - BASF Aparência: pó branco

Solubilidade: solúvel em água e solventes orgânicos

Massa molar média: 1000000 - 1500000

- Poli(etileno glicol) (PEG 300) - Oxiteno

- Ágar tipo técnico nº 3 - Oxoid

- Propano-1,2,3-triol (glicerina) - Oxoid

- 2,2 Difenil-1-picril-hidrazil (DPPH) - Sigma-aldrich

\subsubsection{Reagentes}

- Etanol UV/HPLC, espectroscópico - Vetec

- Acetonitrila grau HPLC - JT Baker

- Ácido ortofosfórico 85\% grau analítico-Merck 


\subsubsection{Materiais}

- Microplacas de 96 poços

- Vidrarias

- Coluna cromatográfica de fase reversa C18 $(5 \mu$ x 250 mm x 4,6 mm) - Chrompack

- Cubetas de quartzo

- Seringas de $1 \mathrm{~mL}$

\subsubsection{Equipamentos}

- Balança analítica, modelo BP121S- Sartorius;

- Seladora-Delgo;

- Extrator Soxhlet;

- Chapa de aquecimento - Quimis;

- Estufa de secagem, modelo Q317M - Quimis;

- Sistema de cromatografia líquida de alta eficiência (HPLC), modelo Äktapurifier - GE;

- Sistema purificador de água (milli q) - Millipore;

- Espectrofotômetro UV-visível, modelo Cary 300 - Varian;

- Gammacell, modelo 220 - Atomic Energy of Canada Limited Commercial Products;

- Estufa incubadora de CO2, modelo CB150-Binder;

- Espectrofotômetro leitor de microplacas, modelo Sunrise - Tecan;

- Incubadora, modelo TE-420 - Tecnal;

- Liofilizador, modelo dura-stop TDS3BOPT5000 - FTS systems;

- Microscópio eletrônico de varredura, modelo XL 30 - Philips;

- Microscópio eletrônico de varredura por emissão de campo, modelo JSM 7401F - Jeol;

- Sistema de cromatografia líquida de alta eficiência acoplada a espectrômetro de massas, modelo esquire 3000 plus - Bruker Daltonics. 


\subsection{Métodos}

\subsubsection{Irradiação das amostras}

As amostras foram irradiadas em irradiador de Cobalto-60 (Co-60) do tipo gammacell 220 (FIG. 12), fabricado em 1974 e localizado no Centro de Tecnologia das Radiações (CTR-IPEN).

O irradiador do tipo Gammacell 220 é composto por duas câmaras, a primária que é fixa e envolta pela fonte de Cobalto-60, composta por 35 lápis de aço inox, contendo sete pastilhas de Co-60 cada (FIG. 13) e a câmara secundária ou câmara de irradiação onde são colocadas as amostras a serem irradiadas (FIG. 12). A câmara de irradiação possui geometria cilíndrica (149 mm de diâmetro e $220 \mathrm{~mm}$ de altura) e é deslocada e encaixada no centro da câmara primária durante a irradiação. Desta forma, toda a câmara de irradiação fica envolta pela câmara primária, que contém as pastilhas de Co-60. Esta geometria permite que o campo de irradiação gama presente na câmara de irradiação seja bastante homogêneo e que a distribuição da radiação na amostra seja mais uniforme do que a obtida em irradiadores do tipo panorâmico (informação verbal Dra. Célia Marina Napolitano). 


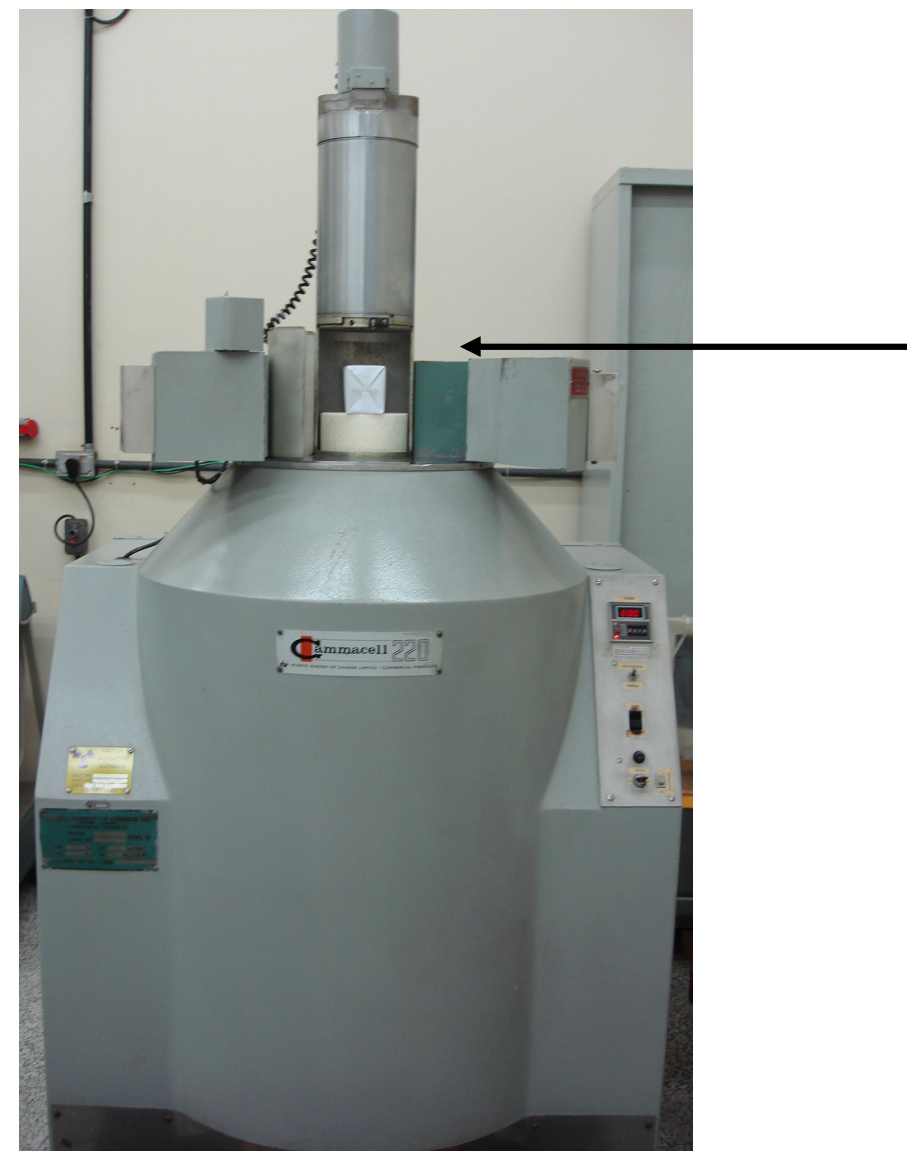

Câmara secundária

FIGURA 12 - Irradiador de Cobalto-60 do tipo gammacell

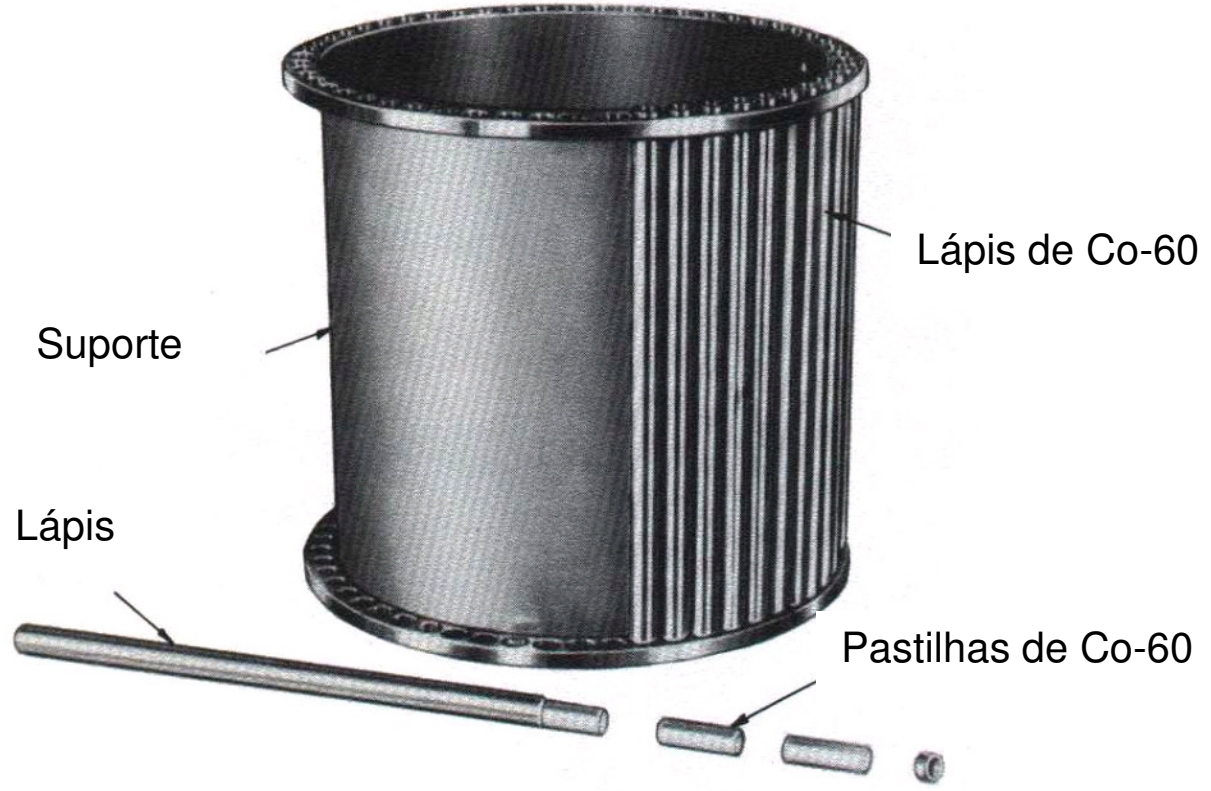

FIGURA 13 - Suporte contendo fontes de Cobalto-60 
A recarga do irradiador Gammacell, localizado no CTR-IPEN, foi realizada em 1997 pela empresa J. L. Shepherd Associates, que forneceu uma curva de isodose onde são especificadas regiões da câmara de irradiação que podem receber dose de radiação acima ou abaixo da dose desejada. Segundo essa curva de isodose quando a amostra é colocada no centro da câmara de irradiação, esta recebe $100 \%$ da dose de radiação esperada e, à medida que a amostra é localizada mais perto das paredes laterais, ou seja, mais próximo da fonte de Co-60, a dose recebida pela amostra pode ser superior, podendo chegar a $115 \%$ da dose desejada. O contrário acontece quando a amostra fica mais próxima à parede superior ou inferior da câmara de irradiação, onde a dose recebida pode ser inferior, chegando a $80 \%$ da dose desejada (informação verbal Engํㅡㄹ Carlos G. da Silveira).

A dosimetria e rastreabilidade das medidas que são realizadas é de responsabilidade do laboratório de dosimetria localizado no CTR-IPEN, que determina anualmente a taxa de dose do gammacell por meio de um dosímetro de referência, o dosímetro de Fricke, que possui qualidade metrológica.

O dosímetro de Fricke é posicionado no centro da câmara secundária e a irradiação é realizada durante um tempo predeterminado. Ao término da irradiação, é realizada uma análise quantitativa em espectrofotômetro, que permite verificar a dose recebida em função do tempo, ou seja, determinar a taxa de dose do Gammacell. Para confirmação de que a metodologia de análise, cálculos realizados, posicionamento do dosímetro e funcionamento do irradiador estão corretos, é realizada uma intercomparação das medidas determinadas no IPEN com o laboratório da Agência Internacional de Energia Atômica (AIEA). Um dosímetro de transferência (dosímetro de alanina) é enviado pela AIEA e é irradiado na mesma posição e durante o mesmo tempo que o dosímetro de Fricke. Após irradiação, o dosímetro de transferência retorna a AIEA para verificação da taxa de dose e comparação com os resultados obtidos no IPEN (informação verbal de Dra. Célia Marina Napolitano).

Embora o dosímetro de Fricke possua qualidade metrológica, este é difícil de ser manuseado, e, por este motivo quando é necessário realizar mapeamento da dose recebida pela amostra, são utilizados dosímetros de rotina, que servem como um controle de qualidade do processo de irradiação. 
Por meio da taxa de dose (kGy/h) apresentada pelo Gammacell foi possível calcular o tempo que a amostra deveria ser irradiada para que esta recebesse a dose de radiação gama desejada. Com auxílio de um suporte de isopor, todas as amostras irradiadas neste trabalho foram posicionadas no centro da câmara de irradiação, para que recebessem 100\% da dose desejada. Além disso, a realização de uma intercomparação das medidas com a AIEA e a presença de um campo de irradiação gama homogêneo não tornam necessário o mapeamento de dose para determinação da dose máxima ou mínima recebida pela amostra irradiada.

\subsubsection{Obtenção da matriz polimérica}

A composição e o procedimento de obtenção das matrizes poliméricas foram baseados no Bandge ${ }^{\circledR}$, um curativo de hidrogel, composto por PVP, PEG e ágar e reticulado a partir da irradiação da solução aquosa do polímero. O Bandge ${ }^{\circledR}$ foi desenvolvido no IPEN por meio da tecnologia transferida no início de 1990 pelo Prof. Dr. Janus A. Rosiak como colaborador da AIEA, que desenvolveu e patenteou o Aqua-Gel ${ }^{\circledR}$, comercializado na Europa.

As características apresentadas pelo Bandge ${ }^{\circledR}$ para aplicação tópica como a boa adesão à pele, facilidade de aplicação e possibilidade de incorporação de princípios ativos motivaram a utilização e adequação desse tipo de hidrogel como matriz polimérica para incorporação de resveratrol. A adição de glicerina teve por objetivo melhorar a elasticidade e resistência à manipulação do hidrogel e o efeito do álcool na reticulação das membranas também foi avaliado, pois o mesmo foi utilizado para solubilizar o resveratrol, permitindo sua incorporação nas membranas, uma vez que este princípio ativo possui baixa solubilidade em água.

Na TAB. 1 estão apresentados os componentes e concentrações das matrizes poliméricas estudadas. 
TABELA 1 - Composição das matrizes poliméricas

\begin{tabular}{ccc}
\hline Matriz polimérica & Composição & Concentração (\%) \\
\hline \multirow{3}{*}{ PVP-PEG } & PVP K90 & 6,0 \\
& PEG 300 & 1,5 \\
& Agar & 0,5 \\
& Água destilada (q.s.p.) & 100,0 \\
\hline \multirow{2}{*}{ PVP-GLI } & PVP K90 & 20,0 \\
& Glicerina & 5,0 \\
& Água destilada (q.s.p.) & 100,0 \\
\hline \multirow{3}{*}{ PVP-PEG-OH } & PVP K90 & 6,0 \\
& PEG 300 & 1,5 \\
& Agar & 0,5 \\
& Álcool etílico & 2,0 \\
& Água destilada (q.s.p.) & 100,0 \\
\hline \multirow{2}{*}{ PVP-GLI-OH } & PVP K90 & 20,0 \\
& Glicerina & 5,0 \\
& Álcool etílico & 2,0 \\
& Água destilada (q.s.p.) & 100,0 \\
\hline
\end{tabular}

Para obtenção do hidrogel de PVP-PEG adicionou-se água destilada ao PVP e PEG previamente pesados. A mistura ficou em repouso por pelo menos $24 \mathrm{~h}$ para solubilização e, após este período, adicionou-se o ágar sob aquecimento e agitação até completa homogeneização.

O hidrogel PVP-GLI foi obtido adicionando-se água destilada ao PVP e glicerina previamente pesados e a mistura obtida deixada em repouso por $24 \mathrm{~h}$ para solubilização e foi misturada até completa homogeneização.

A preparação dos hidrogéis PVP-PEG-OH e PVP-GLI-OH foi semelhante às descritas anteriormente, adicionando-se o álcool ao PVP previamente pesado e, em seguida, água destilada.

As membranas de hidrogel foram obtidas vertendo-se cerca de $5 \mathrm{~mL}$ da solução em moldes circulares de $5 \mathrm{~cm}$ de diâmetro e $0,15 \mathrm{~cm}$ de espessura, que foram selados e enviados para irradiação na dose de $20 \mathrm{kGy}$ em fonte de raios gama de Co-60, com taxa de dose 2,36 kGy/h. 


\subsubsection{Caracterização da matriz de hidrogel}

\subsubsection{Fração Gel}

Os ensaios de fração gel foram realizados utilizando amostras dos hidrogéis (triplicata) secas em estufa à temperatura de $50^{\circ} \mathrm{C}$ até massa constante.

As amostras secas foram acondicionadas em saquinho de tecido non woven e colocadas em um extrator de Soxhlet (FIG. 14) por 40 horas para extração da fração solúvel, utilizando água destilada como solvente, conforme norma ASTM D 2765-01 (ASTM, 2006). Após extração, as amostras foram secas novamente até massa constante.

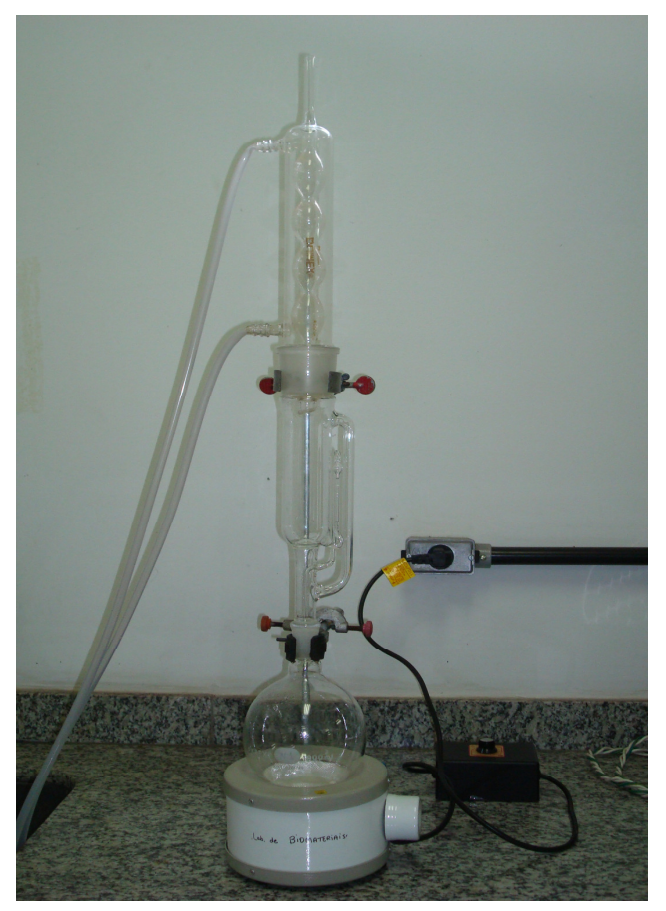

FIGURA 14 - Extrator Soxhlet

Os cálculos da fração sol (polímero solúvel) e fração gel (polímero reticulado) foram obtidos utilizando as Equações 1 e 2, respectivamente:

$$
\begin{aligned}
& S(\%)=\frac{(m i-m f)}{m i} \times 100 \\
& G(\%)=100-S(\%)
\end{aligned}
$$




$$
\begin{aligned}
& \text { Sendo: } \\
& \mathrm{mi}=\text { massa inicial desidratada; } \\
& \mathrm{mf}=\text { massa final desidratada; } \\
& \mathrm{S}(\%)=\text { porcentagem da fração sol; } \\
& \mathrm{G}(\%)=\text { porcentagem da fração gel. }
\end{aligned}
$$

\subsubsection{Intumescimento}

Para determinação do grau de intumescimento foram utilizadas amostras dos hidrogéis (triplicata) secas em estufa à temperatura de $50^{\circ} \mathrm{C}$ até massa constante.

A capacidade de intumescimento dos hidrogéis foi verificada pela imersão de cada amostra seca em $50 \mathrm{~mL}$ de solução tampão fosfato salina (PBS) de $\mathrm{pH} 5$, durante 24 horas. A determinação do grau de intumescimento foi verificada a cada hora durante as primeiras 6 horas de ensaio e após $24 \mathrm{~h}$.

O cálculo do grau de intumescimento foi obtido utilizando a Equação (3), de acordo com a norma ASTM D 570 (ASTM, 1998):

$$
\% \operatorname{Int}=\frac{\mathrm{mf}-\mathrm{mo}}{\mathrm{mo}} \times 100
$$

\footnotetext{
Sendo:

mo = massa inicial;

$\mathrm{mf}=$ massa final.
}

\subsubsection{Citotoxicidade}

A biocompatibilidade preliminar dos hidrogéis obtidos foi verificada in vitro utilizando o método de incorporação do vermelho neutro seguindo normas internacionais (ISO 10993-1, 10993-5 1992) e metodologia descrita anteriormente (Rogero et. al., 2003). Péletes de poli(cloreto de vinila) (PVC) foram utilizados como controle negativo e solução de fenol 0,02\% como controle positivo.

Para obtenção dos extratos, as amostras e os controles foram imersos em meio mínimo de Eagle (MEM) adicionado de soro fetal bovino e aminoácidos não essenciais e incubados durante $24 \mathrm{~h}$ a $37^{\circ} \mathrm{C}$. Para cada $1 \mathrm{~cm}^{2}$ de área 
superficial da amostra foi adicionado $1 \mathrm{~mL}$ de MEM e para cada $0,3 \mathrm{~g}$ de péletes foram adicionados $5 \mathrm{~mL}$ do meio de cultura.

Após este período, os extratos obtidos foram diluídos em série $(100 \%$, $50 \%, 25 \%, 12,5 \%$ e $6,25 \%$ ) e colocados em contato com uma monocamada de células da linhagem NCTC Clone 929 (células de tecido conectivo de camundongo) do American Type Culture Colection (ATCC) cultivadas em microplaca de 96 poços (FIG. 15). A microplaca contendo os extratos foi colocada em estufa com atmosfera úmida e $5 \%$ de $\mathrm{CO}_{2}$, a $37^{\circ} \mathrm{C}$ por 24 horas. O cultivo das células e a distribuição da suspensão celular na microplaca foram feitos e cedidos pela Seção de Culturas Celulares do Instituto Adolfo Lutz.

Os extratos foram substituídos por solução de corante vermelho neutro e a microplaca foi novamente colocada em estufa à $37^{\circ} \mathrm{C}$ durante $3 \mathrm{~h}$, para que 0 corante fosse incorporado pelas células vivas.

Após 3 horas, a solução de vermelho neutro foi desprezada, a microplaca lavada com solução tampão fosfato de $\mathrm{pH} 7,4$ e cada poço da microplaca preenchido com $200 \mu \mathrm{L}$ de solução de lavagem (10\% de $\mathrm{CaCl}_{2}$ em solução de formaldeído $0,5 \%$ ). Após lavagem, foram colocados $200 \mu \mathrm{L}$ de solução de extração ( $50 \%$ de ácido acético $2 \%$ e etanol $50 \%$ ) para lise das células vivas e liberação do corante incorporado.

A porcentagem de viabilidade celular foi calculada pelas leituras de densidade óticas (DOs) realizadas a $540 \mathrm{~nm}$ em espectrofotômetro modelo Sunrise da Tecan, tomando-se como referência a DO do controle de células no ensaio.

A medida da citotoxicidade foi realizada pelo cálculo do índice de citotoxicidade $\mathrm{IC} 50 \%$ que é a concentração do extrato que reduz em $50 \%$ a viabilidade celular no ensaio. O IC50\% foi obtido colocando-se em gráfico a porcentagem de viabilidade celular em relação à concentração do extrato. 


\begin{tabular}{|c|c|c|c|c|c|c|c|c|c|c|c|c|}
\hline & 1 & 2 & 3 & 4 & 5 & 6 & 7 & 8 & 9 & 10 & 11 & 12 \\
\hline A & $100 \%$ & $100 \%$ & $100 \%$ & $100 \%$ & $100 \%$ & $100 \%$ & $100 \%$ & $100 \%$ & $100 \%$ & $100 \%$ & $100 \%$ & $100 \%$ \\
\hline B & $50 \%$ & $50 \%$ & $50 \%$ & $50 \%$ & $50 \%$ & $50 \%$ & $50 \%$ & $50 \%$ & $50 \%$ & $50 \%$ & $50 \%$ & $50 \%$ \\
\hline C & $25 \%$ & $25 \%$ & $25 \%$ & $25 \%$ & $25 \%$ & $25 \%$ & $25 \%$ & $25 \%$ & $25 \%$ & $25 \%$ & $25 \%$ & $25 \%$ \\
\hline D & $12,5 \%$ & $12,5 \%$ & $12,5 \%$ & $12,5 \%$ & $12,5 \%$ & $12,5 \%$ & $12,5 \%$ & $12,5 \%$ & $12,5 \%$ & $12,5 \%$ & $12,5 \%$ & $12,5 \%$ \\
\hline E & $6,25 \%$ & $6,25 \%$ & $6,25 \%$ & $6,25 \%$ & $6,25 \%$ & $6,25 \%$ & $6,25 \%$ & $6,25 \%$ & $6,25 \%$ & $6,25 \%$ & $6,25 \%$ & $6,25 \%$ \\
\hline F & MEM & MEM & $100 \%$ & $50 \%$ & $25 \%$ & $12,5 \%$ & $6,25 \%$ & $100 \%$ & $50 \%$ & $25 \%$ & $12,5 \%$ & $6,25 \%$ \\
\hline G & MEM & MEM & $100 \%$ & $50 \%$ & $25 \%$ & $12,5 \%$ & $6,25 \%$ & $100 \%$ & $50 \%$ & $25 \%$ & $12,5 \%$ & $6,25 \%$ \\
\hline H & MEM & MEM & $100 \%$ & $50 \%$ & $25 \%$ & $12,5 \%$ & $6,25 \%$ & $100 \%$ & $50 \%$ & $25 \%$ & $12,5 \%$ & $6,25 \%$ \\
\hline
\end{tabular}

FIGURA 15 - Esquema da distribuição dos extratos das amostras e controle na microplaca. Legenda:
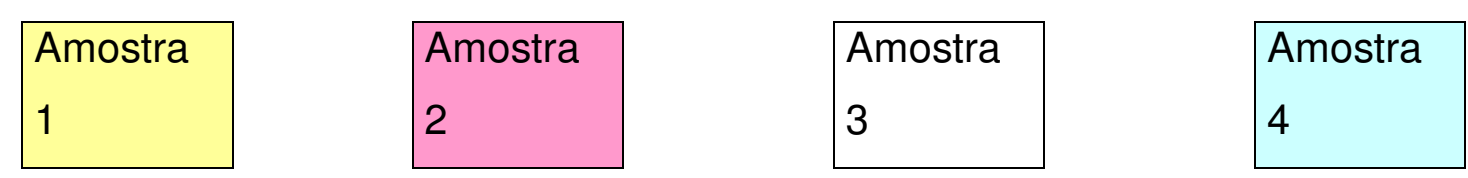

\begin{tabular}{|l|}
\hline $\begin{array}{l}\text { Controle de } \\
\text { células }\end{array}$ \\
\hline
\end{tabular}
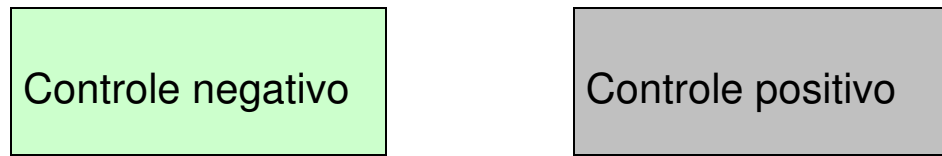

\subsubsection{Quantificação do resveratrol por cromatografia líquida de alta eficiência (HPLC)}

A cromatografia líquida de alta eficiência é uma técnica muito utilizada para quantificação e separação de compostos, pois possui alta resolução, eficiência e sensibilidade, podendo atingir detecção de parte por bilhão (ppb). Isoladamente, a HPLC não é um processo que permite a identificação de compostos, mas que fornece dados auxiliares para esta identificação, como a determinação do tempo de retenção do composto submetido à análise para comparação com seu respectivo padrão. As limitações no uso desta técnica envolvem a necessidade de solventes e equipamentos de alto custo e de mão de obra especializada. 
Conforme apresentado na FIG. 16, o sistema de HPLC é formado basicamente por injetor, coluna, reservatório, sistema de bombeamento da fase móvel, detector e registrador de dados (Holler et al., 2009).

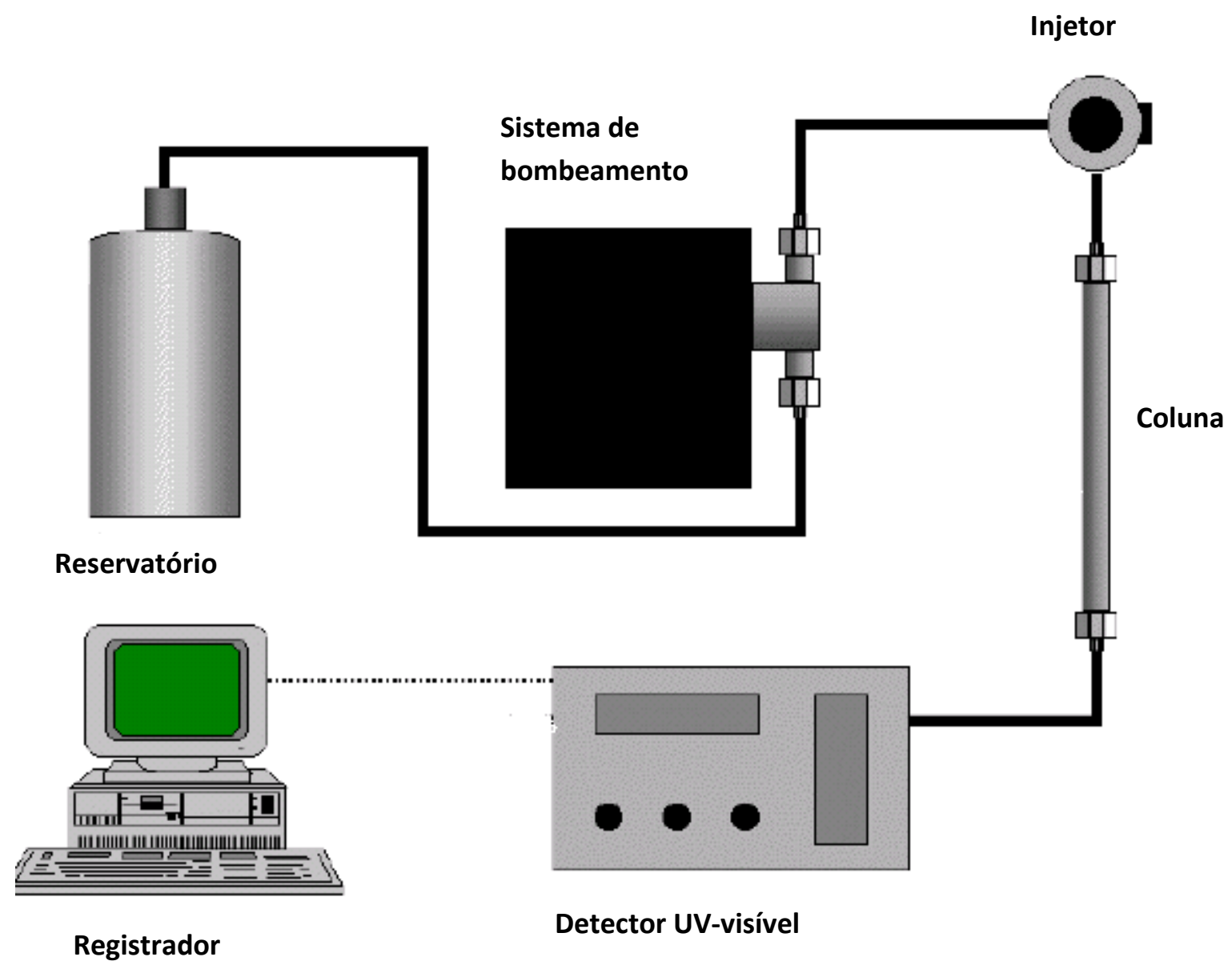

FIGURA 16 - Sistema de cromatografia líquida de alta eficiência

A análise da amostra pode ser realizada utilizando sistema isocrático ou gradiente. No sistema isocrático, a fase móvel é constituída por um único solvente ou por uma mistura de solventes de composição constante e no gradiente dois ou mais solventes são empregados e suas porcentagens variam durante a análise (Holler et al., 2009).

A quantificação do resveratrol foi realizada por meio de HPLC, utilizando sistema isocrático, coluna de fase reversa C18 (5 $\mu 250 \mathrm{~mm} \times$ 4,6 $\mathrm{mm}$ ) proveniente da Chrompack, fase móvel composta por $75 \%$ de água purificada em um sistema Milli-Q pH 3 corrigido com ácido ortofosfórico e 25\% de acetonitrila grau HPLC e fluxo de $1 \mathrm{~mL} / \mathrm{min}$ (Souto et al., 2001). 
O volume de amostra injetada foi $100 \mu \mathrm{L}$ e a detecção realizada a 306 $\mathrm{nm}$, considerado o comprimento de onda com máximo de absorção para o isômero trans.

\subsubsection{Estudo do efeito da radiação no resveratrol}

O comportamento do resveratrol sob irradiação e a influência da radiação em sua capacidade antioxidante foram estudadas, tendo em vista que o "processo Bandge|®" de produção de hidrogéis promove a reticulação e esterilização simultânea de toda a solução por meio de radiação ionizante.

Preparou-se uma solução padrão de resveratrol em álcool etílico e água purificada no sistema Milli $Q(50: 50$, v:v) na concentração de 0,1 mg/mL. Parte desta solução ficou protegida da luz e parte foi enviada para irradiação a 20 kGy em uma fonte de raios gama de Co-60, com taxa de dose 2,28 kGy/h.

Como controle foi utilizado solução de álcool e água (50:50, v:v) não irradiada e irradiada à 20 kGy, nas mesmas condições que a solução de resveratrol.

O comportamento do resveratrol frente à radiação foi verificado por cromatografia líquida de alta eficiência (HPLC), conforme descrito no item 4.2 .4 e espectrometria de massas, utilizada como auxiliar para verificação da degradação do resveratrol e formação de novos produtos, por meio da identificação do peso molecular dos compostos presentes. O espectrômetro de massas foi acoplado a um sistema de cromatografia líquida de alta eficiência, utilizado para injeção das amostras e identificação dos picos formados. $O$ volume de injeção da amostra foi $10 \mu \mathrm{L}$, temperatura de secagem $320^{\circ} \mathrm{C}$ e fluxo para massa de $90 \mu \mathrm{L} / \mathrm{min}$.

\subsubsection{Avaliação da capacidade antioxidante}

A avaliação da capacidade antioxidante do resveratrol antes e após irradiação foi verificada utilizando o 2,2-difenil-1-picril-hidrazil (DPPH•) como radical livre. A reação deste radical com antioxidantes pode ser monitorada por meio da diminuição da absorbância do radical livre, conforme descrito pelo método de Brand-Willians et al. (1995).

Foram realizados cerca de 8 ensaios para padronização e adequação do método de avaliação da capacidade antioxidante. Problemas como 
evaporação do solvente, interferência da temperatura, degradação do DPPH• decorrente da exposição à lâmpada do espectrofotômetro foram solucionados.

Preparou-se uma solução padrão de DPPH• em etanol na concentração de $4,5 \times 10^{-2} \mathrm{mg} / \mathrm{mL}$ e sua absorbância foi verificada a $515 \mathrm{~nm}$ em espectrofotômetro modelo Cary 300, utilizando etanol como branco. Esta leitura de absorbância foi considerada a absorbância inicial do ensaio referente à concentração inicial de DPPH• antes da reação com o resveratrol.

Partindo da solução padrão, foram realizadas oito diluições utilizando álcool etílico, obtendo soluções de DPPH• com concentrações de 4,5 x 10² a 4,15 $\times 10^{-4} \mathrm{mg} / \mathrm{mL}($ TAB. 2).

TABELA 2 - Concentrações de DPPH• para construção da curva padrão

\begin{tabular}{cc}
\hline Solução & Concentração $(\mathbf{m g} / \mathbf{m L})$ \\
\hline 1 & $4,5 \times 10^{-2}$ \\
2 & $2,075 \times 10^{-2}$ \\
3 & $1,0375 \times 10^{-2}$ \\
4 & $0,83 \times 10^{-2}$ \\
5 & $0,6225 \times 10^{-2}$ \\
6 & $5,1875 \times 10^{-3}$ \\
7 & $4,15 \times 10^{-3}$ \\
8 & $4,15 \times 10^{-4}$ \\
\hline
\end{tabular}

A curva padrão foi obtida colocando-se em gráfico os valores de absorbância de cada solução em relação à sua concentração, obtendo-se a equação (4):

$$
\begin{aligned}
& \operatorname{Abs}_{515 n m}=0,0389 \times\left(C_{D P P H}\right)-0,0001 \\
& R^{2}=0,9999
\end{aligned}
$$

Sendo:

Abs $_{515 \mathrm{~nm}}=$ absorbância em $515 \mathrm{~nm}$;

$\left(\mathrm{C}_{\mathrm{DPPH}}\right)=$ concentração de DPPH•. 
Por se tratar de um radical livre que ficaria exposto à lâmpada do espectrofotômetro durante algumas horas, considerou-se que poderia haver uma degradação do mesmo. Para eliminar esta interferência foram realizadas leituras da absorbância da solução padrão a cada 10 minutos durante 90 minutos. A curva de degradação do DPPH• foi obtida colocando-se em gráfico os valores de absorbância em cada tempo.

Para avaliação da capacidade antioxidante do resveratrol adicionou-se 3,9 mL da solução padrão de DPPH• a 0,1 mL da solução de resveratrol (irradiada ou não irradiada). Em cubeta de quartzo, o consumo do radical livre pelo resveratrol foi monitorado à $1^{\circ} \mathrm{C}$ pela leitura da absorbância em $515 \mathrm{~nm}$ a cada 10 minutos durante 190 minutos, utilizando etanol como branco. Para evitar a evaporação do solvente e a interferência da luz, a cubeta permaneceu fechada e não foi retirada do espectrofotômetro entre cada leitura.

A concentração de DPPH• nos diferentes tempos foi calculada utilizando a Equação (4), obtida por meio da curva padrão.

A capacidade do resveratrol em captar radicais livres foi determinada comparando a porcentagem de DPPH • remanescente nos diferentes tempos, utilizando a Equação (5):

$$
\%(\mathrm{DPPH}) \mathrm{rem}=\frac{(\mathrm{DPPH}) \mathrm{t}}{(\mathrm{DPPH}) \mathrm{i}} \times 100
$$

Sendo:

$\%(\mathrm{DPPH})_{\text {rem }}=$ porcentagem de DPPH remanescente;

(DPPH)t = concentração de DPPH nos diferentes tempos;

$(\mathrm{DPPH}) \mathrm{i}=$ concentração de DPPH inicial.

\subsubsection{Avaliação do comportamento do resveratrol frente à luz ultravioleta}

Tendo em vista que as atividades biológicas estão relacionadas especialmente à forma isômera trans, foi realizado um estudo a fim de certificar que o resveratrol utilizado apresentava-se com esta isomeria, conforme garantido pela empresa Attivos Magisttrais, que comercializa o Resvetrol ${ }^{\circledR}$ (forma trans pura padronizada $100 \%)$.

Preparou-se uma solução padrão de resveratrol em álcool etílico e água purificada no sistema Milli $Q(50: 50$, v:v) na concentração de $0,1 \mathrm{mg} / \mathrm{mL}$. A 
partir desta solução foram realizadas diluições utilizando água purificada no sistema Milli $Q$, obtendo uma solução com concentração de 1,25 x $10^{-2} \mathrm{mg} / \mathrm{mL}$. Parte desta solução ficou protegida da luz e parte foi exposta à luz solar durante 6h, período em que já seria possível observar uma conversão de trans para cisresveratrol.

A quantificação do trans-resveratrol presente nas soluções $\left(1,25 \times 10^{-2}\right.$ $\mathrm{mg} / \mathrm{mL}$ ) antes e após exposição à luz solar foi realizada em HPLC, conforme descrito no item 4.2.4.

As absorbâncias de cada solução foram verificadas em espectrofotômetro modelo Cary 300 em uma faixa de comprimento de onda de 200 a $800 \mathrm{~nm}$. Para que a leitura de absorbância ficasse entre 0 e 1, as soluções foram diluídas utilizando água purificada no sistema Milli $Q$, obtendo soluções com concentração igual a $6,25 \times 10^{-3} \mathrm{mg} / \mathrm{mL}$

Os perfis espectrofotométricos antes e após exposição à luz solar foram comparados com espectros de trans e cis-resveratrol da literatura, permitindo a observação da conversão do trans para cis-resveratrol.

\subsubsection{Obtenção do dispositivo}

Os dispositivos foram obtidos pela incorporação direta ou indireta do resveratrol na matriz polimérica.

\subsubsection{Método Direto}

A incorporação direta do resveratrol foi realizada durante a preparação da matriz polimérica, antes do envio para irradiação. Concentrações diferentes de resveratrol foram avaliadas, conforme descrito na TAB. 3. 
TABELA 3 - Composição do dispositivo obtido pelo método direto

\begin{tabular}{ccccc}
\hline \multirow{2}{*}{ Componentes } & \multicolumn{4}{c}{ Concentração (\%) } \\
\cline { 2 - 5 } & PVP-RES 0,05 & PVP-RES 0,1 & GLI-RES 0,05 & GLI-RES 0,1 \\
\hline PVP K90 & 6,0 & 6,0 & 20,0 & 20,0 \\
PEG 300 & 1,5 & 1,5 & - & - \\
Agar & 0,5 & 0,5 & - & - \\
Glicerina & - & - & 5,0 & 5,0 \\
Etanol & 2 & 4 & 2 & 4 \\
Resveratrol & 0,05 & 0,1 & 0,05 & 0,1 \\
\hline
\end{tabular}

Para obtenção dos dispositivos contendo PVP e PEG, o resveratrol foi dissolvido no álcool e a solução adicionada ao PVP e PEG previamente pesados, a água destilada foi adicionada em seguida. A mistura ficou em repouso por pelo menos 24 horas para intumescimento e após este período, adicionou-se o ágar sob aquecimento e agitação até completa homogeneização.

Os dispositivos contendo PVP e glicerina foram sintetizados adicionando-se a solução de resveratrol e álcool ao PVP e glicerina previamente pesados. Adicionou-se água destilada e a mistura obtida ficou em repouso por 24 horas para intumescimento. A solução obtida foi misturada até completa homogeneização.

Os dispositivos foram obtidos vertendo-se cerca de $5 \mathrm{~mL}$ da solução em moldes circulares de $5 \mathrm{~cm}$ de diâmetro e $0,15 \mathrm{~cm}$ de espessura, que foram selados e enviados para irradiação na dose de $20 \mathrm{kGy}$ em uma fonte de raios gama de Co-60, com taxa de dose 2,14 kGy/h.

Os dispositivos obtidos foram caracterizados pelos ensaios de fração gel, intumescimento e citotoxicidade, conforme descrito nos itens 4.2.3.1, 4.2.3.2 e 4.2.3.3, respectivamente.

\subsubsection{Método Indireto}

A obtenção do dispositivo pelo método indireto foi realizada pelo intumescimento da matriz polimérica previamente obtida em solução contendo o princípio ativo. 
Este tipo de incorporação tem como objetivo prevenir a degradação e consequentemente perda ou diminuição da atividade do princípio ativo decorrente da exposição do mesmo à radiação ionizante.

Devido à baixa solubilidade do resveratrol em água ou PBS, a capacidade de intumescimento das matrizes poliméricas foi realizada em álcool, com o objetivo de verificar se as mesmas eram capazes de absorver o volume de álcool necessário para solubilização do resveratrol.

\section{Intumescimento das matrizes poliméricas em álcool etílico}

As amostras dos hidrogéis (triplicata) foram secas em estufa à temperatura de $50^{\circ} \mathrm{C}$ até massa constante. A determinação do grau de intumescimento dos hidrogéis foi verificada pela imersão de cada amostra seca em $50 \mathrm{~mL}$ de álcool etílico durante 24 horas.

A capacidade de intumescimento foi verificada a cada hora durante as primeiras 6 horas de ensaio e após $24 \mathrm{~h}$.

Pela diferença de massa antes e após intumescimento, foi possível observar a capacidade de absorver álcool em função do tempo, uma vez que a liberação seria realizada logo após a incorporação.

O cálculo do grau de intumescimento foi obtido utilizando a Equação (3).

\section{Incorporação do resveratrol}

O método de incorporação indireto foi realizado para obtenção de dispositivos contendo $0,1 \%$ de resveratrol (PVP-PEG-RES e PVP-GLI-RES).

A quantidade de resveratrol incorporada foi calculada tendo como base o volume vertido de solução $(5 \mathrm{~mL})$ para obtenção dos dispositivos por método direto.

Após irradiação, as matrizes de hidrogéis obtidas foram cortadas ao meio e secas em estufa à 50ㄷ até obtenção de massa constante. Após secagem, foram imersas em solução contendo $0,0025 \mathrm{mg}$ de resveratrol e 1,5 $\mathrm{mL}$ de álcool etílico e deixadas em repouso até intumescimento total da solução.

A massa do recipiente utilizado foi verificada antes e após intumescimento para certificar que todo resveratrol havia sido incorporado pela matriz. 


\subsubsection{Cinética de liberação e doseamento do resveratrol}

\subsubsection{Intumescimento dos dispositivos em PBS}

A capacidade de intumescimento dos dispositivos foi verificada, uma vez que os mesmos serão utilizados hidratados e que a capacidade de absorção de água influencia na liberação do princípio ativo pela matriz polimérica.

O ensaio foi realizado conforme descrito no item 4.2.3.2 utilizando amostras dos dispositivos hidratados.

\subsubsection{Cinética de liberação}

Os ensaios de liberação foram realizados in vitro utilizando metade dos dispositivos obtidos, imersos em $35 \mathrm{~mL}$ de PBS de $\mathrm{pH} 5$ em frasco de vidro protegido da luz. Os frascos foram acondicionados em incubadora da Tecnal, modelo TE-420, sob agitação a 2600 rpm e $36^{\circ} \mathrm{C}$.

Alíquotas de $1 \mathrm{~mL}$ foram coletadas a cada hora durante as primeiras 6 horas de ensaio e após 24 horas. A cada coleta, o volume retirado foi resposto com PBS de $\mathrm{pH} 5$.

As alíquotas coletadas ficaram protegidas da luz e foram mantidas em geladeira até o momento da quantificação do resveratrol liberado.

\subsubsection{Quantificação do resveratrol liberado}

A quantificação do resveratrol liberado foi realizada por cromatografia líquida de alta eficiência (HPLC), conforme descrito no item 4.2.4. O volume de injeção foi $100 \mu \mathrm{L}$ e detecção realizada a $306 \mathrm{~nm}$.

Preparou-se uma solução padrão de resveratrol em álcool etílico e água purificada no sistema Milli Q (50:50) na concentração de 0,1 mg/mL. A partir desta solução foram realizadas diluições utilizando álcool etílico e água (50:50) obtendo soluções com concentrações de $10^{-1}$ a $10^{-5} \mathrm{mg} / \mathrm{mL}$.

Para quantificar o resveratrol liberado, foi construída uma curva padrão utilizando os valores das concentrações em relação à área do pico, obtida pela análise no HPLC. Por meio da curva padrão, foi obtida a Equação 6, utilizada para calcular a concentração de resveratrol liberada. 


$$
\begin{aligned}
& \text { Área do pico }=10^{8}\left(\mathrm{C}_{\mathrm{RES}}\right)-16023 \\
& \mathrm{R}^{2}=0,9997
\end{aligned}
$$

Onde:

Área do pico = área do pico obtida pela análise em HPLC;

$\left(C_{R E S}\right)=$ Concentração de resveratrol em $\mathrm{mg} / \mathrm{mL}$.

\subsubsection{Avaliação da capacidade antioxidante do resveratrol liberado pelo dispositivo}

Para que o dispositivo seja considerado um sistema de liberação de resveratrol adequado, além de demonstrar capacidade de liberar o princípio ativo incorporado, o resveratrol deve apresentar atividade após liberação.

A avaliação da capacidade antioxidante do resveratrol liberado pelos dispositivos foi realizada conforme descrito anteriormente no item 4.2.5.1. Adicionou-se $3,9 \mathrm{~mL}$ da solução padrão de $\mathrm{DPPH} \bullet$ a $0,1 \mathrm{~mL}$ da alíquota coletada após 24 horas de liberação, obtida no ensaio de cinética de liberação.

O consumo do radical livre pelo resveratrol liberado dos dispositivos foi monitorado pela leitura da absorbância em $515 \mathrm{~nm}$ a cada 10 minutos durante 210 minutos.

\subsubsection{Análise dos dispositivos obtidos por método direto}

\section{Análise da superfície dos dispositivos por Microscopia eletrônica de varredura (MEV)}

Os dispositivos GLI-RES 0,05 e PVP-RES 0,05 foram observados ao microscópio eletrônico de varredura antes e após serem submetidos ao ensaio de liberação, com o objetivo de verificar se havia presença de cavidades e como era a distribuição do resveratrol pelos dispositivos.

Os dispositivos intactos, ou após serem submetidos durante 24 horas ao ensaio de liberação, foram liofilizados, fraturados e suas amostras mantidas em frasco fechado a vácuo até o momento do tratamento para realização da MEV.

As amostras dos dispositivos intactos foram fixadas com adesivo de carbono em um suporte, recobertas com ouro e levadas ao microscópio eletrônico 
de varredura para visualização do interior. As amostras dos dispositivos submetidos ao ensaio de liberação foram colocadas em suporte e observadas em microscópio eletrônico de varredura de emissão de campo.

\section{Espectrometria de massas das alíquotas obtidas no ensaio de liberação}

A dose de radiação utilizada para reticulação das membranas poderia levar à degradação do resveratrol e consequentemente poderia haver liberação dos produtos de degradação pelos dispositivos obtidos pelo método direto. Desta maneira, as alíquotas coletadas após 24 horas de liberação dos dispositivos PVPRES 0,05 e GLI-RES 0,05 foram analisadas por espectrometria de massas, conforme descrito no item 4.2.5, para verificar se havia liberação de compostos de degradação.

A hipótese de que poderia haver proteção do resveratrol pelos componentes da formulação foi considerada e uma solução de resveratrol em álcool etílico e água purificada no sistema Milli Q (50:50, v:v) na concentração de $0,1 \mathrm{mg} / \mathrm{mL}$ foi irradiada a $600 \mathrm{~Gy}$, dose menor do que a utilizada na reticulação das membranas, para que seu espectro de massas fosse utilizado em comparação aos espectros das alíquotas de liberação. 


\section{RESULTADOS E DISCUSSÃO}

\subsection{Obtenção da matriz polimérica}

Como esperado, a matriz polimérica PVP-PEG apresentou características semelhantes às do Bandgel ${ }^{\circledR}$, mostrando-se adequada ao manuseio, com boa adesividade à pele e transparência. A adição de glicerina ou álcool não alterou estas características (FIG. 17) e todas as matrizes obtidas foram consideradas adequadas para incorporação de resveratrol.

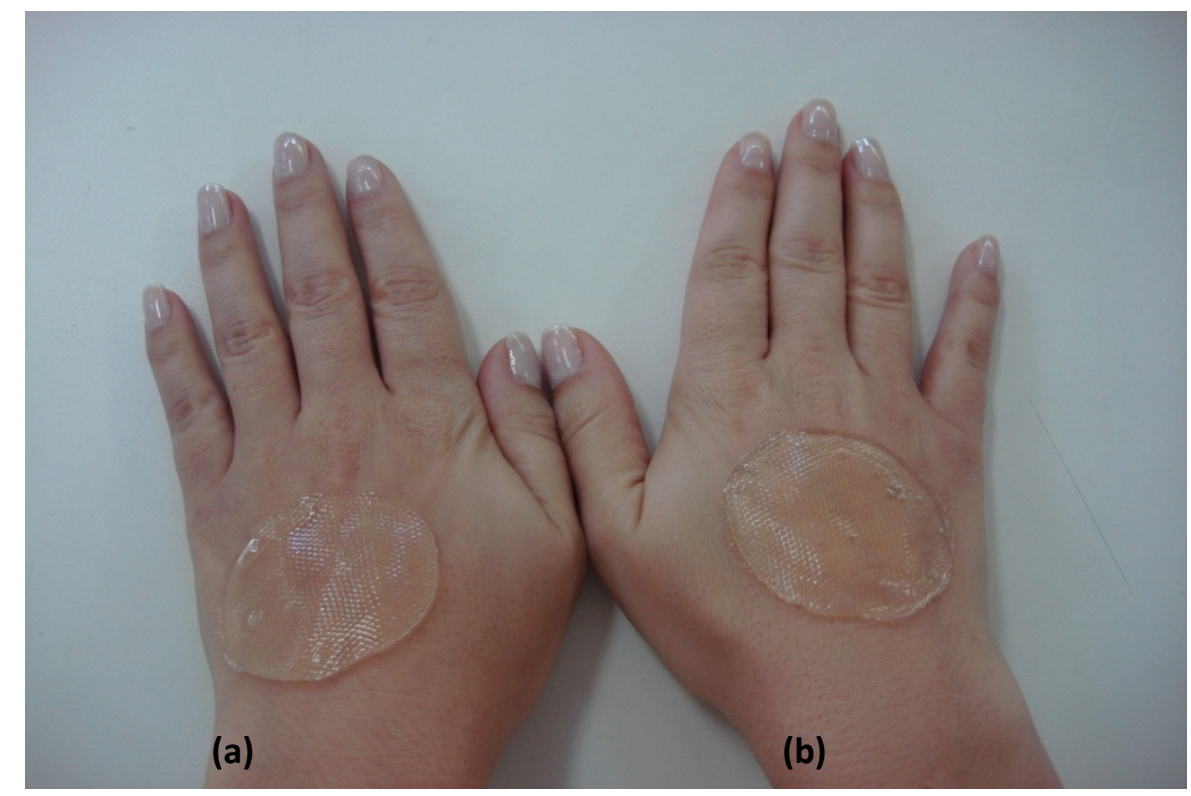

FIGURA 17 - Matrizes poliméricas: (a) PVP-PEG-OH e (b) PVP-GLI-OH

\subsection{Caracterização da matriz de hidrogel}

\subsubsection{Fração Gel}

O ensaio de fração gel permite identificar a fração de polímero reticulado em relação ao total de polímero presente.

A porcentagem de fração gel obtida foi de aproximadamente $80 \%$ para todas as matrizes, conforme apresentado na TAB. 4, indicando um conteúdo de gel elevado, ou seja, um alto grau de reticulação para todas as matrizes estudadas. 
Os resultados obtidos foram semelhantes aos apresentados por Ajii et al. (2005) que estudaram matrizes de hidrogéis compostas por PVP em diferentes concentrações, PEG e ágar. Neste estudo, o hidrogel contendo 6\% de PVP irradiado a 25 kGy apresentou porcentagem de fração gel igual a 81\% (Ajji et al., 2005).

TABELA 4 - Resultados dos ensaios de fração gel das matrizes de hidrogel

\begin{tabular}{cc}
\hline Matriz & Fração gel (\%) \\
\hline PVP-PEG & $88 \pm 0,1$ \\
PVP-GLI & $81 \pm 1,1$ \\
\hline PVP-PEG-OH & $77 \pm 1,8$ \\
PVP-GLI-OH & $78 \pm 0,7$ \\
\hline
\end{tabular}

Segundo estudo realizado por Razzak et al. (2001), blendas de PVP e PVA irradiadas a 20 kGy apresentaram cerca de $80 \%$ de fração gel, valor semelhante ao obtido neste trabalho, como pode ser observado na TAB. 4.

A presença de glicerina e/ou álcool resultou em uma diminuição na reticulação das matrizes, como consequência de sua ação como seqüestrador de radicais livres, o que diminui a formação e recombinação de radicais poliméricos e consequentemente uma diminuição na formação de ligações cruzadas. Além disso, o aumento da concentração de PVP e a presença da glicerina na matriz PVP-GLI podem ter acarretado uma diminuição na mobilidade das cadeias poliméricas, evitando a recombinação dos radicais poliméricos e a formação de ligações cruzadas.

\subsubsection{Intumescimento}

O intumescimento é definido como a quantidade de água absorvida pelo material polimérico no equilíbrio, quando o mesmo é submerso em água por um período de tempo suficiente para que o sistema atinja volume constante (Flory, 1986).

Segundo Rosiak (1991), os fatores mais importantes que determinam a capacidade de intumescimento são a hidrofilicidade da cadeia polimérica e a densidade de reticulação. 
Na TAB. 5 e FIG. 18 estão apresentados os resultados e as curvas de intumescimento das matrizes estudadas. Pode-se observar que todas as matrizes apresentaram boa capacidade de intumescimento e que, durante as seis primeiras horas, o intumescimento foi rápido.

As matrizes PVP-PEG e PVP-PEG-OH atingiram equilíbrio após 24 horas de ensaio, o que não foi observado para os hidrogéis PVP-GLI e PVP-GLI$\mathrm{OH}$, indicando que provavelmente a presença de glicerina diminua a densidade de reticulação, o que possibilita maior capacidade de absorção.

Durante as seis primeiras horas de ensaio, as matrizes contendo álcool apresentaram perfil e capacidade de intumescimento semelhantes. No entanto, a PVP-GLI-OH não atingiu equilíbrio, apresentando uma diferença de 26\% após 24 horas em relação à PVP-PEG-OH.

TABELA 5 - Resultados de intumescimento das matrizes de hidrogel

\begin{tabular}{ccccc}
\hline \multirow{2}{*}{ Tempo (h) } & \multicolumn{4}{c}{ Intumescimento (\%) \pm DP } \\
\cline { 2 - 5 } & PVP-PEG & PVP-PEG-OH & PVP-GLI & PVP-GLI-OH \\
\hline 1 & $915 \pm 29$ & $577 \pm 57$ & $386 \pm 44$ & $494 \pm 40$ \\
2 & $1291 \pm 36$ & $885 \pm 50$ & $639 \pm 78$ & $813 \pm 39$ \\
3 & $1513 \pm 51$ & $1135 \pm 71$ & $864 \pm 96$ & $1057 \pm 46$ \\
4 & $1663 \pm 23$ & $1309 \pm 91$ & $1039 \pm 129$ & $1259 \pm 61$ \\
5 & $1777 \pm 48$ & $1461 \pm 96$ & $1221 \pm 148$ & $1454 \pm 56$ \\
6 & $1839 \pm 34$ & $1624 \pm 92$ & $1318 \pm 150$ & $1600 \pm 92$ \\
24 & $2049 \pm 40$ & $2061 \pm 41$ & $2307 \pm 133$ & $2796 \pm 123$ \\
\hline
\end{tabular}




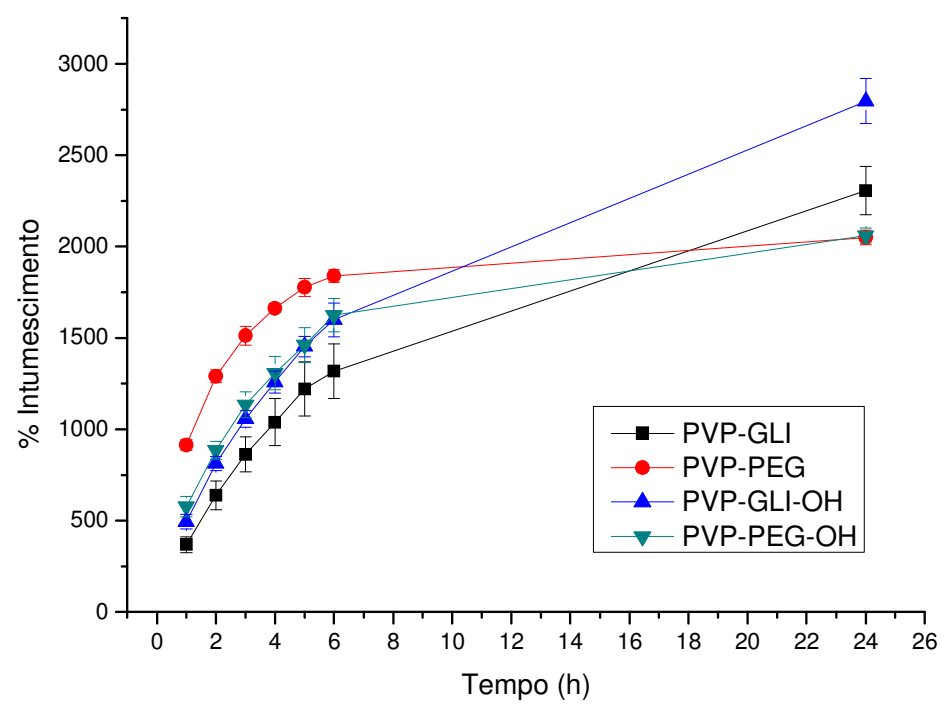

FIGURA 18 - Curvas de intumescimento dos hidrogéis

Em estudo realizado por Ajji et al. (2005), hidrogéis contendo 6\% de PVP e irradiados a $25 \mathrm{kGy}$ apresentaram grau de intumescimento de aproximadamente $1800 \%$ após 24 horas. Estes resultados foram semelhantes aos das matrizes PVP-PEG e PVP-PEG-OH, cujos valores de intumescimento foram próximos a $2000 \%$.

\subsubsection{Citotoxicidade}

A biocompatibilidade pode ser definida como a capacidade de um material funcionar com uma resposta apropriada do hospedeiro em uma aplicação específica (Williams, 1986). O primeiro critério para verificar a biocompatibilidade de um material é a avaliação de sua citotoxicidade. A utilização de testes in vitro funciona como uma triagem inicial na primeira fase de avaliação da biocompatibilidade, minimizando o uso de animais em pesquisa.

Os resultados obtidos nesta fase inicial direcionam se deve haver ou não continuidade nos testes e utilização de animais para verificação de outros critérios como irritabilidade e alergenicidade, que também determinam a biocompatibilidade. Desta maneira, apenas não apresentar citotoxicidade não implica necessariamente em biocompatibilidade do material.

A biocompatibilidade preliminar dos hidrogéis foi verificada in vitro por meio do teste de citotoxicidade. A medida da citotoxicidade foi realizada pelo 
cálculo do índice de citotoxicidade $\mathrm{IC}_{50 \%}$ que determina quantitativamente $\mathrm{O}$ potencial citotóxico do material testado e indica a concentração do extrato que reduz em $50 \%$ a viabilidade celular no ensaio.

As curvas de viabilidade celular e o $\mathrm{IC}_{50 \%}$ foram obtidos colocando-se em gráfico os valores de porcentagem de viabilidade celular em relação à concentração do extrato. Os resultados e as curvas de viabilidade celular obtidas estão apresentados na TAB. 6 e FIG. 19, onde pode ser observado que as matrizes estudadas mostraram comportamento semelhante ao controle negativo, ou seja, não toxicidade. Somente o controle positivo apresentou-se tóxico, com $\mathrm{IC}_{50 \%}$ de 72 indicando que o extrato do controle positivo na concentração de $72 \%$ provocou a morte de $50 \%$ da população celular no ensaio.

O comportamento apresentado pelos hidrogéis e controles foi semelhante ao encontrado em trabalhos publicados anteriormente que também avaliaram in vitro a citotoxicidade de hidrogéis de PVP (Lopérgolo et al., 2003; Higa et al., 1999).

TABELA 6 - Resultados da viabilidade celular do ensaio de citotoxicidade dos hidrogéis PVP-PEG e PVP-GLI

\begin{tabular}{ccccc}
\hline & \multicolumn{4}{c}{ Viabilidade Celular (\%) \pm dp } \\
\cline { 2 - 5 } Concentração & Controle & Controle & PVP-PEG & PVP- GLI \\
Extrato (\%) & negativo & Positivo & & \\
\hline 100 & $117 \pm 9$ & $0 \pm 0$ & $99 \pm 14$ & $92 \pm 18$ \\
50 & $106 \pm 12$ & $86 \pm 4$ & $93 \pm 16$ & $80 \pm 19$ \\
25 & $105 \pm 13$ & $137 \pm 13$ & $85 \pm 10$ & $80 \pm 4$ \\
12,5 & $100 \pm 10$ & $112 \pm 17$ & $98 \pm 7$ & $81 \pm 11$ \\
6,25 & $129 \pm 11$ & $133 \pm 13$ & $100 \pm 17$ & $104 \pm 0$ \\
\hline
\end{tabular}




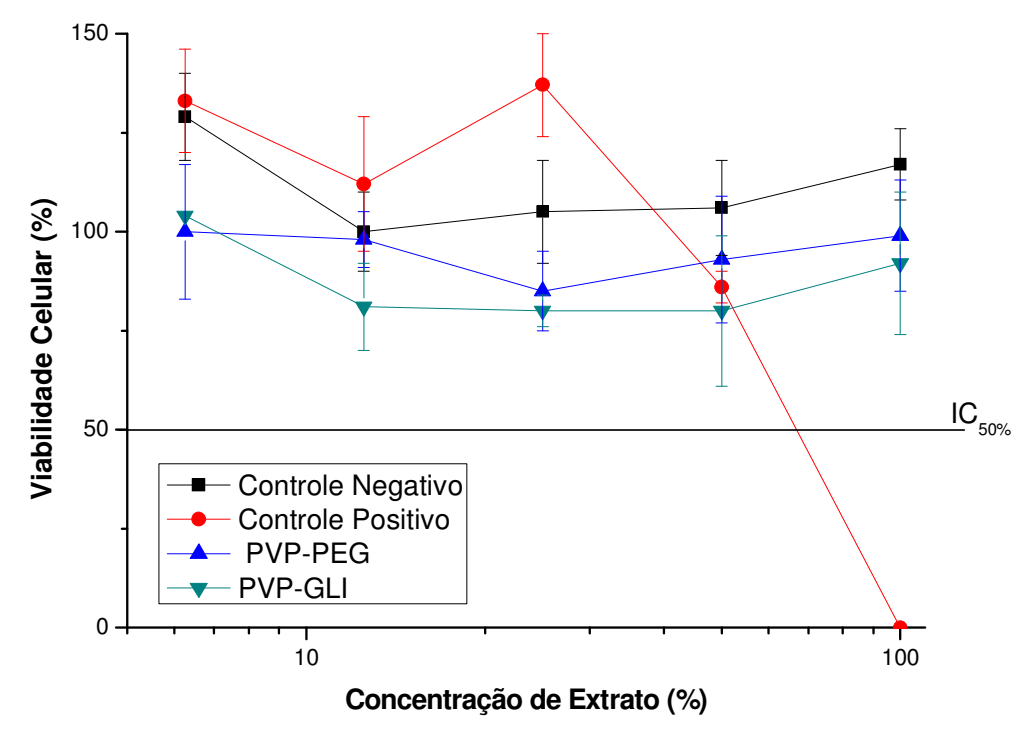

FIGURA 19 - Curvas de viabilidade celular dos hidrogéis de PVP-PEG e PVP-GLI no ensaio de citotoxicidade

\subsection{Estudo do efeito da radiação no resveratrol}

\subsubsection{Avaliação da integridade}

Na TAB. 7 estão apresentados os tempos de retenção e área dos picos das soluções de resveratrol. O tempo de retenção do resveratrol foi de aproximadamente 12 minutos e área do pico de 10362953 para a solução não irradiada e 2078 para a irradiada.

Os cromatogramas das soluções de resveratrol não irradiada e irradiada estão apresentados nas FIG. 20 e 21, respectivamente. Após irradiação, podemos observar quase completa degradação do resveratrol e o aparecimento de seis novos picos, indicando a formação de produtos de degradação.

As alterações observadas após irradiação são resultado da interação direta e indireta da radiação com a molécula do resveratrol. De forma indireta, ocorre por meio dos "produtos da radiólise da água", que também interagem com o resveratrol danificando-o.

Os resultados obtidos foram semelhantes aos apresentados por Bader et al. (2008) que detectaram degradação estrutural e formação de produtos de decomposição do resveratrol, após irradiação em solução aquosa à 1 kGy.

Nos cromatogramas de etanol/água não foram observados picos antes ou após irradiação. 
TABELA 7 - Tempos de retenção e áreas dos picos das soluções de resveratrol não irradiada e irradiada a 20 kGy

\begin{tabular}{ccccc}
\hline Dose (kGy) & Pico & $\begin{array}{c}\text { Tempo de } \\
\text { retenção (min) }\end{array}$ & Área & Área (\%) \\
\hline 1 & 2.612 & 5108 & 0.049 \\
0 & 2 & 7.703 & 1041 & 0.010 \\
& 3 & 8.627 & 1002 & 0.010 \\
& 4 & 12.033 & 10362953 & 99.917 \\
\hline 1 & 2.014 & 6131 & 7.390 \\
& 2 & 2.563 & 10171 & 12.260 \\
& 3 & 3.108 & 34737 & 41.870 \\
& 4 & 4.678 & 11685 & 14.085 \\
& 5 & 5.565 & 10279 & 12.389 \\
6 & 7.758 & 3445 & 4.153 \\
& 7 & 8.675 & 1105 & 1.332 \\
8 & 9.527 & 2029 & 2.446 \\
9 & 12.035 & 2078 & 2.505 \\
10 & 12.620 & 1302 & 1.570 \\
\hline
\end{tabular}

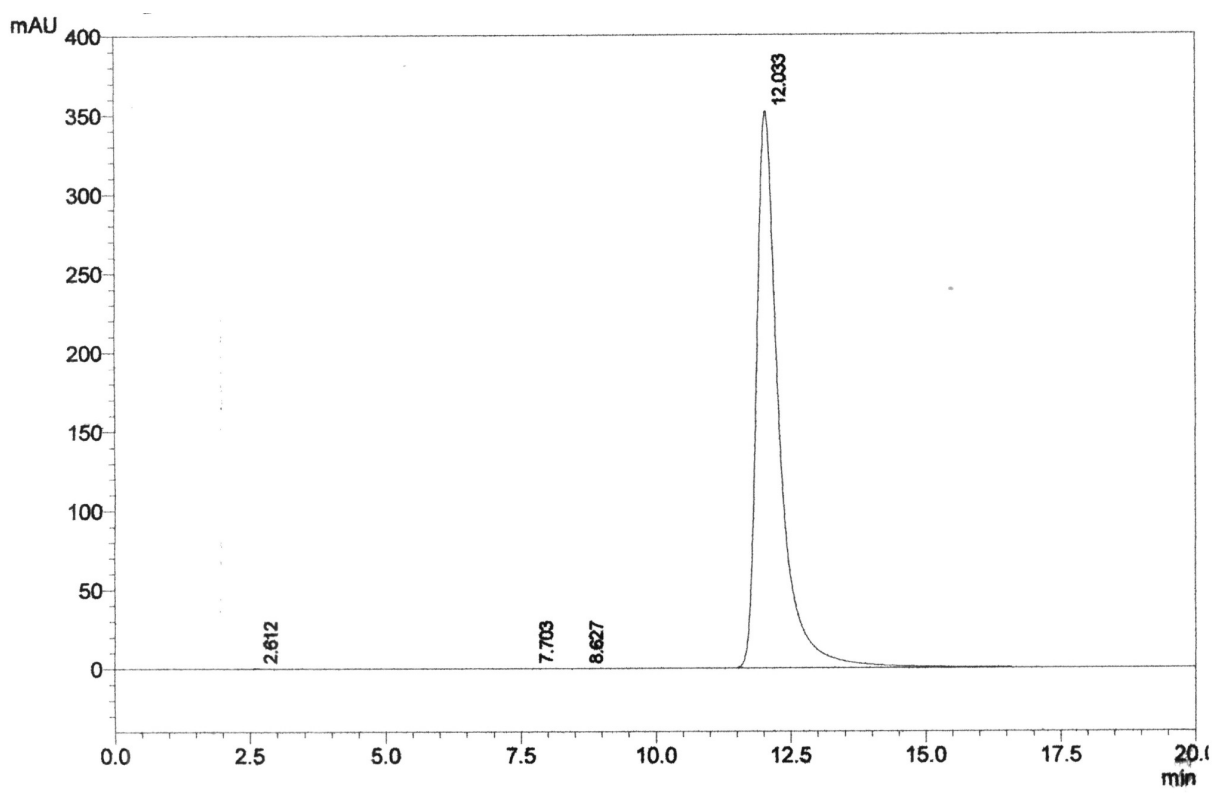

FIGURA 20 - Cromatograma da solução de resveratrol não irradiada 


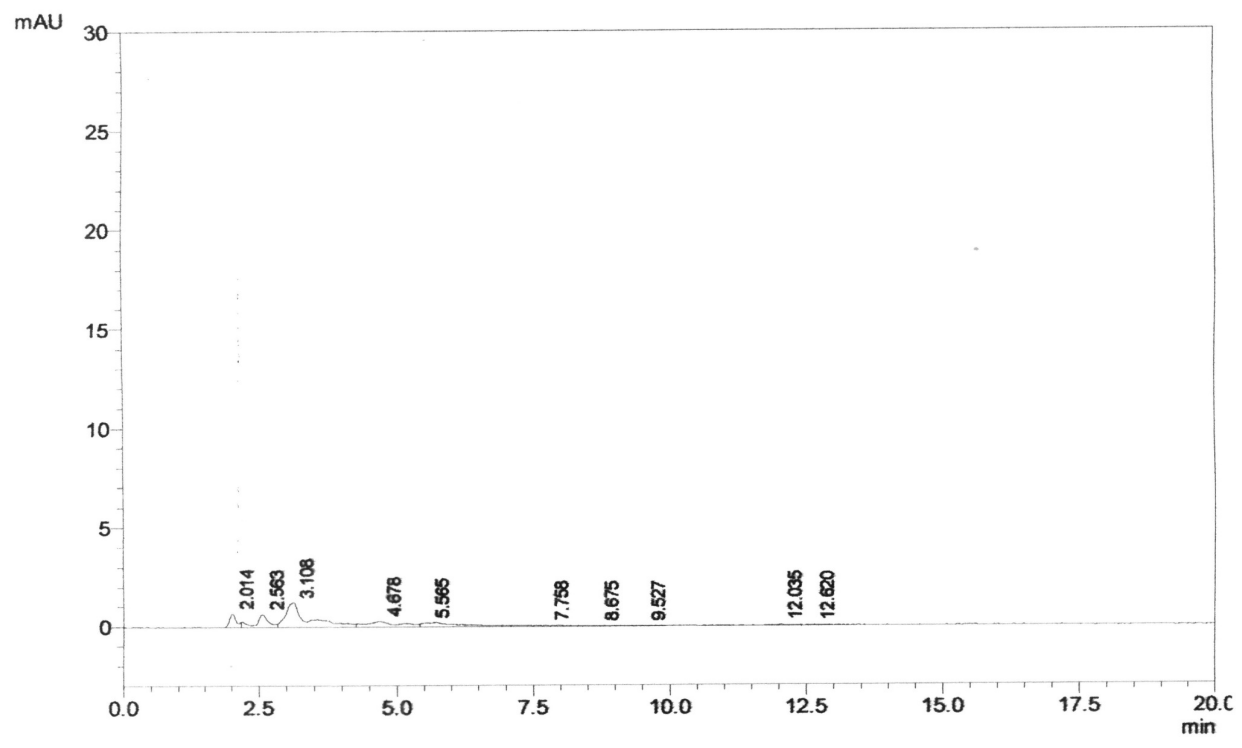

FIGURA 21 - Cromatograma da solução de resveratrol irradiada a 20 kGy

Os espectros de massas das soluções de resveratrol não irradiada e irradiada estão apresentados nas FIG. 22 e 23, respectivamente.

A espectrometria de massas possibilitou a confirmação da completa degradação do resveratrol após irradiação a 20 kGy, sugerida inicialmente pelos cromatogramas obtidos por HPLC. Na solução de resveratrol não irradiada podemos observar a identificação de apenas um composto, com massa equivalente à massa do resveratrol. No espectro da solução irradiada não observamos a presença do resveratrol, mas a identificação de quatro novos compostos, confirmando a degradação completa do resveratrol e a formação de produtos de degradação.

Como pode ser observado na FIG. 23, as massas moleculares apresentadas pelos produtos de degradação são, em sua maioria, superiores à massa do resveratrol, sugerindo que, após irradiação, ocorre quebra da molécula de resveratrol e recombinação dos produtos originados pela quebra, resultando na formação de compostos de degradação com massa superior à do resveratrol. 

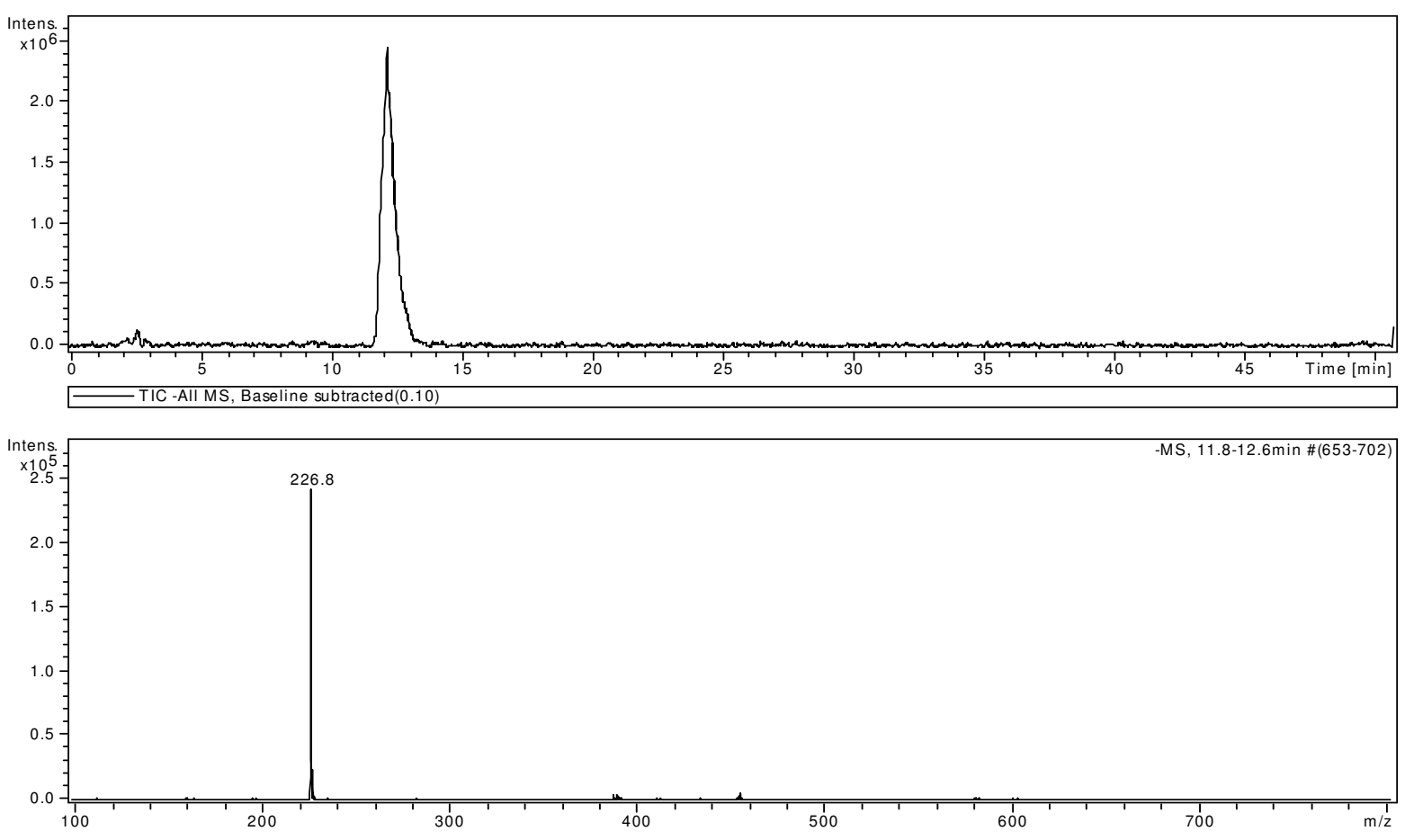

FIGURA 22 - Espectro de massas da solução de resveratrol não irradiada
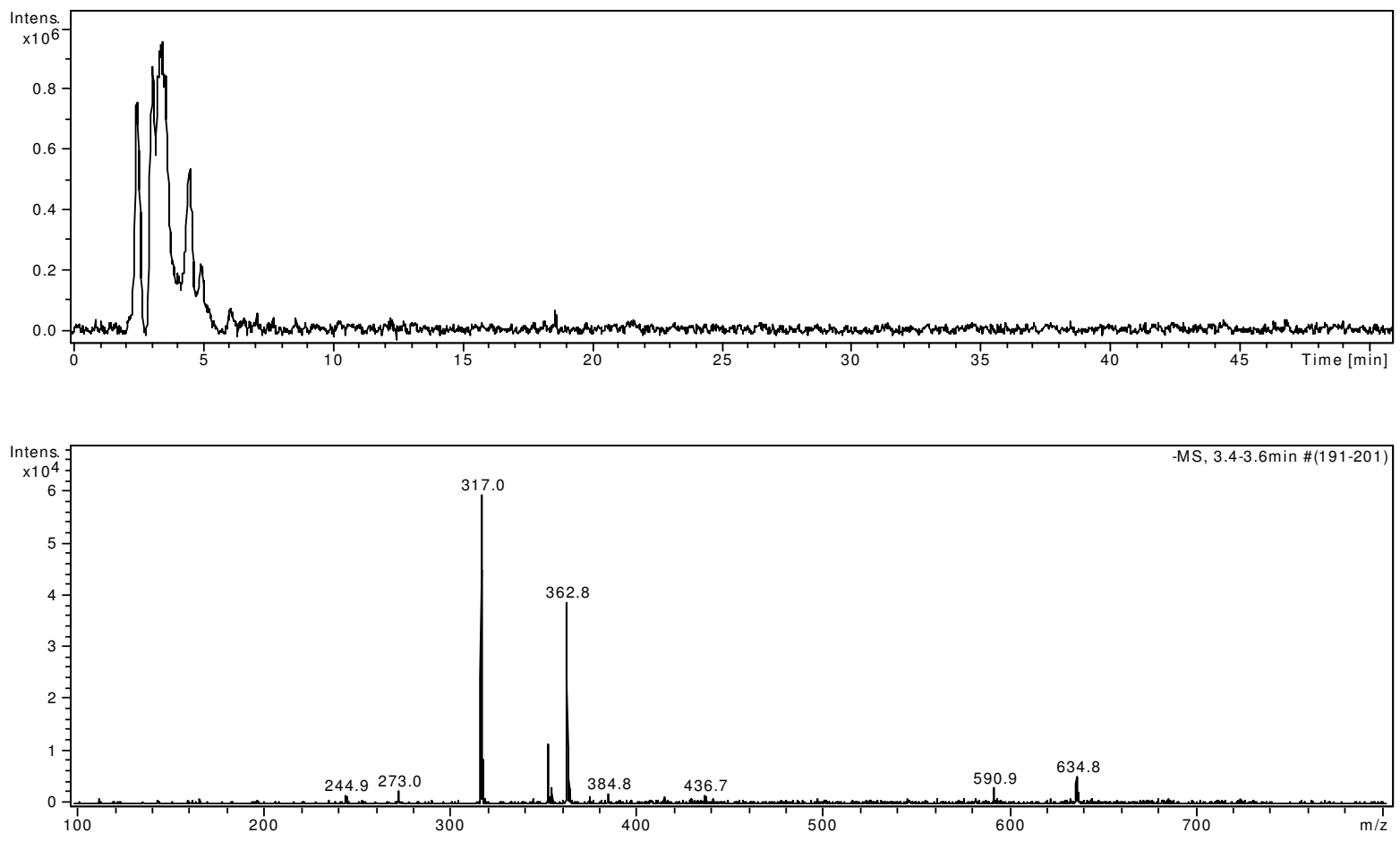


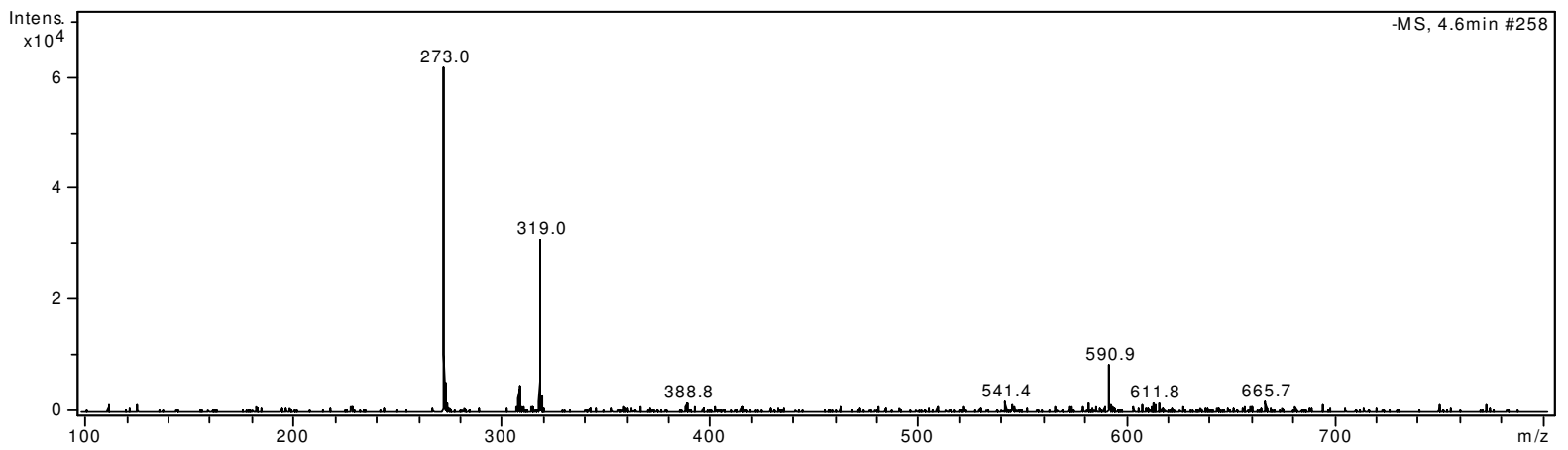

FIGURA 23 - Espectros de massas da solução de resveratrol irradiada a 20 kGy

\subsubsection{Avaliação da Capacidade antioxidante}

A avaliação da capacidade antioxidante das soluções de resveratrol foi determinada pela capacidade de captar o radical livre DPPH•, conforme descrito no item 4.2.5.1 em materiais e métodos.

Por meio das medidas de absorbância da solução padrão de DPPH• durante exposição à luz do espectrofotômetro e de sua respectiva curva de degradação, apresentados na TAB. 8 e FIG. 24 pode-se observar que o DPPH• sofre degradação quando exposto à luz do espectrofotômetro.

De acordo com a TAB. 8, após 30 minutos de exposição as diferenças nas medidas de absorbância de tempos consecutivos são observadas sempre na última casa decimal. Desta forma, para avaliar a capacidade antioxidante do resveratrol padronizou-se que o platô seria obtido quando a diferença entre as medidas de absorbância fosse observada de forma permanente na última casa decimal, uma vez que esta diminuição na absorbância é resultado de uma degradação natural do radical livre e não da capacidade do resveratrol em captálos. 
TABELA 8 - Valores de absorbância da solução padrão de DPPH exposta à luz do espectrofotômetro

\begin{tabular}{cc}
\hline Tempo & Absorbância \\
\hline 0 & 1,1582 \\
10 & 1,1538 \\
20 & 1,1527 \\
30 & 1,1519 \\
40 & 1,1513 \\
50 & 1,1511 \\
60 & 1,1505 \\
70 & 1,1501 \\
80 & 1,1498 \\
90 & 1,1494 \\
\hline
\end{tabular}

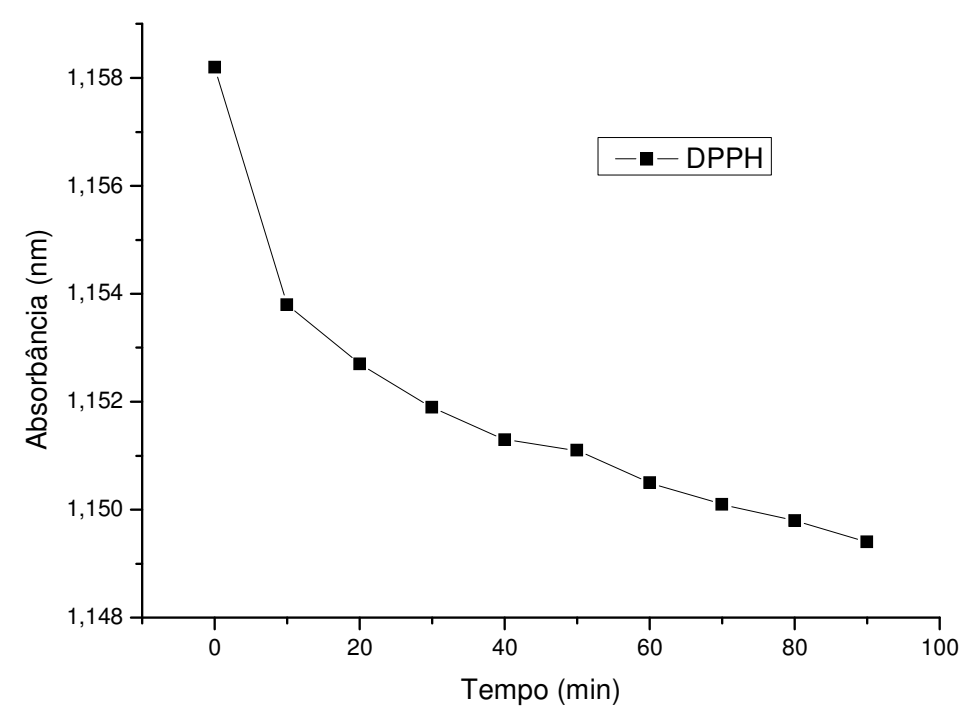

FIGURA 24 - Curva de degradação do DPPH exposto a luz do espectrofotômetro

As cinéticas da reação entre o DPPH e as soluções de resveratrol apresentadas na FIG. 25 permitem observar que após 190 minutos, a porcentagem de DPPH remanescente foi aproximadamente $72 \%$ e $85 \%$ para as soluções de resveratrol não irradiada e irradiada a 20 kGy, respectivamente.

Após 20 minutos, a porcentagem de DPPH remanescente (TAB. 9) foi próxima a $85 \%$ para o resveratrol não irradiado. Este valor só foi atingido pela 
solução irradiada após 3 horas de reação, sugerindo que a capacidade de captar radicais livres foi reduzida após irradiação.

A capacidade de captar radicais livres apresentada pela solução de resveratrol irradiada pode ser resultado da formação de produtos de degradação após irradiação do resveratrol.

TABELA 9 - Resultados de porcentagem de DPPH remanescente para as soluções de resveratrol a 0 e 20 kGy

\begin{tabular}{|c|c|c|}
\hline \multirow{2}{*}{ Tempo } & \multicolumn{2}{|c|}{ DPPH Remanescente (\%) } \\
\hline & 0 kGy & 20 kGy \\
\hline 0 & 100,00 & 100,00 \\
\hline 1 & 93,49 & 95,37 \\
\hline 10 & 87,85 & 91,81 \\
\hline 20 & 85,2 & 91,21 \\
\hline 30 & 83,22 & 90,94 \\
\hline 40 & 81,91 & 90,63 \\
\hline 50 & 80,73 & 89,90 \\
\hline 60 & 79,56 & 89,36 \\
\hline 70 & 78,82 & 88,96 \\
\hline 80 & 78,05 & 88,59 \\
\hline 90 & 77,31 & 88,22 \\
\hline 100 & 76,5 & 87,88 \\
\hline 110 & 75,93 & 87,51 \\
\hline 120 & 75,43 & 87,21 \\
\hline 130 & 74,89 & 86,91 \\
\hline 140 & 74,35 & 86,61 \\
\hline 150 & 73,28 & 86,30 \\
\hline 160 & 72,91 & 86,04 \\
\hline 170 & 72,54 & 85,83 \\
\hline 180 & 72,21 & 85,57 \\
\hline 190 & 72,14 & 85,30 \\
\hline
\end{tabular}




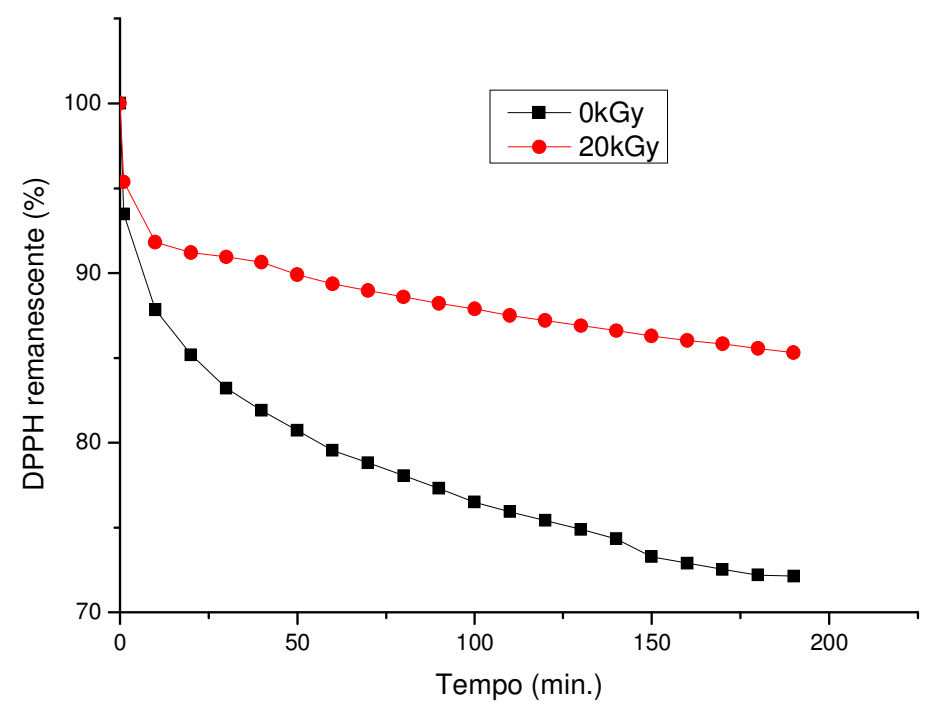

FIGURA 25 - Cinética de DPPH das soluções de resveratrol não irradiadas ou irradiada a 20 kGy

\subsection{Avaliação do comportamento do resveratrol frente à luz ultravioleta}

A exposição das soluções de resveratrol à luz solar levariam a uma conversão da forma trans para cis-resveratrol, uma vez que soluções hidroalcoólicas de trans-resveratrol apresentam estabilidade em ausência de luz e tendência a isomeria quando expostas a luz ultravioleta (Trela \& Waterhouse,1996).

Os cromatogramas das soluções de resveratrol antes e após exposição à luz ultravioleta estão apresentados nas FIG. 26 e 27, respectivamente. O tempo de retenção foi aproximadamente 12 minutos e após exposição solar podemos observar diminuição na área do pico obtido de 202.88164 para 3.3753, sugerindo que houve conversão de trans para cis-resveratrol. 


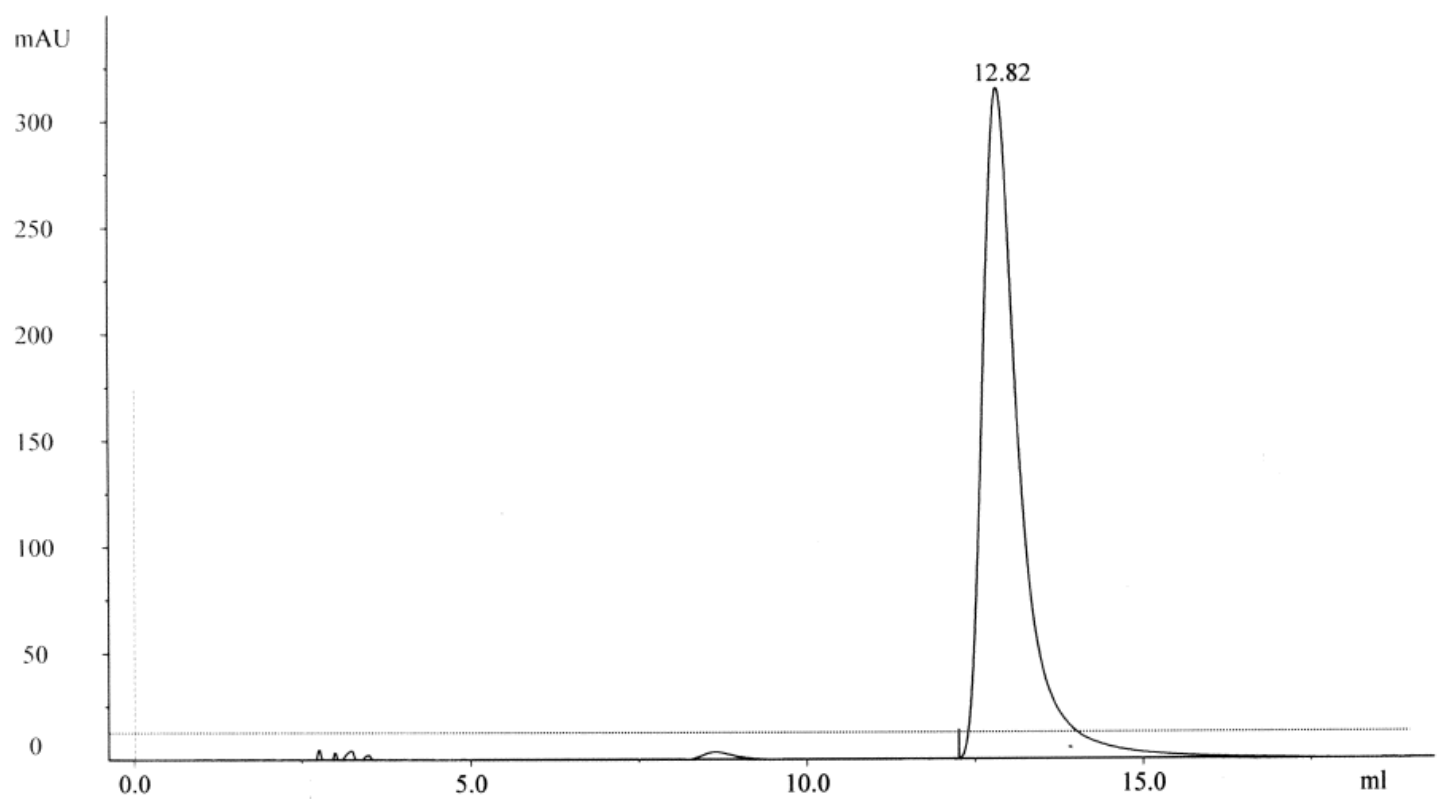

FIGURA 26 - Cromatograma do resveratrol não exposto à luz ultravioleta

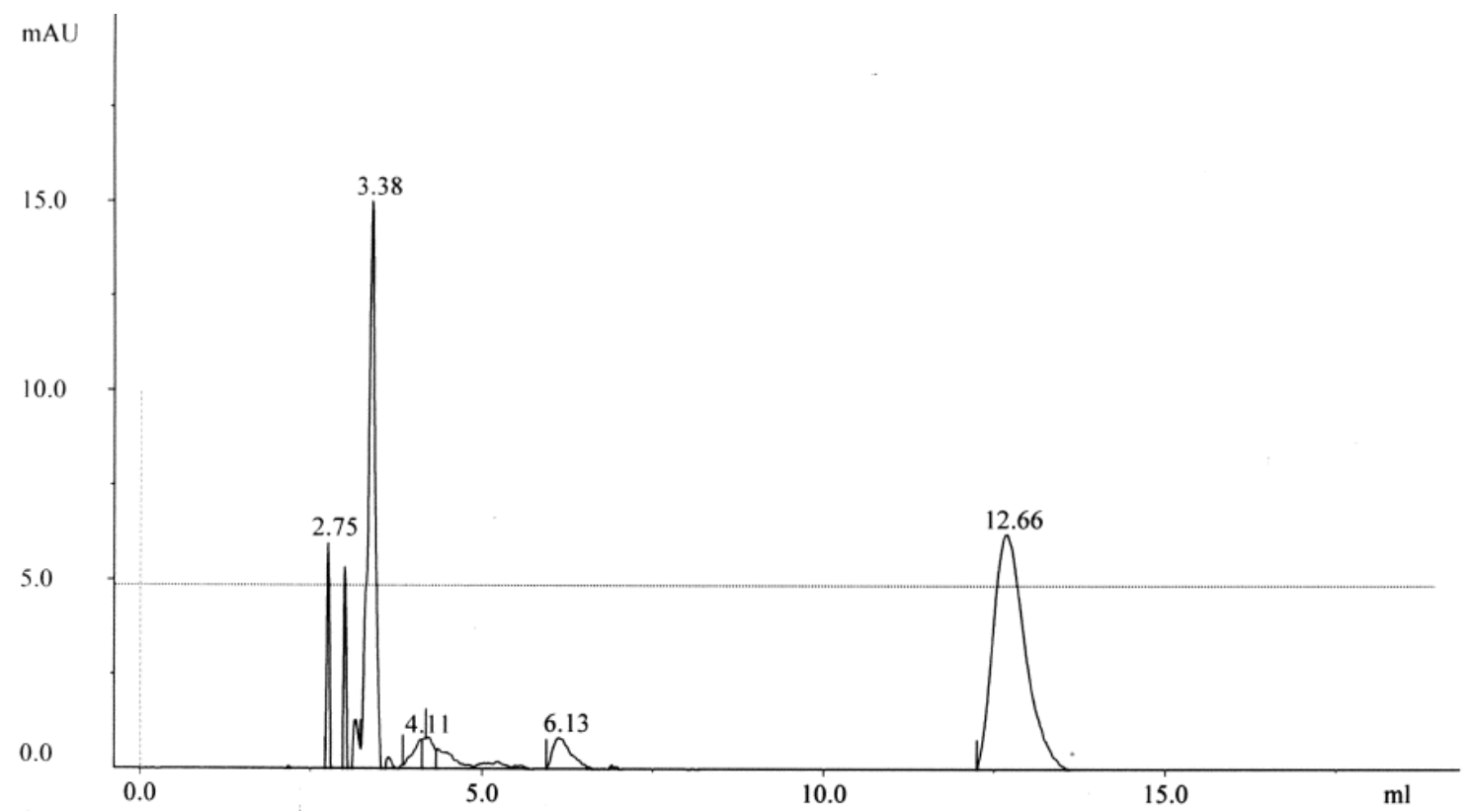

FIGURA 27 - Cromatograma do resveratrol exposto à luz ultravioleta

A confirmação de que a diminuição na área do pico de resveratrol após exposição solar tratava-se realmente de uma conversão de trans para cisresveratrol foi demonstrada pela comparação dos espectros das soluções com espectros de trans e cis-resveratrol da literatura. 
Os espectros correspondentes às soluções de resveratrol antes e após exposição à luz solar (FIG. 28) foram semelhantes aos espectros de trans e cisresveratrol apresentados por Trela \& Waterhouse (1996).

Camont e colaboradores (2009) observaram que espectros de soluções de resveratrol expostas à luz solar apresentavam aumento na absorbância na região próxima a $250 \mathrm{~nm}$ e diminuição em $306 \mathrm{~nm}$ em comparação à mesma solução protegida da luz. Estes resultados são semelhantes aos apresentados na FIG. 28, onde pode ser observado um deslocamento do pico de 306 para $250 \mathrm{~nm}$ e um aumento na absorbância nesta região, após exposição à luz.

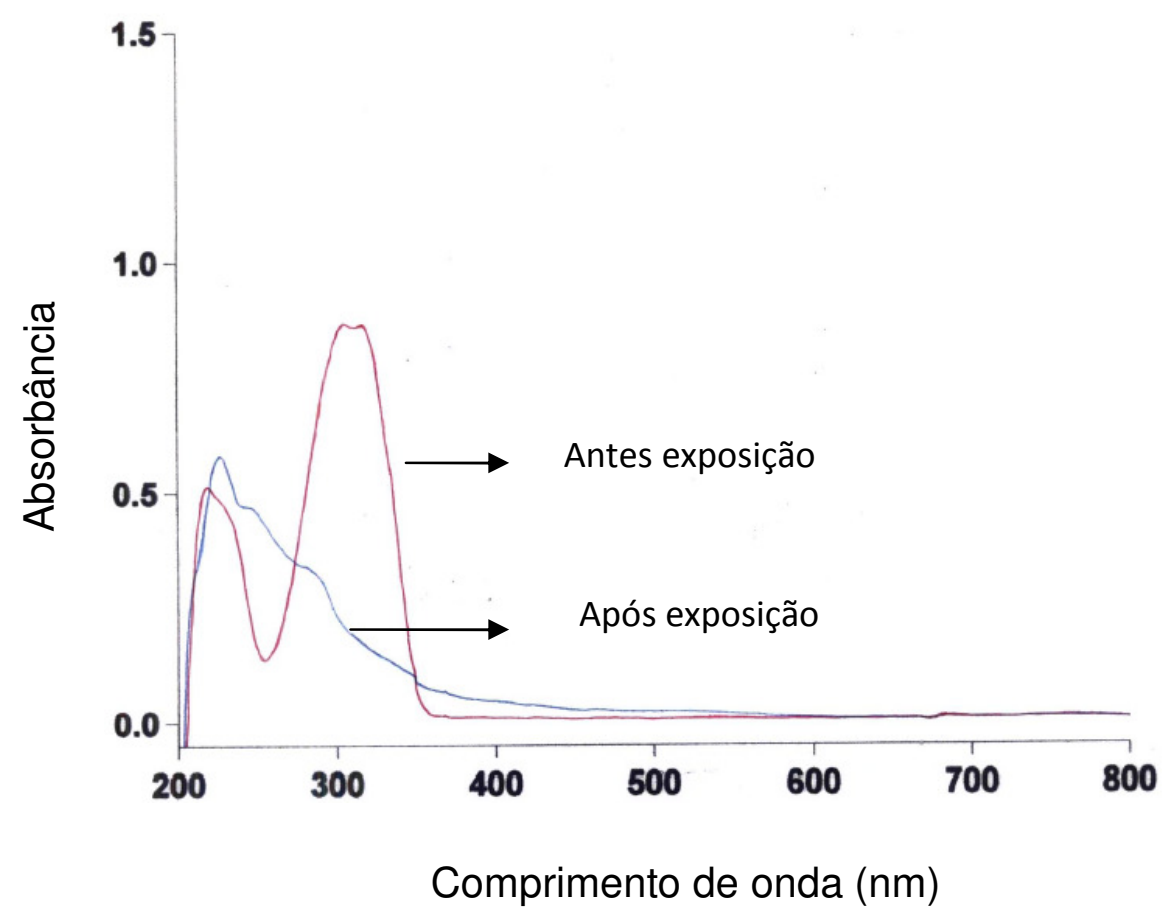

FIGURA 28 - Espectro de absorção da solução de resveratrol antes (trans) e após (cis) exposição à luz ultravioleta

As análises cromatográficas das soluções antes e após exposição associada à comparação dos espectros obtidos aos da literatura permitiram a confirmação de que o resveratrol utilizado tratava-se da forma isômera trans, que foi convertido em cis-resveratrol após 6 horas de exposição à luz solar. 


\subsection{Obtenção do dispositivo}

\subsubsection{Método Direto}

Embora o resveratrol não tenha mantido sua integridade após a irradiação a 20 kGy, a hipótese de que haveria proteção do resveratrol pelos componentes da formulação foi considerada, obtendo-se dispositivos pelo método direto.

Homogeneidade, transparência, flexibilidade, maciez e propriedades mecânicas adequadas à manipulação foram requisitos utilizados para avaliar se os dispositivos apresentavam propriedades visuais e táteis adequadas para serem utilizados como um sistema de liberação de resveratrol.

Apenas os dispositivos contendo $0,05 \%$ de resveratrol apresentaram todos estes requisitos (FIG. 29 e 30). Os dispositivos contendo $0,1 \%$ de resveratrol (FIG. 31) foram descartados, pois não apresentaram propriedades mecânicas adequadas ao manuseio, perdendo sua forma durante a manipulação dos mesmos, devido ao aumento na quantidade de álcool utilizada para solubilização do resveratrol.

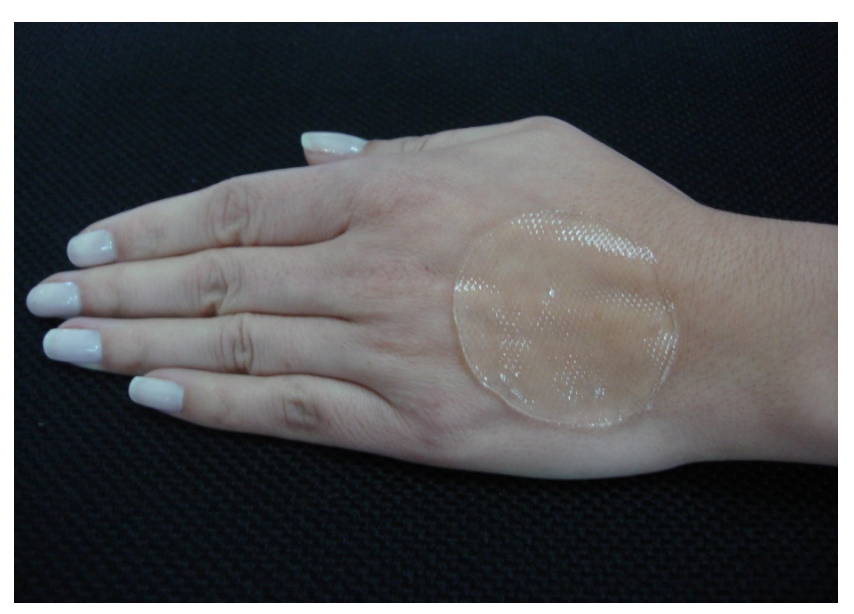

FIGURA 29 - Dispositivo PVP-RES 0,05 


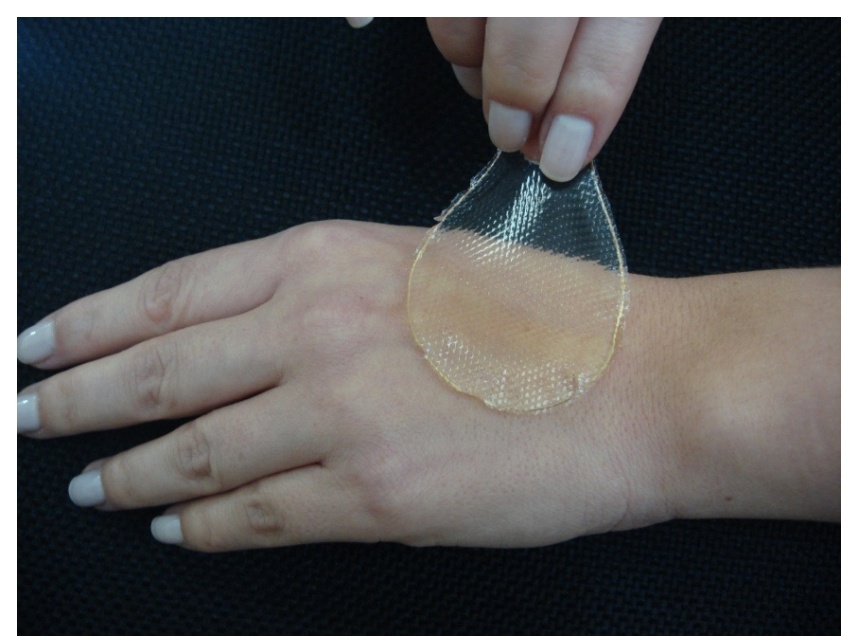

FIGURA 30 - Dispositivo GLI-RES 0,05

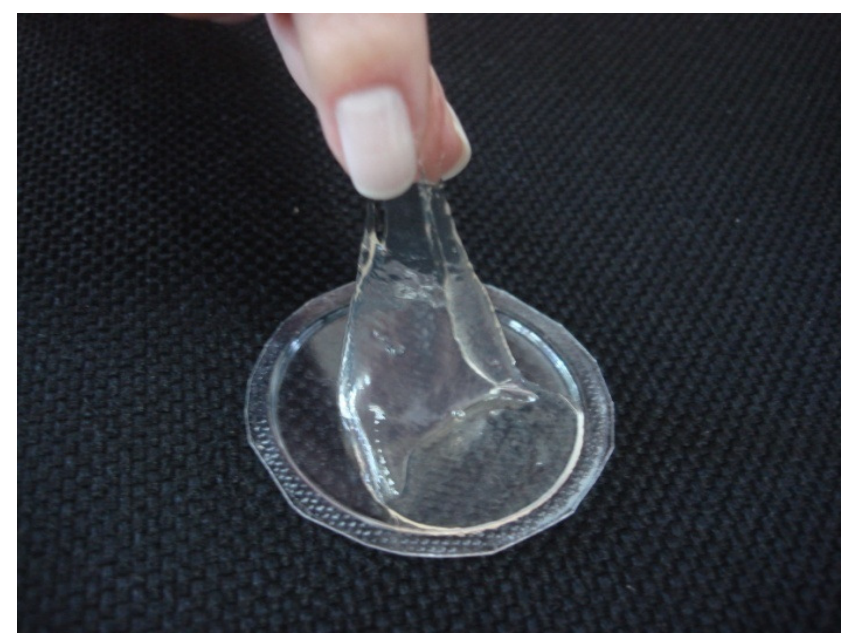

FIGURA 31 - Dispositivo PVP-RES 0,1

\subsubsection{Caracterização dos dispositivos}

Os dispositivos contendo $0,05 \%$ de resveratrol, considerados adequados visualmente e manualmente foram caracterizados pelos ensaios de fração gel, intumescimento e citotoxicidade, com o objetivo de verificar se os mesmos mantinham as características físico-químicas e apresentavam-se não citotóxicos após incorporação do resveratrol.

A presença de resveratrol não alterou a porcentagem de fração gel, que permaneceu em torno de 80\%, como pode ser observado na TAB. 10.

Os valores obtidos foram muito semelhantes aos das matrizes PVPPEG-OH e PVP-GLI-OH, 77 e 78\%, respectivamente. 
TABELA 10 - Resultados dos ensaios de fração gel dos dispositivos

\begin{tabular}{cc}
\hline Dispositivo & Fração gel (\%) \\
\hline PVP-RES 0,05 & $81 \pm 0,2$ \\
\hline GLI-RES 0,05 & $78 \pm 0,9$ \\
\hline
\end{tabular}

Como apresentado na TAB. 11 e FIG. 32, os dispositivos apresentaram capacidade de intumescimento adequada, permitindo a difusão do PBS pelo hidrogel. Durante todo o ensaio, os resultados foram próximos aos valores de intumescimento apresentados pelas matrizes contendo álcool, indicando que a presença de resveratrol não alterou o perfil de intumescimento.

TABELA 11 - Resultados de intumescimento dos dispositivos

\begin{tabular}{ccc}
\hline \multirow{2}{*}{ Tempo (h) } & \multicolumn{2}{c}{ Intumescimento (\%) \pm DP } \\
\cline { 2 - 3 } & PVP-RES 0,05 & GLI-RES 0,05 \\
\hline 1 & $535 \pm 28$ & $531 \pm 121$ \\
2 & $840 \pm 38$ & $884 \pm 193$ \\
4 & $1089 \pm 55$ & $1148 \pm 239$ \\
5 & $1301 \pm 114$ & $1352 \pm 218$ \\
6 & $1457 \pm 140$ & $1541 \pm 248$ \\
24 & $1608 \pm 174$ & $1682 \pm 257$ \\
\hline
\end{tabular}




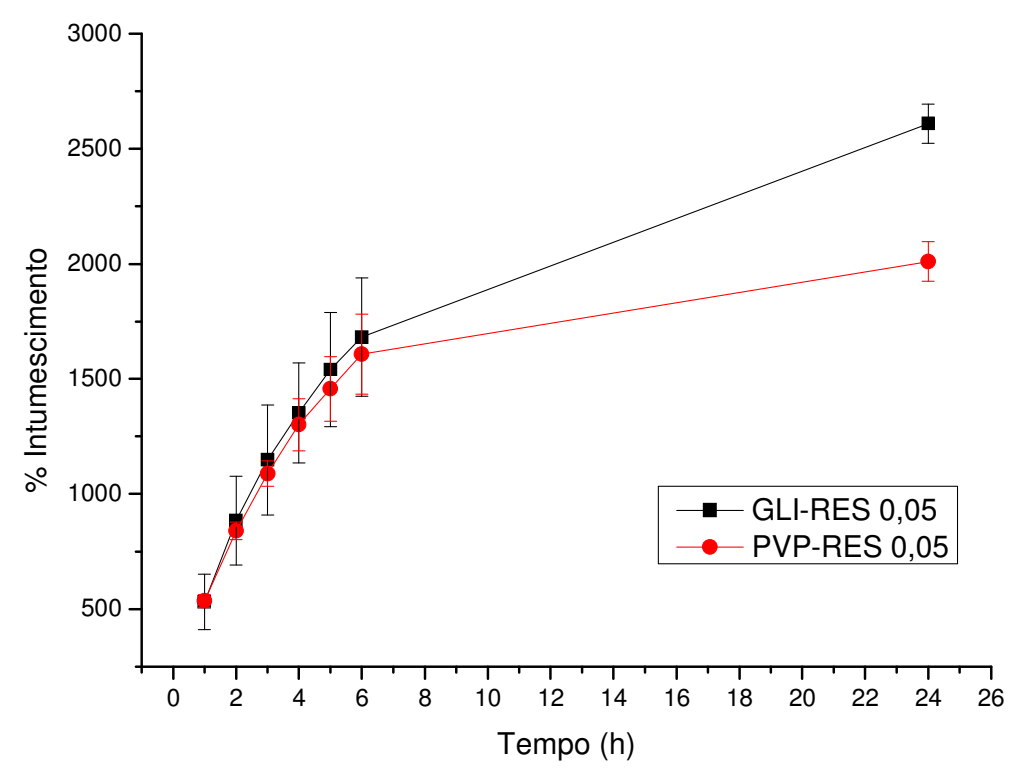

FIGURA 32 - Perfil de intumescimento dos dispositivos GLI-RES 0,05 e PVP-RES 0,05

Os resultados e as curvas de viabilidade celular obtidas estão apresentados na TAB. 12 e FIG. 33, respectivamente, onde pode ser observado que os dispositivos mostraram comportamento semelhante ao controle negativo, ou seja, não toxicidade. Somente o controle positivo apresentou-se tóxico, com $I_{50 \%}$ de 40 indicando que o extrato do controle positivo na concentração de $40 \%$ provocou a morte de $50 \%$ da população celular no ensaio.

TABELA 12 - Resultados da viabilidade celular do ensaio de citotoxicidade dos dispositivos

\begin{tabular}{ccccc}
\hline & \multicolumn{5}{c}{ Viabilidade Celular (\%) \pm dp } \\
Concentração & Controle & Controle & PVP-RES & GLI-RES \\
Extrato (\%) & negativo & Positivo & $\mathbf{0 , 0 5}$ & $\mathbf{0 , 0 5}$ \\
\hline 100 & $91 \pm 10$ & $8 \pm 11$ & $141 \pm 3$ & $122 \pm 4$ \\
50 & $109 \pm 4$ & $9 \pm 5$ & $127 \pm 10$ & $117 \pm 3$ \\
25 & $84 \pm 7$ & $108 \pm 12$ & $123 \pm 6$ & $109 \pm 2$ \\
12,5 & $71 \pm 9$ & $88 \pm 12$ & $121 \pm 6$ & $111 \pm 7$ \\
6,25 & $100 \pm 3$ & $98 \pm 12$ & $123 \pm 4$ & $117 \pm 4$ \\
\hline
\end{tabular}




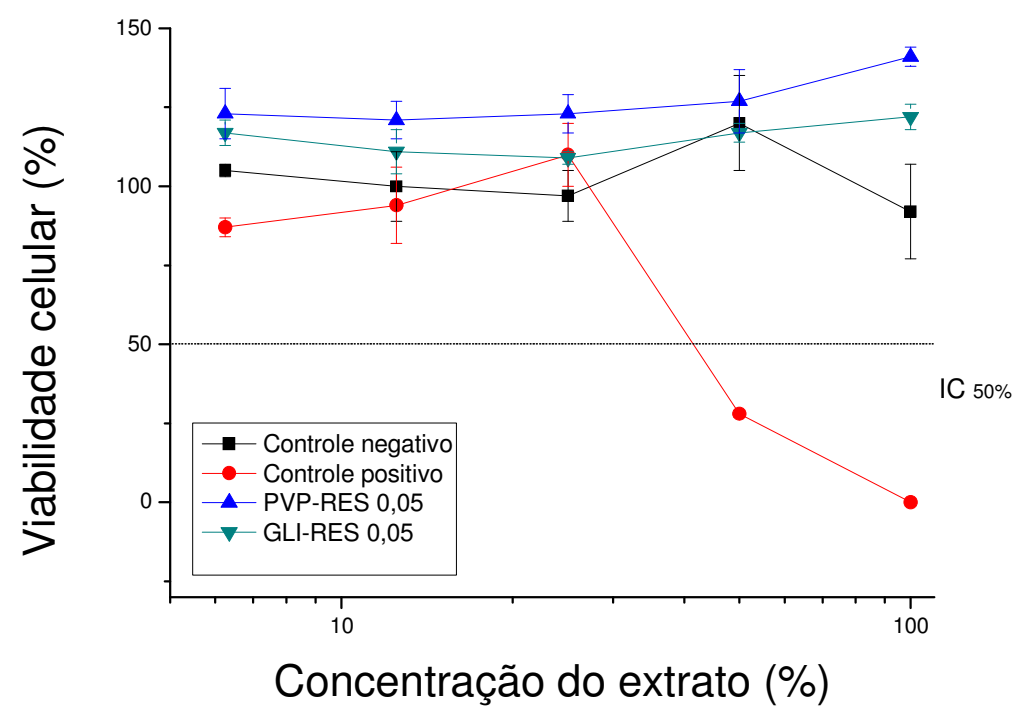

FIGURA 33 - Curvas de viabilidade celular dos dispositivos PVP-RES 0,05 e GLIRES 0,05 no ensaio de citotoxicidade

\subsubsection{Método Indireto}

O método de incorporação indireto foi realizado para obtenção de dispositivos contendo $0,1 \%$ de resveratrol, que não apresentaram propriedades adequadas para compor um sistema de liberação quando obtidos pelo método direto. Além disso, a incorporação de resveratrol por este método pode prevenir a degradação do mesmo, que não manteve sua integridade após irradiação a 20 kGy.

Devido à baixa solubilidade do resveratrol em água ou PBS, foi verificado a capacidade de intumescimento em álcool. Podemos observar que assim como no intumescimento em PBS pH 5, os hidrogéis PVP-GLI apresentaram maior capacidade de intumescimento em relação ao PVP-PEG (TAB. 13 e FIG. 34). No entanto, ambos mostraram capacidade de incorporar 1,5 $\mathrm{mL}$ de álcool, volume necessário para dissolver $0,0025 \mathrm{~g}$ de resveratrol. 
TABELA 13 - Resultados de intumescimento das matrizes de hidrogel em álcool etílico

\begin{tabular}{ccc}
\hline \multirow{2}{*}{ Tempo (h) } & \multicolumn{2}{c}{ Intumescimento (\%) \pm DP } \\
\cline { 2 - 3 } & PVP-GLI & PVP-PEG \\
\hline 1 & $217 \pm 1$ & $603 \pm 86$ \\
3 & $362 \pm 12$ & $794 \pm 78$ \\
4 & $520 \pm 23$ & $913 \pm 69$ \\
5 & $668 \pm 24$ & $986 \pm 57$ \\
6 & $806 \pm 23$ & $1041 \pm 53$ \\
24 & $920 \pm 27$ & $1072 \pm 39$ \\
\hline
\end{tabular}

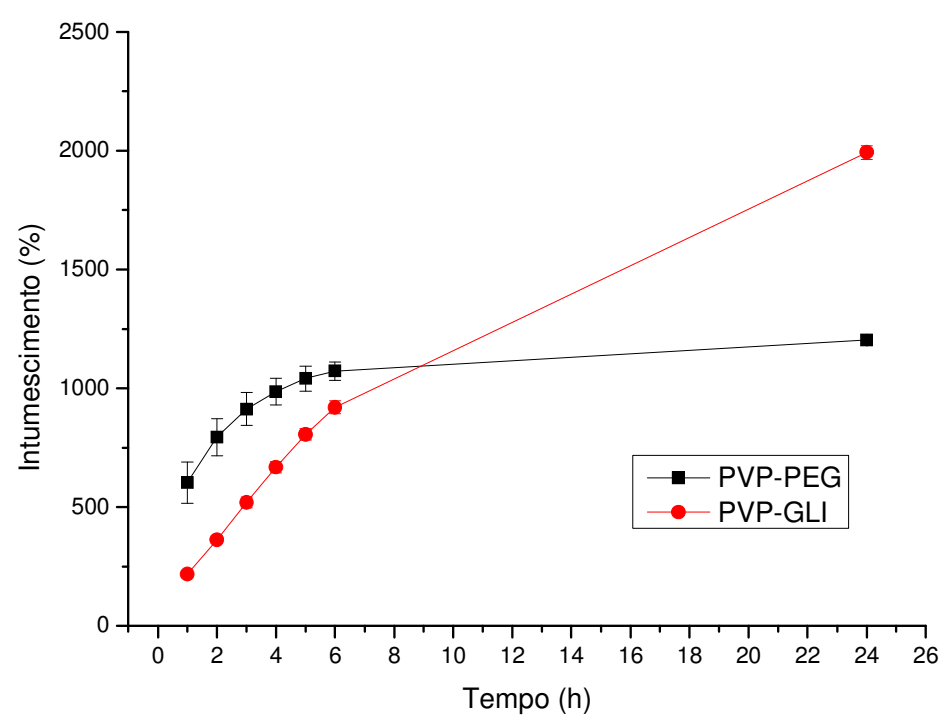

FIGURA 34 - Perfil de intumescimento em álcool etílico dos hidrogéis de PVPPEG e PVP-GLI

Após intumescimento completo da solução de resveratrol pelo hidrogel, os dispositivos obtidos apresentaram-se adequados visualmente e ao manuseio para serem utilizados como sistemas para liberação de resveratrol. 


\subsection{Cinética de liberação e doseamento do ativo}

\subsubsection{Intumescimento dos dispositivos em PBS}

Considerando que os dispositivos seriam utilizados hidratados, foi realizado um estudo para verificar a capacidade de intumescimento dos dispositivos intactos. O conhecimento desta propriedade é importante quando se objetiva a utilização de hidrogéis em sistemas de liberação de fármacos, pois a capacidade de absorção de água permite a difusão do soluto pelo hidrogel, influenciando na liberação do princípio ativo pela matriz polimérica (Peppas, 1996).

Os resultados estão apresentados na TAB. 14 e FIG. 35, onde podemos observar que o dispositivo GLI-RES 0,05 apresentou maior capacidade de intumescimento que o PVP-RES 0,05, sendo que o intumescimento atingido pelo dispositivo GLI-RES 0,05 em duas horas de ensaio foi maior do que o apresentado pelo PVP-RES 0,05 em 24 horas.

TABELA 14 - Resultados de intumescimento dos dispositivos GLI-RES 0,05 e PVP-RES 0,05 em PBS

\begin{tabular}{ccc}
\hline \multirow{2}{*}{ Tempo (h) } & \multicolumn{2}{c}{ Intumescimento (\%) +/- DP } \\
\cline { 2 - 3 } & GLI-RES 0,05 & PVP-RES 0,05 \\
\hline 1 & $125 \pm 10$ & $55 \pm 13$ \\
2 & $191 \pm 19$ & $89 \pm 18$ \\
3 & $232 \pm 23$ & $103 \pm 14$ \\
4 & $274 \pm 24$ & $118 \pm 13$ \\
5 & $307 \pm 28$ & $133 \pm 12$ \\
6 & $336 \pm 27$ & $145 \pm 13$ \\
24 & $571 \pm 15$ & $163 \pm 2$ \\
\hline
\end{tabular}




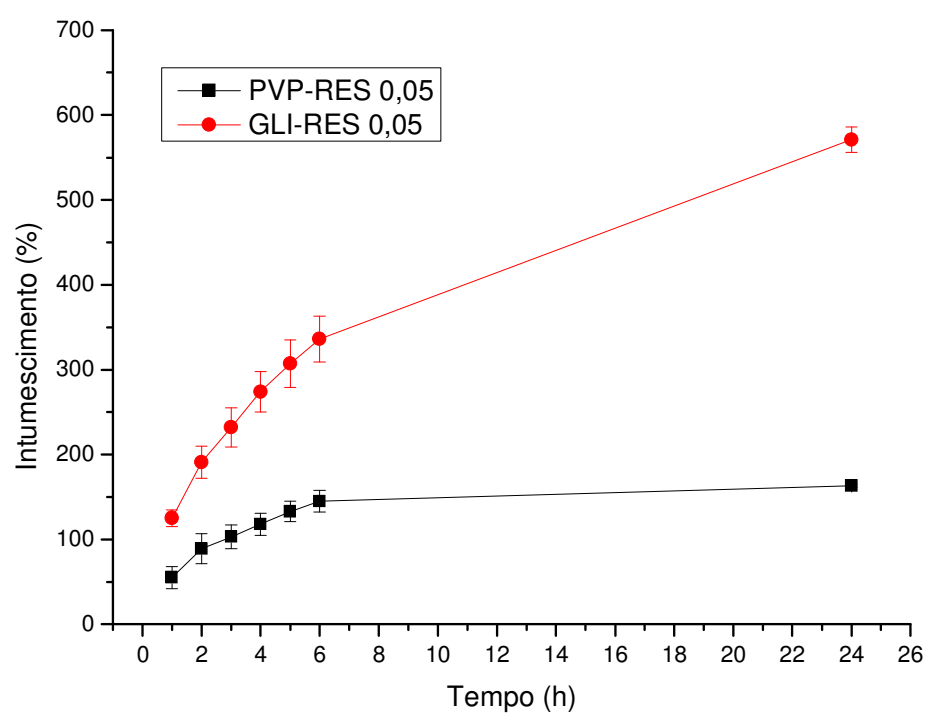

FIGURA 35 - Perfil de intumescimento dos dispositivos de GLI-RES 0,05 e PVPRES 0,05 em PBS

A capacidade de intumescimento permite estimar o comportamento em sistemas de liberação de fármacos (Sen, 1999), indicando que possivelmente o dispositivo GLI-RES 0,05 apresente maior capacidade de liberar o resveratrol incorporado, pois a presença de glicerina proporciona uma estrutura mais relaxada, possibilitando maior capacidade de absorção e difusão do soluto pelo hidrogel.

\subsubsection{Quantificação do resveratrol liberado}

Para correlacionar as áreas dos picos obtidas pela análise de HPLC com a concentração de resveratrol liberada, construiu-se uma curva padrão, conforme descrito no item 4.2.8.3. A concentração de resveratrol liberada dos dispositivos em cada tempo foi calculada utilizando a Equação (6), obtida por meio da curva padrão. Para controle do ensaio foram utilizadas membranas das matrizes de PVP-PEG e PVP-GLI e seus cromatogramas estão apresentados nas FIG. 36 e 37, respectivamente. 


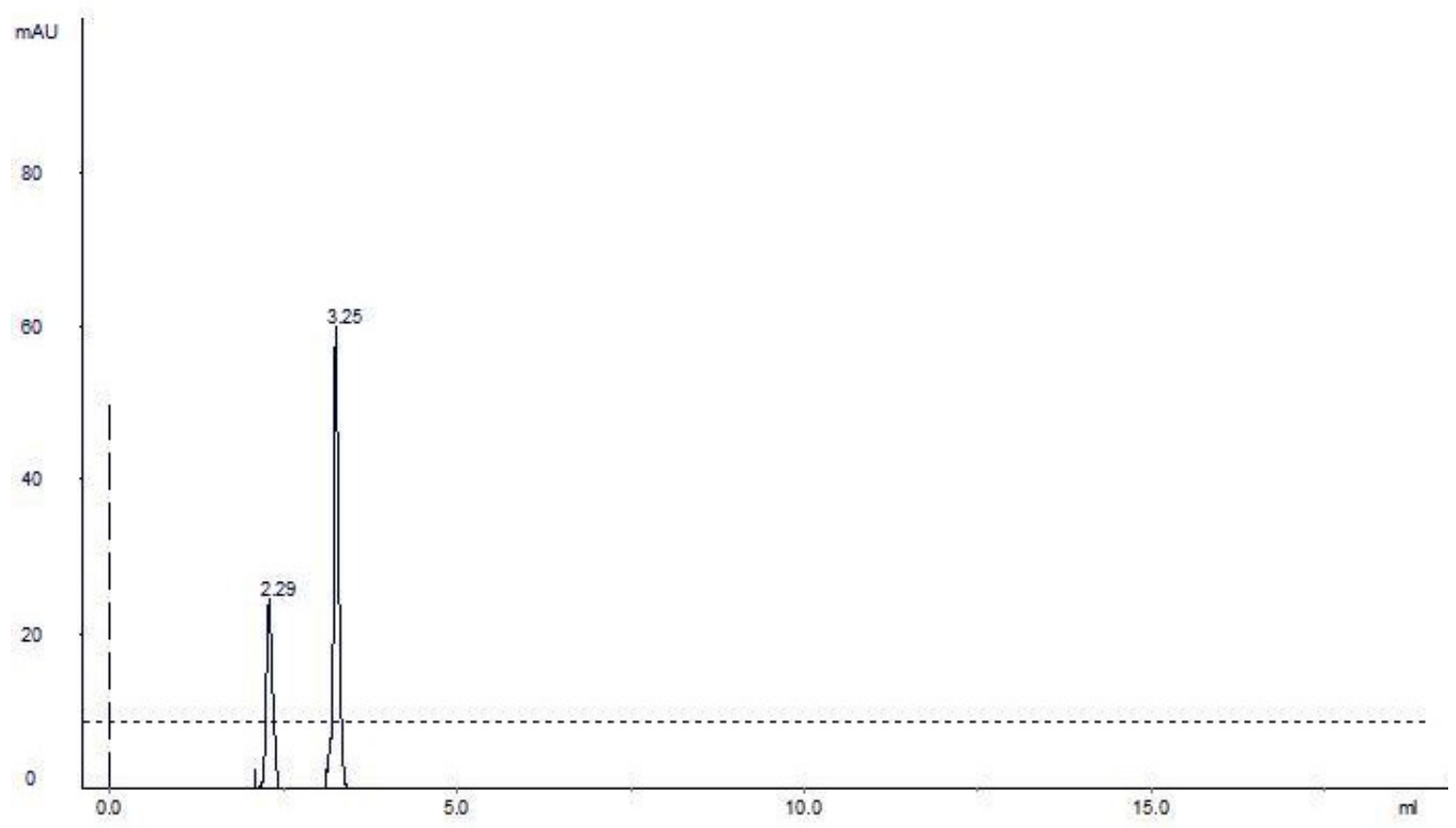

FIGURA 36 - Cromatograma da liberação da membrana controle PVP-GLI após 1 hora

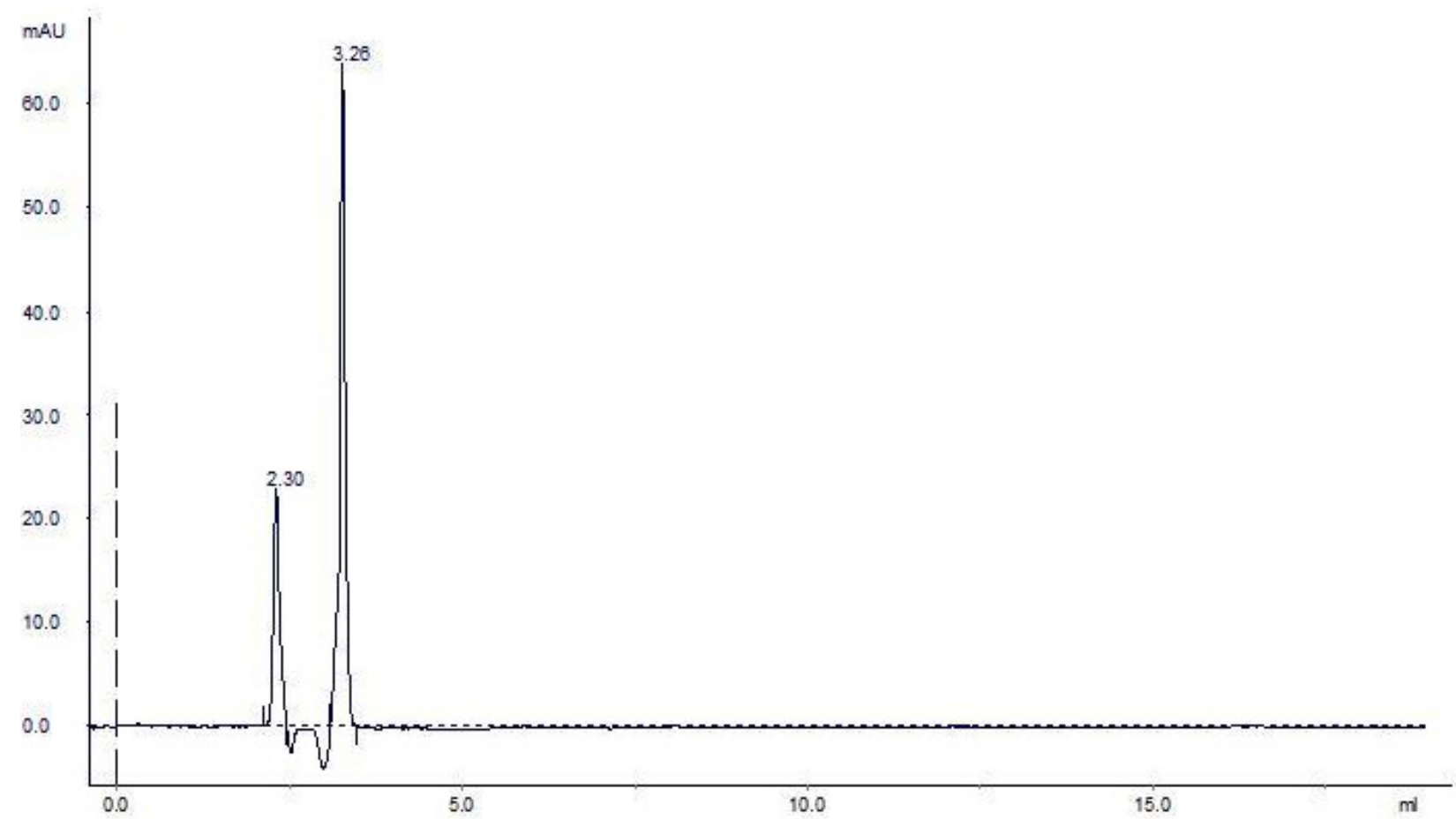

FIGURA 37 - Cromatograma da liberação da membrana controle PVP-PEG após 1 hora 
Os dispositivos obtidos por método direto não apresentaram liberação de resveratrol, seus cromatogramas foram semelhantes aos das membranas controle sugerindo que o resveratrol ficou retido no dispositivo ou que sofreu degradação como foi observado na solução irradiada, apresentado no item 5.3.1.

A TAB. 15 apresenta as áreas dos picos $\mathrm{e}$ as respectivas concentrações de resveratrol liberado pelos dispositivos obtidos por incorporação indireta.

TABELA 15 - Resultados do ensaio da cinética de liberação do resveratrol dos dispositivos obtidos por método indireto

\begin{tabular}{|c|c|c|c|c|}
\hline Amostra & $\begin{array}{c}\text { Tempo de } \\
\text { liberação (h) }\end{array}$ & $\begin{array}{c}\text { Tempo de } \\
\text { retenção } \\
\text { (min) }\end{array}$ & Área do pico & $\begin{array}{c}\text { Resveratrol } \\
(\mathrm{mg} / \mathrm{mL})\end{array}$ \\
\hline \multirow{7}{*}{ PVP-PEG-RES } & 1 & 14,03 & 66.3467 & 0,00679 \\
\hline & 2 & 14,14 & 76.9437 & 0,00805 \\
\hline & 3 & 13,81 & 91.5989 & 0,00955 \\
\hline & 4 & 13,59 & 84.5067 & 0,00888 \\
\hline & 5 & 13,22 & 99.0676 & 0,01032 \\
\hline & 6 & 14,39 & 109.0971 & 0,01136 \\
\hline & 24 & 14,62 & 148.4086 & 0,01533 \\
\hline \multirow{7}{*}{ PVP-GLI-RES } & 1 & 14,28 & 63.3431 & 0,00693 \\
\hline & 2 & 14,17 & 74.1860 & 0,00778 \\
\hline & 3 & 14,24 & 80.4288 & 0,00843 \\
\hline & 4 & 13,68 & 88.1827 & 0,00922 \\
\hline & 5 & 14,49 & 99.4284 & 0,01037 \\
\hline & 6 & 12,93 & 117.5771 & 0,01221 \\
\hline & 24 & 12,76 & 151.5795 & 0,01567 \\
\hline
\end{tabular}

As FIG. 38 e 39 apresentam os cromatogramas obtidos após $24 \mathrm{~h}$ de liberação dos dispositivos PVP-PEG-RES e PVP-GLI-RES, respectivamente. 


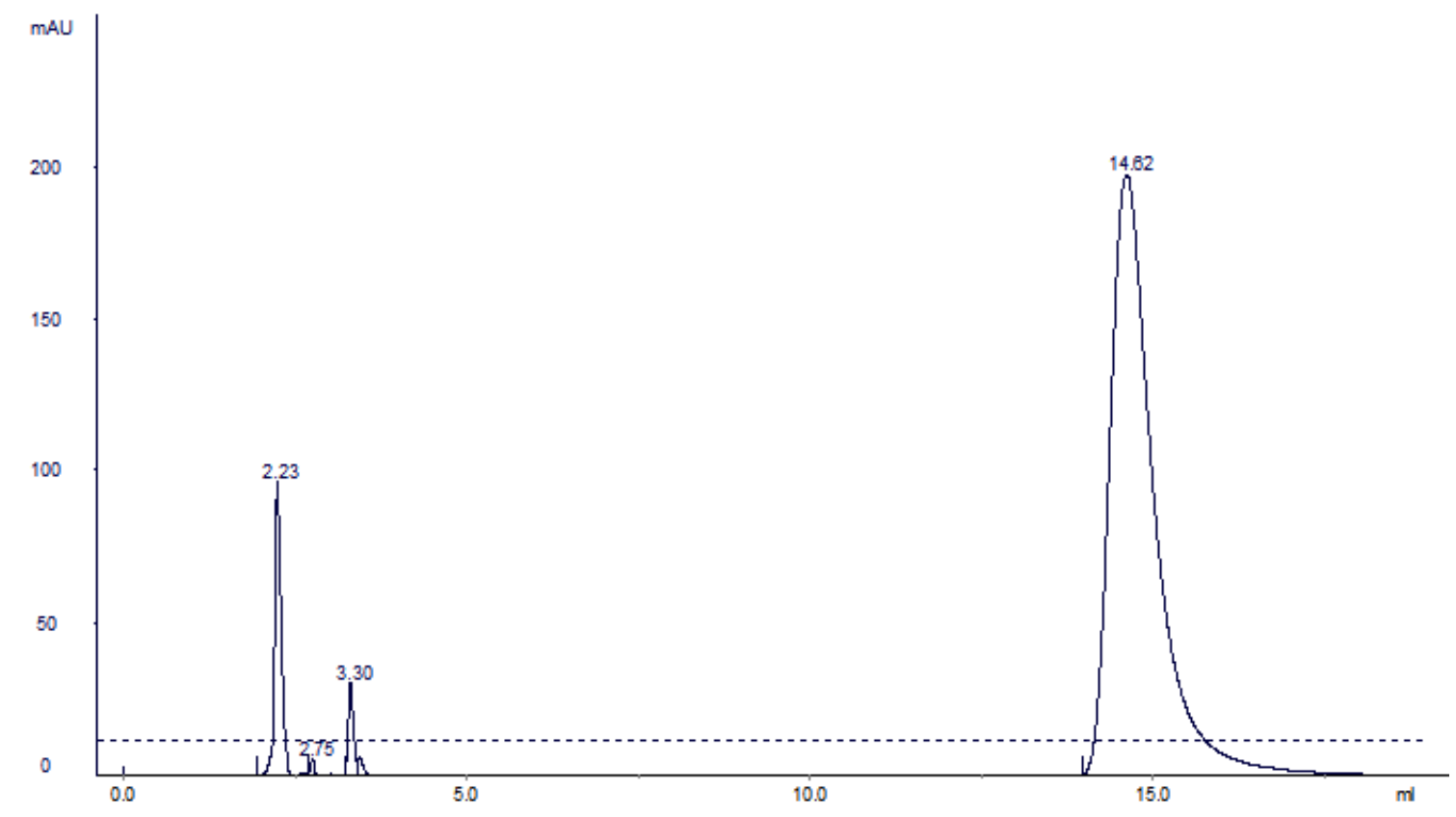

FIGURA 38 - Cromatograma da liberação de resveratrol do dispositivo PVP-PEGRES após 24 horas

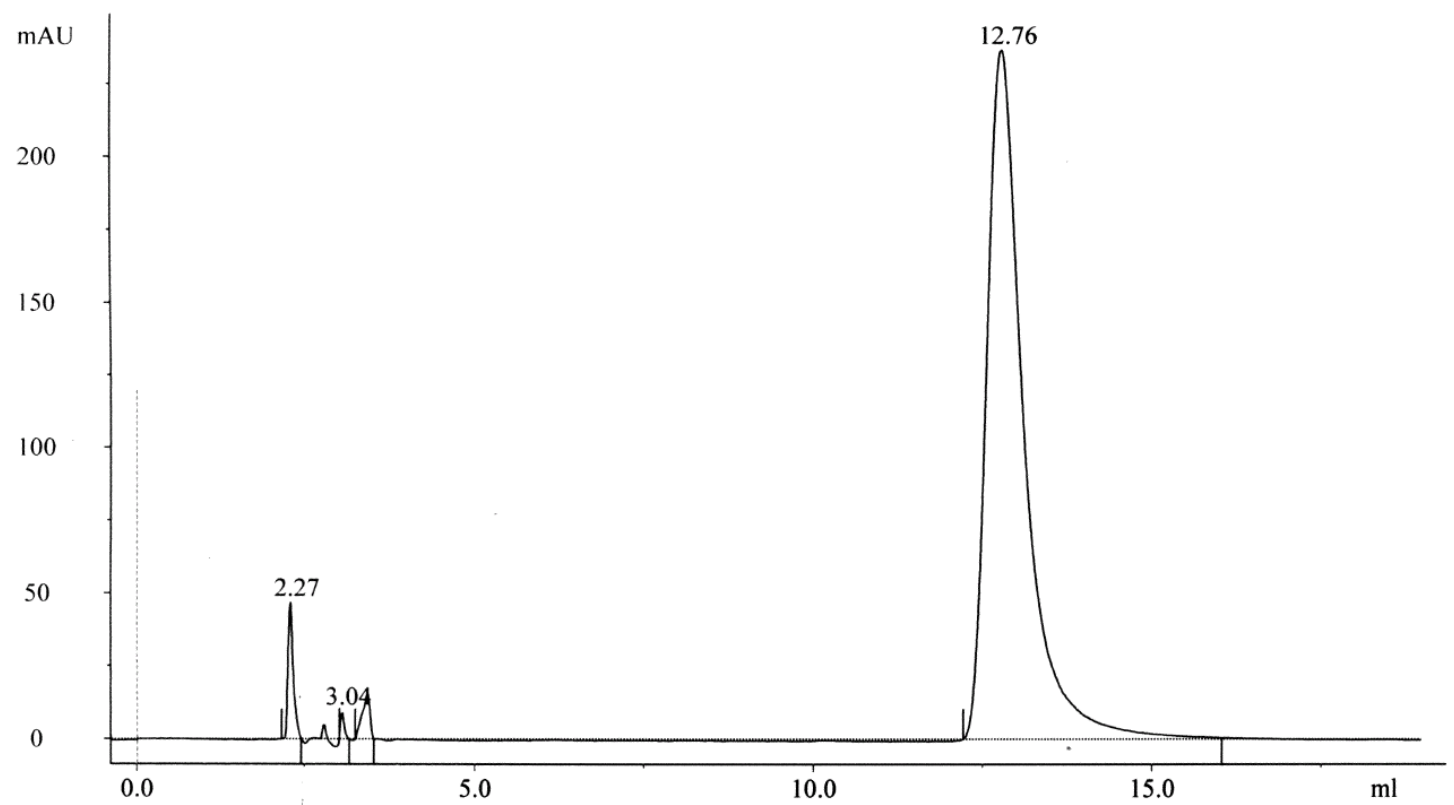

FIGURA 39 - Cromatograma da liberação de resveratrol do dispositivo PVP-GLIRES após 24 horas

Conforme descrito no item 4.2.8.2, a cada coleta de alíquota o volume retirado foi reposto com solução tampão, portanto para encontrar a concentração 
real liberada pelos dispositivos, foi necessária a correção das concentrações obtidas na análise por HPLC.

A concentração de resveratrol em $\mathrm{mg} / \mathrm{mL}$ obtida no ensaio em HPLC foi multiplicada por $35 \mathrm{~mL}$, o valor encontrado corresponde à concentração total liberada e à este valor foi somada a quantidade obtida em $1 \mathrm{~mL}$ da coleta anterior.

Como pode ser observado nas FIG. 40 e 41, os dispositivos obtidos por incorporação indireta, apresentaram capacidade de liberar o princípio ativo. 0 perfil de liberação foi semelhante, apresentando liberação em todas as horas analisadas. A porcentagem de liberação em relação à quantidade total de resveratrol incorporada foi de aproximadamente 21,4 e 21,9\% para os dispositivos PVP-PEG-RES e PVP-GLI-RES, respectivamente.

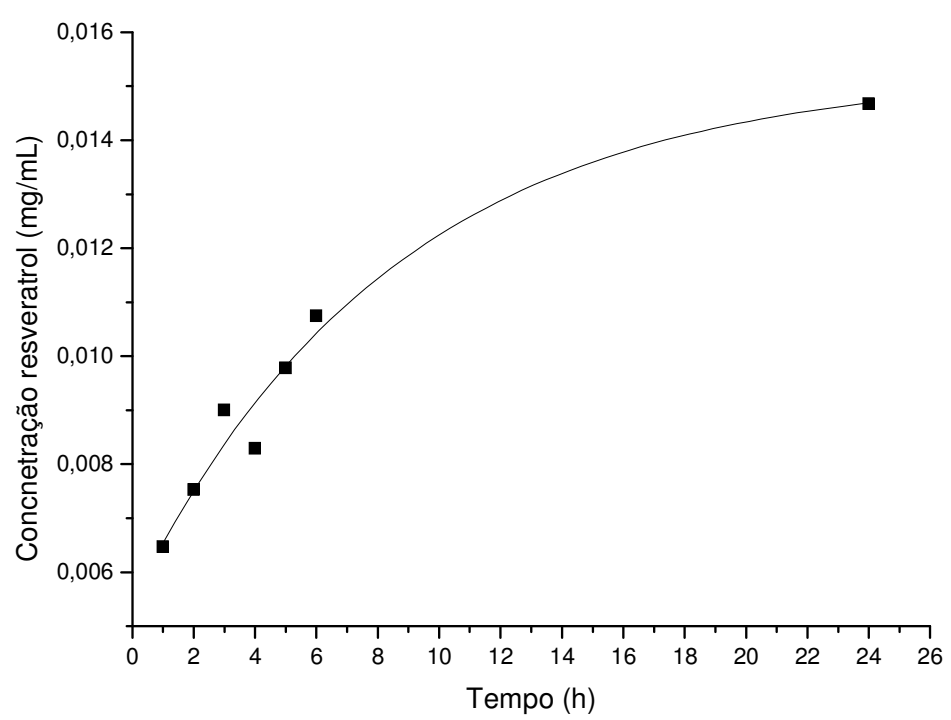

FIGURA 40 - Perfil de liberação do resveratrol do dispositivo PVP-PEG-RES 


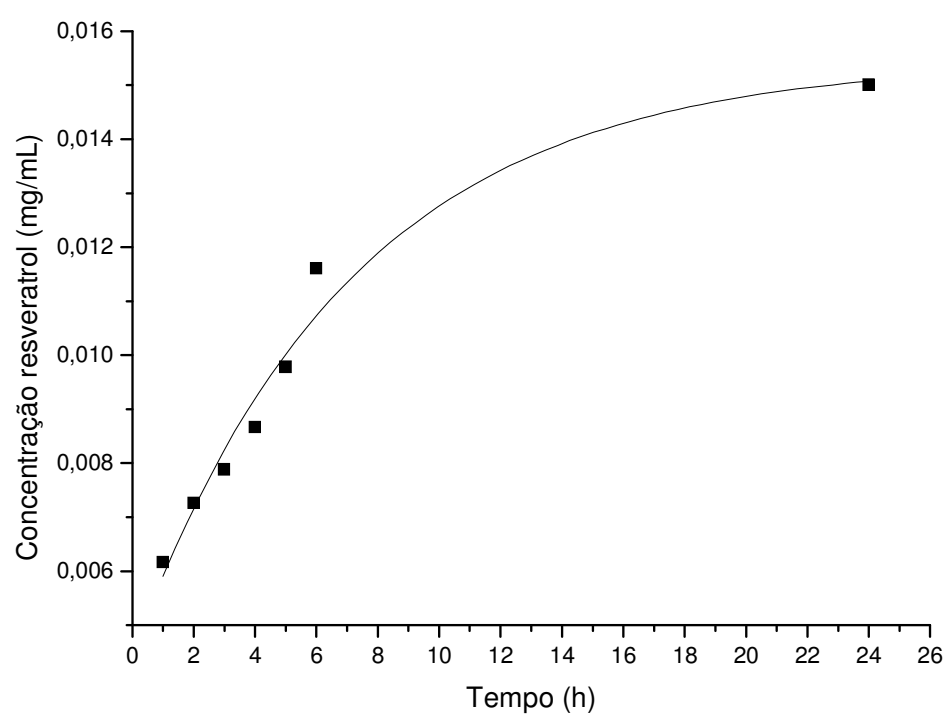

FIGURA 41 - Perfil de liberação do resveratrol do dispositivo PVP-GLI-RES

\subsubsection{Capacidade antioxidante do resveratrol liberado}

A capacidade antioxidante do resveratrol liberado dos dispositivos PVP-PEG-RES e PVP-GLI-RES foi verificada por meio de sua capacidade de captar radicais livres.

Conforme apresentado na TAB. 16 podemos observar que o resveratrol liberado apresentou capacidade de captar o DPPH e que após 210 minutos a porcentagem de DPPH remanescente foi semelhante para os dois dispositivos, uma vez que as porcentagens de resveratrol liberado também foram próximas, conforme apresentado no item 5.6.2. 
TABELA 16 - Resultados de DPPH remanescente para o resveratrol liberado dos dispositivos PVP-PEG-RES e PVP-GLI-RES

\begin{tabular}{|c|c|c|}
\hline \multirow{2}{*}{ Tempo } & \multicolumn{2}{|c|}{ DPPH Remanescente (\%) } \\
\hline & PVP-PEG-RES & PVP-GLI-RES \\
\hline 0 & 100 & 100,00 \\
\hline 1 & 95 & 96 \\
\hline 10 & 94 & 95 \\
\hline 20 & 93 & 94 \\
\hline 30 & 93 & 94 \\
\hline 40 & 92 & 94 \\
\hline 50 & 92 & 93 \\
\hline 60 & 92 & 93 \\
\hline 70 & 91 & 93 \\
\hline 80 & 91 & 93 \\
\hline 90 & 91 & 93 \\
\hline 100 & 91 & 92 \\
\hline 110 & 91 & 92 \\
\hline 120 & 90 & 92 \\
\hline 130 & 90 & 92 \\
\hline 140 & 90 & 92 \\
\hline 150 & 90 & 92 \\
\hline 160 & 90 & 91 \\
\hline 170 & 90 & 91 \\
\hline 180 & 90 & 91 \\
\hline 190 & 89 & 91 \\
\hline 200 & 89 & 91 \\
\hline 210 & 89 & 91 \\
\hline
\end{tabular}

Após 210 minutos de reação não foi possível observar um platô, ou seja, o resveratrol ainda apresentava capacidade antioxidante após este período, mas a reação acontecia lentamente.

As porcentagens de DPPH remanescente obtidas para o resveratrol liberado dos dispositivos PVP-PEG-RES e PVP-GLI-RES foram muito próximas, 
aproximadamente $89 \%$ e $91 \%$, respectivamente, indicando que o resveratrol apresentava capacidade antioxidante após liberação.

\subsection{Análise dos dispositivos obtidos por método direto}

Por meio das análises de HPLC apresentadas no item 5.6.2, podemos observar que os dispositivos obtidos por método direto não apresentaram capacidade de liberar o resveratrol incorporado, sugerindo que o resveratrol ficou retido no dispositivo ou que sofreu degradação como observado em solução irradiada.

Conforme apresentado nas FIG. 42 e 43, a análise da superfície permitiu observar a presença de grânulos de resveratrol nas paredes dos dispositivos. Provavelmente devido à baixa solubilidade em água, o resveratrol encontra-se na forma de aglomerados aderidos ao material polimérico, o que dificulta sua liberação pelo dispositivo.

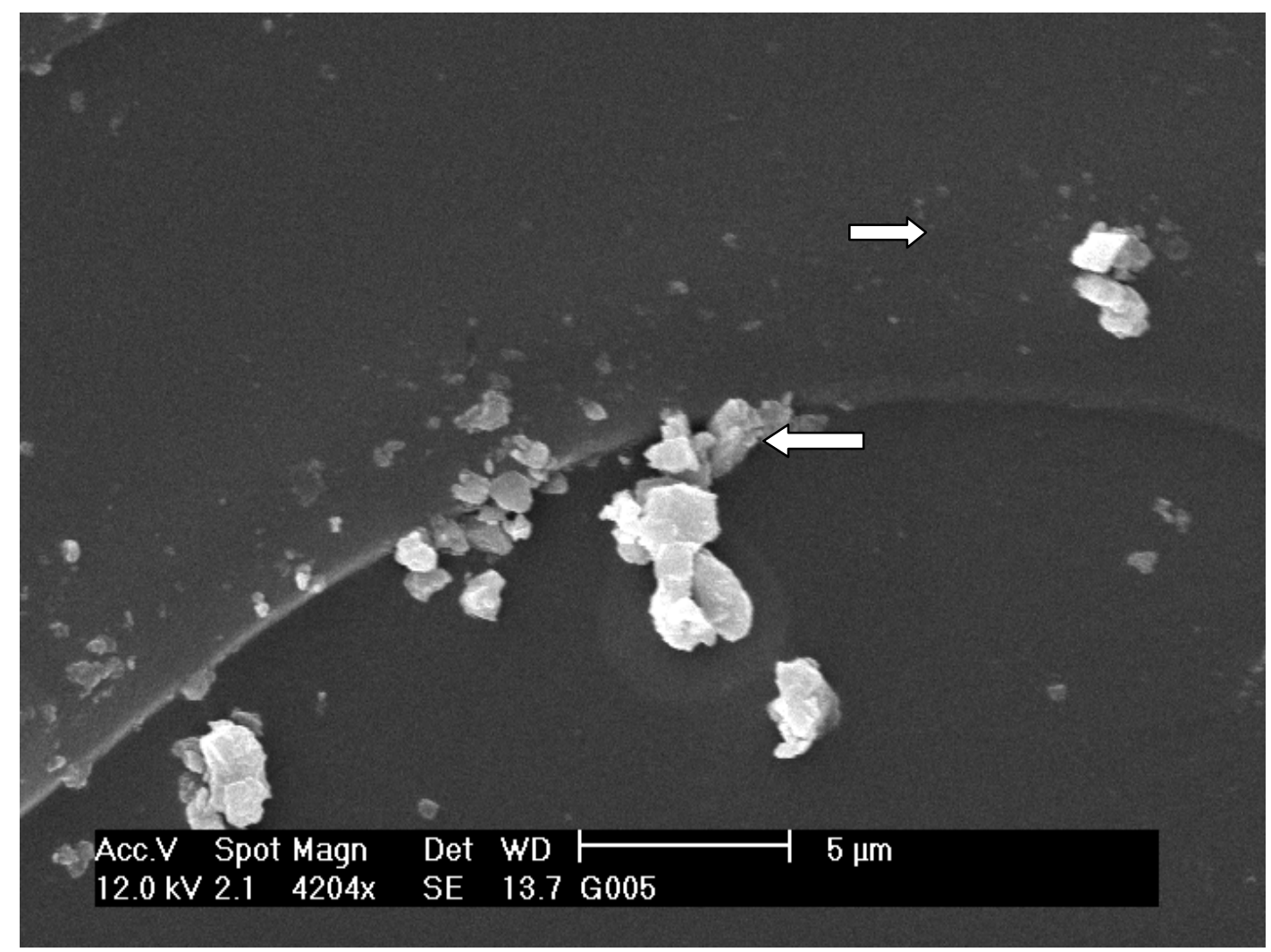

FIGURA 42 - Micrografia obtida por MEV: Presença de resveratrol no dispositivo GLI-RES 0,05 antes de ser submetido ao ensaio de liberação 


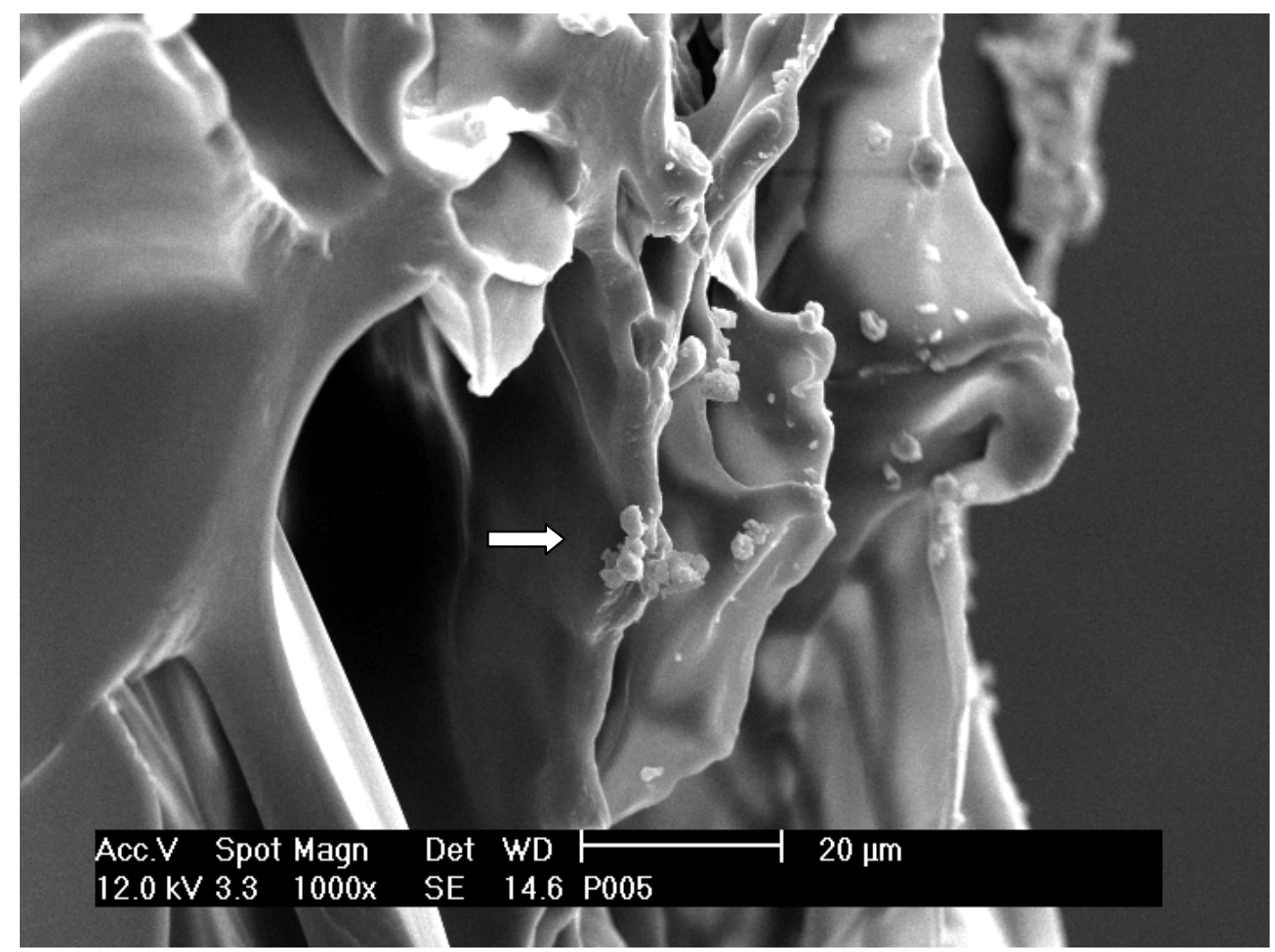

FIGURA 43 - Micrografia obtida por MEV: Presença de resveratrol no dispositivo PVP-RES 0,05 antes de ser submetido ao ensaio de liberação

Conforme apresentado nas FIG. 44 e 45, é possível observar em ambos dispositivos a presença de cavidades, que são maiores e estão em menor quantidade no dispositivo GLI-RES 0,05. A formação de cavidades (FIG. 46 e 47) permitiria que o resveratrol incorporado fosse liberado, no entanto a presença de resveratrol em forma de aglomerados aderidos ao material polimérico pode ter dificultado a liberação do mesmo. 


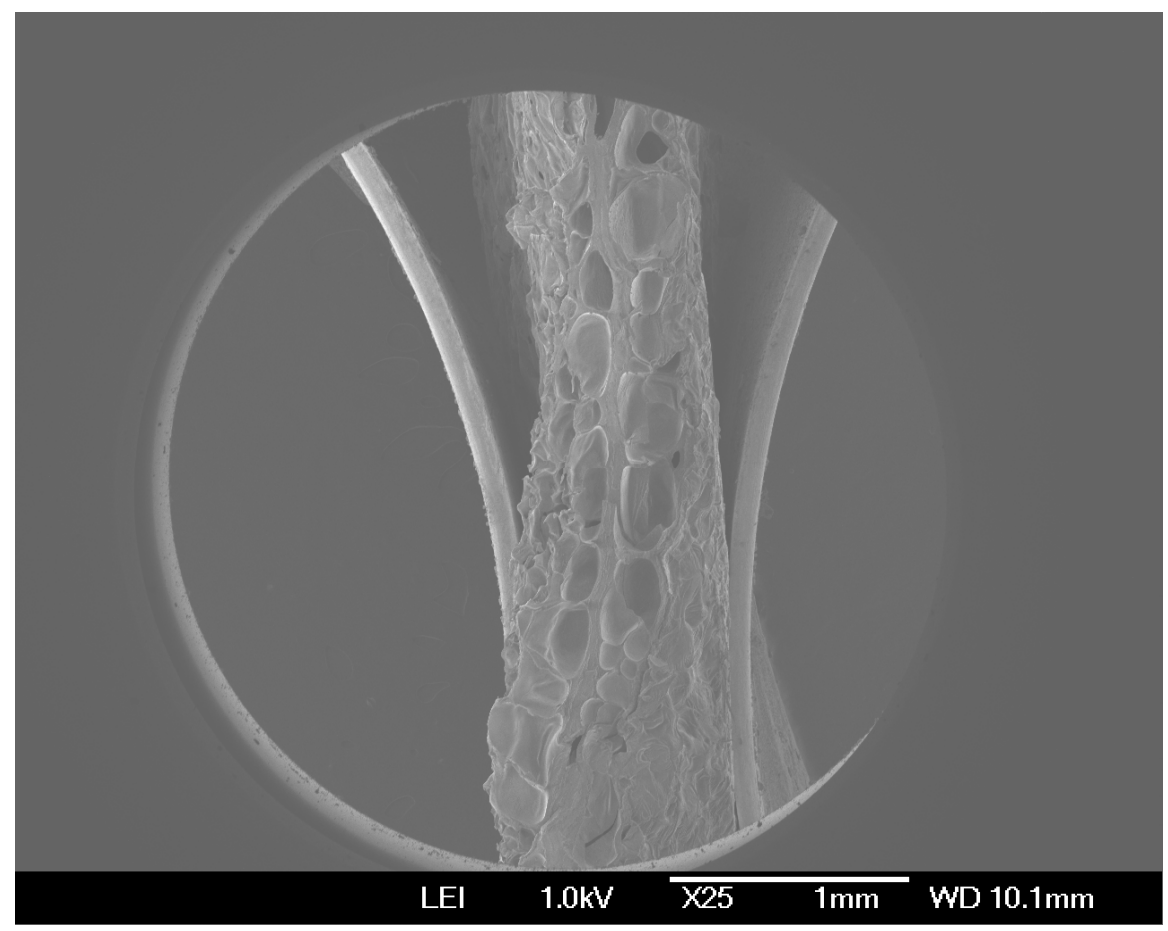

FIGURA 44 - Micrografia obtida por MEV: Dispositivo GLI-RES 0,05 após ser submetido ao ensaio de liberação

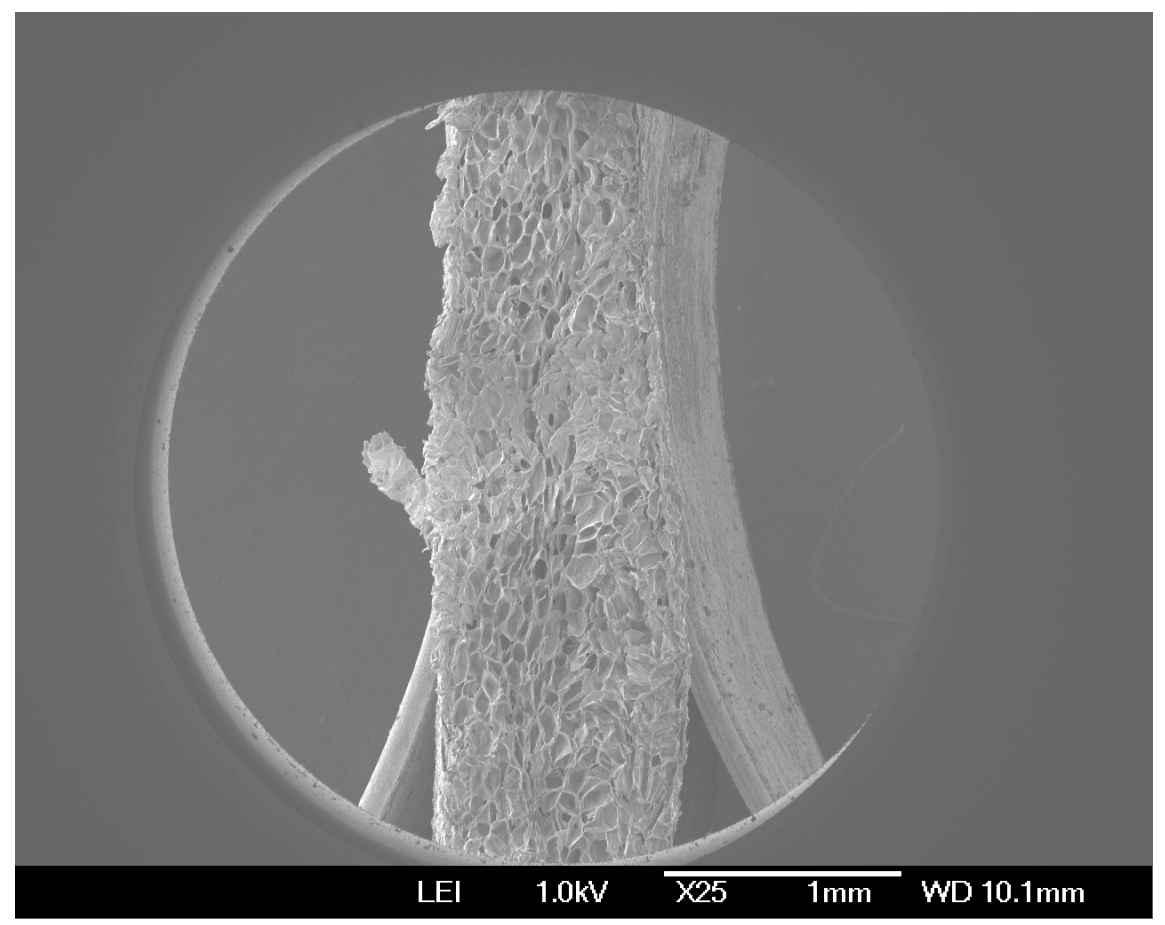

FIGURA 45 - Micrografia obtida por MEV: Dispositivo PVP-RES 0,05 após ser submetido ao ensaio de liberação 


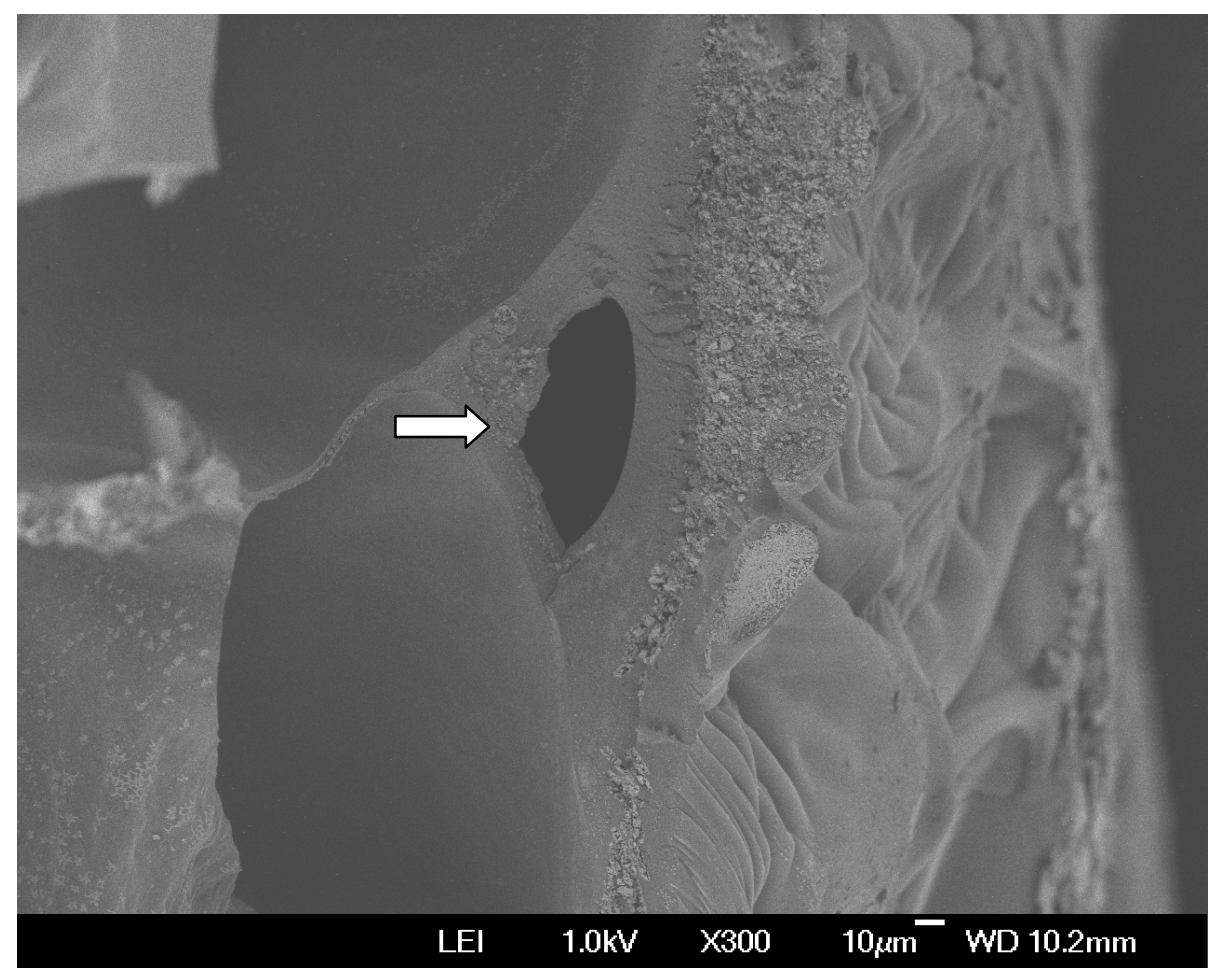

FIGURA 46 - Micrografia obtida por MEV: Presença de cavidade no dispositivo GLI-RES 0,05 após ser submetido ao ensaio de liberação

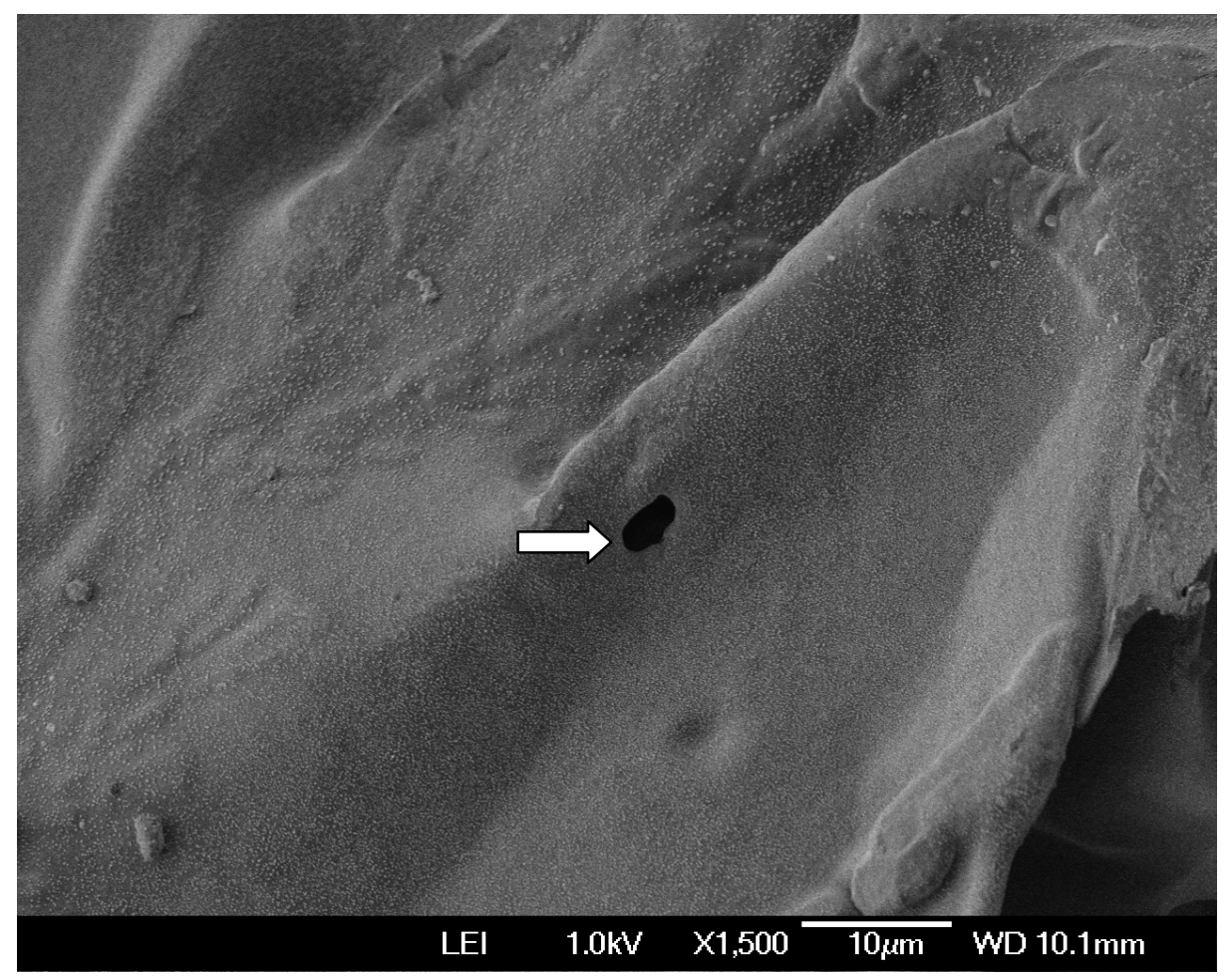

FIGURA 47 - Micrografia obtida por MEV: Presença de cavidade no dispositivo PVP-RES 0,05 após ser submetido ao ensaio de liberação 
Por meio dos espectros de massas das alíquotas coletadas no ensaio de liberação dos dispositivos PVP-RES 0,05 e GLI-RES 0,05 apresentados nas FIG. 48 e 49, respectivamente não foi possível verificar a presença do resveratrol, confirmando que não houve liberação do mesmo. No entanto, verificamos a presença de compostos com massas diferentes da massa do resveratrol, sugerindo que ambos dispositivos apresentam capacidade de liberar o resveratrol incorporado, mas que o mesmo encontra-se degradado em função da exposição à radiação ionizante.
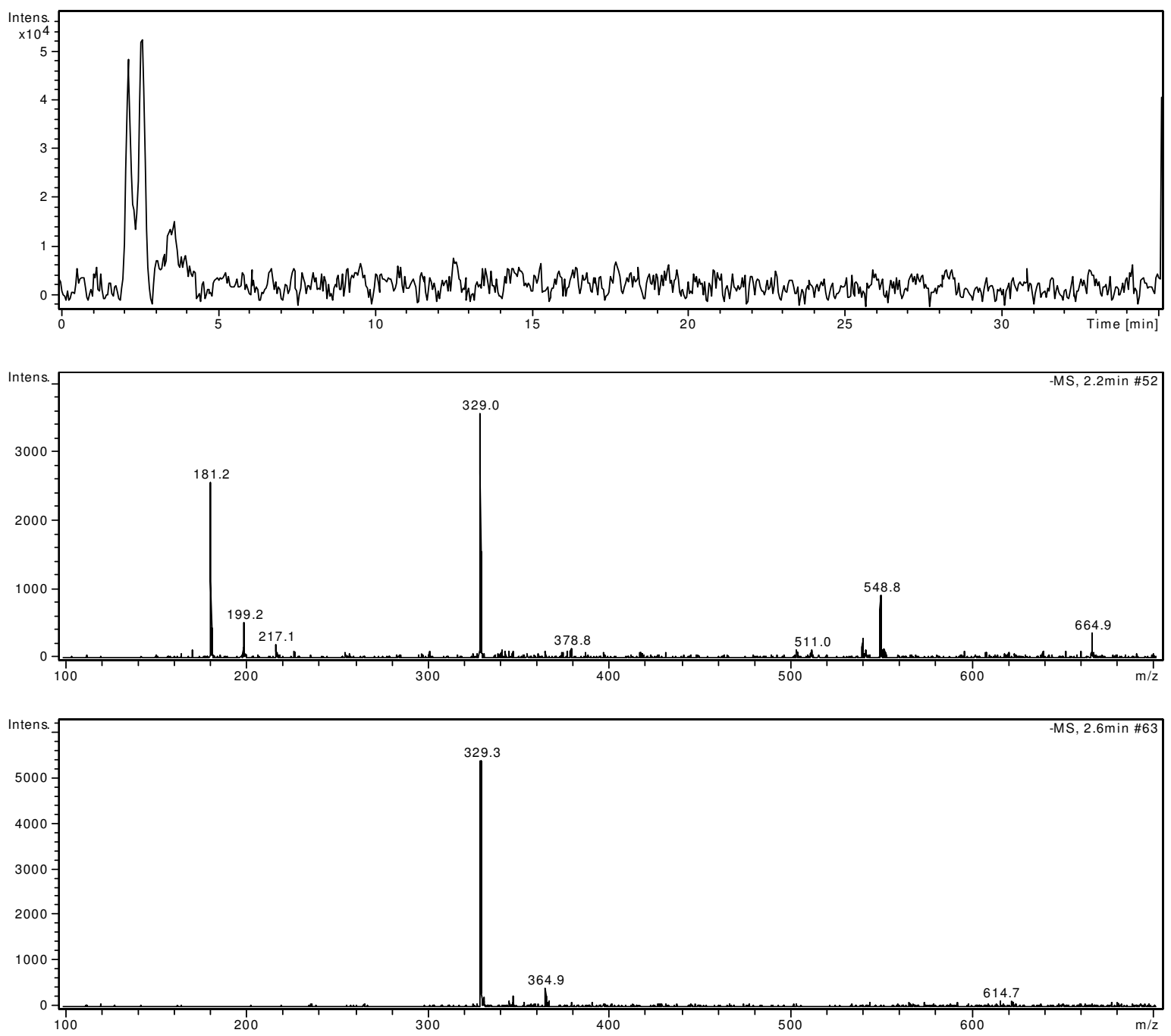

FIGURA 48 - Espectros de massas da alíquota coletada do dispositivo GLI-RES 0,05 

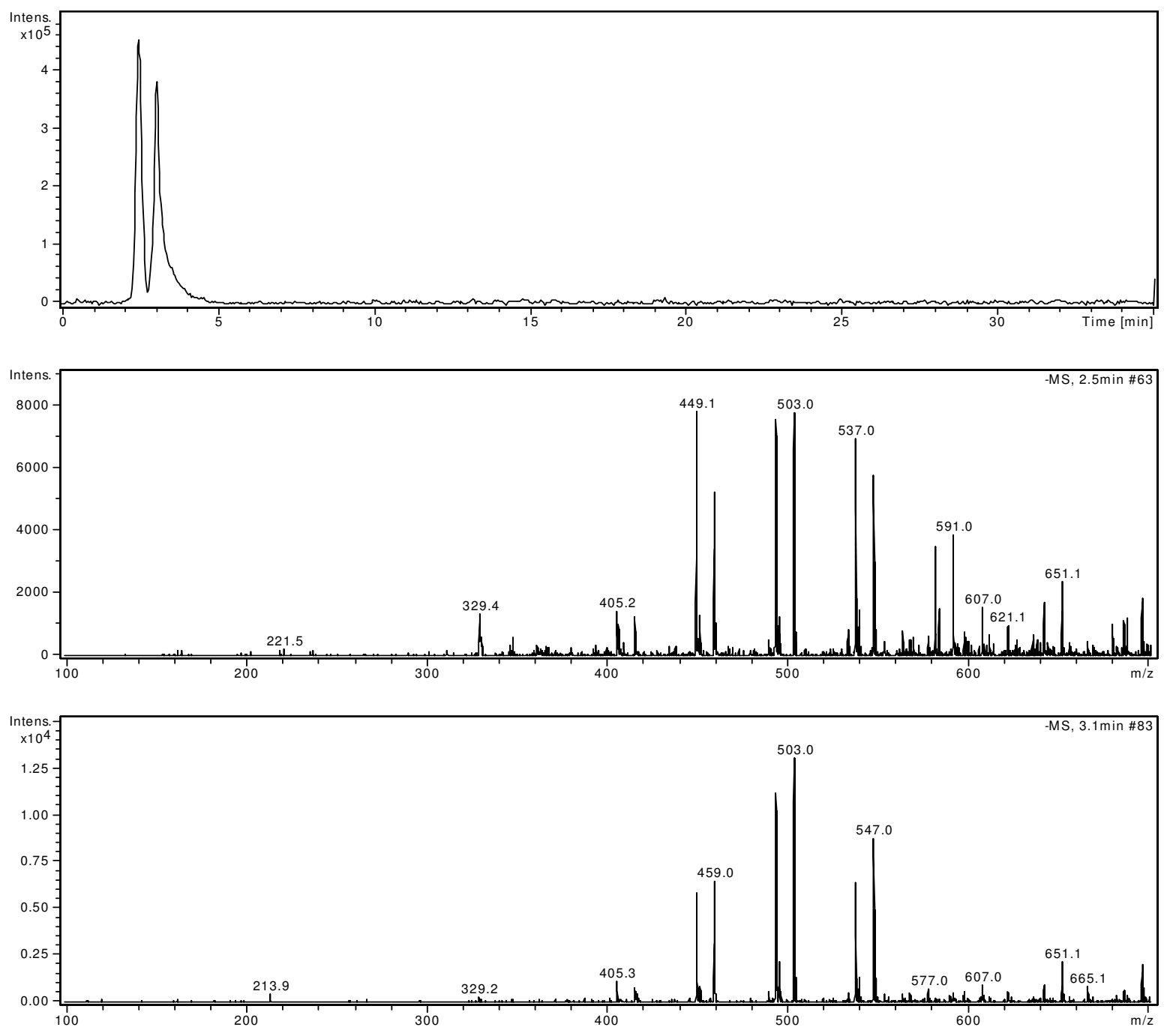

FIGURA 49 - Espectros de massas da alíquota coletada do dispositivo PVP-RES 0,05

Conforme apresentado nas FIG. 48 e 49, todos os produtos de degradação que são formados pela exposição do resveratrol à radiação ionizante e liberados pelos dispositivos foram identificados antes dos 5 minutos, assim como observado na solução de resveratrol irradiada a 20 kGy, apresentado na FIG. 23.

As massas dos compostos de degradação liberados pelos dispositivos não correspondem às massas identificadas no espectro da solução irradiada a 20 kGy. No entanto, comparando-se o espectro de liberação do dispositivo GLI-RES 0,05 com o espectro de uma solução de resveratrol irradiada a 600 Gy, apresentado na FIG. 50, verificamos a presença de compostos com a mesma 
massa (329.3), sugerindo que os componentes da membrana podem ter protegido o resveratrol da radiação.
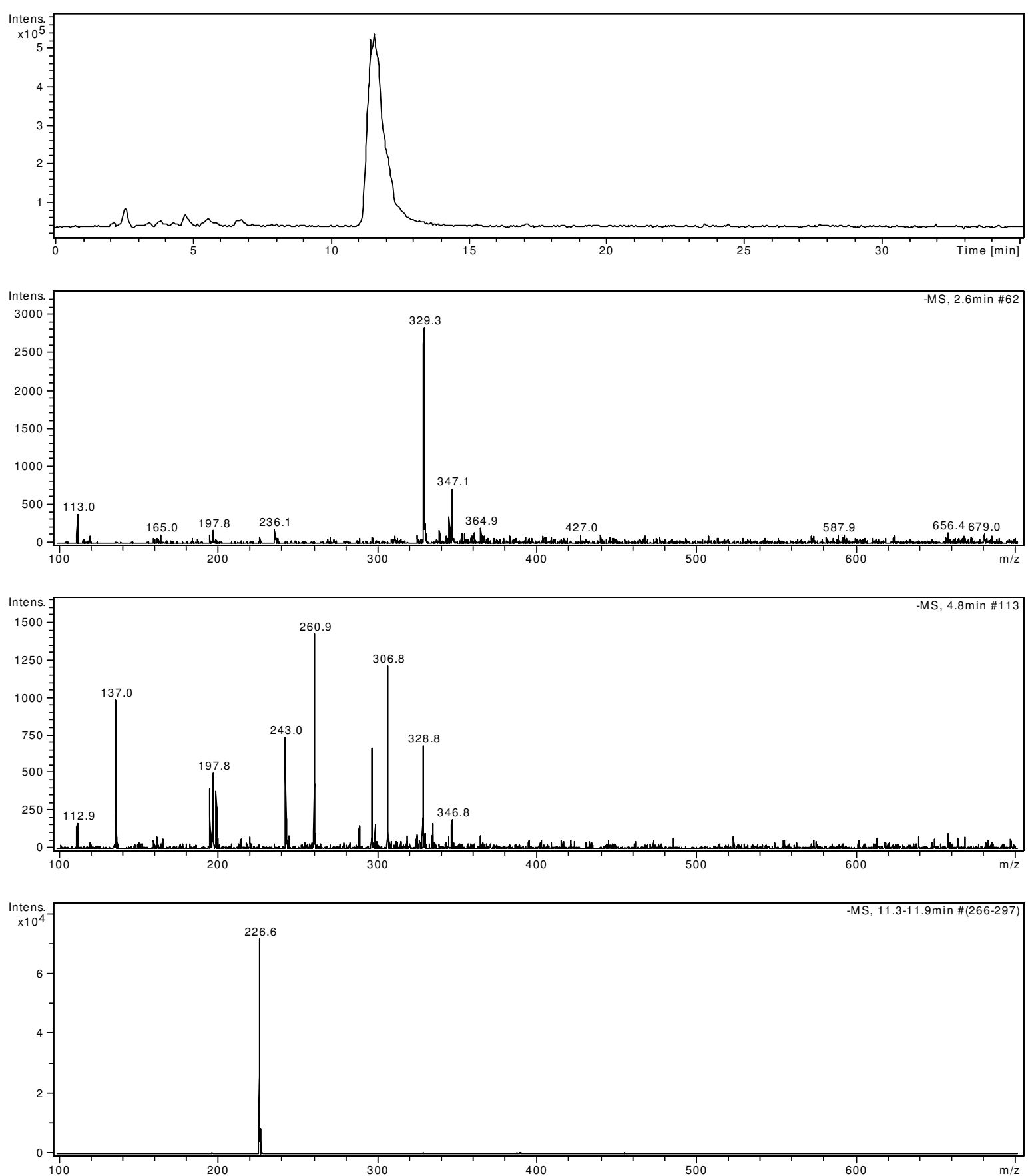

FIGURA 50 - Espectro de massas da solução de resveratrol irradiada a 600 Gy

Desta forma, a visualização da superfície do dispositivo por MEV e a análise das alíquotas de liberação por espectrometria de massas sugerem que uma fração do resveratrol incorporado ficou aderida à parede do dispositivo e não 
conseguiu ser liberada enquanto outra foi liberada pelo dispositivo, mas encontrase degradada em função da exposição à radiação ionizante, explicando a ausência de liberação de resveratrol pelos dispositivos obtidos por método direto, observada nos cromatogramas das análises de HPLC. 


\section{CONCLUSÕES}

Por meio dos resultados obtidos pode-se observar que as matrizes poliméricas se mostraram adequadas para incorporação de resveratrol. A adição de $2 \%$ de álcool não alterou as características físico-químicas apresentadas pelas matrizes poliméricas, que permaneceram adequadas ao manuseio e para incorporação de resveratrol. O mesmo não foi observado após adição de $4 \%$ de álcool, pois as matrizes obtidas não apresentaram propriedades mecânicas adequadas ao manuseio, perdendo sua forma durante a manipulação.

Apesar da baixa solubilidade do resveratrol em água, foi possível incorporar o resveratrol pelo método direto, obtendo-se dispositivos com características semelhantes às das matrizes poliméricas. No entanto, estes dispositivos não foram considerados adequados para compor um sistema de liberação de resveratrol, pois não apresentaram liberação do mesmo.

Os dispositivos obtidos pelo método indireto (PVP-PEG-RES e PVPGLI-RES) apresentaram capacidade semelhante em liberar o resveratrol e possibilitaram a liberação de aproximadamente $20 \%$ do resveratrol incorporado, que apresentou capacidade antioxidante após liberação.

Desta forma, os dispositivos obtidos pelo método indireto mostraram-se mais adequados para serem utilizados como sistema de liberação de resveratrol, uma vez que apresentaram propriedades visuais e táteis adequadas e mostraram capacidade de liberar parte do resveratrol incorporado. 


\section{REFERÊNCIAS BIBLIOGRÁFICAS}

1 ADELMAN, R. C.; ROTER, G. S. Testing the theories of aging. Boca Raton: CRC press, 1982.

2 AFAQ, F.; ADHAMI, V. M.; AHMAD, N. Prevention of short-term ultraviolet B radiation-mediated damages by resveratrol in $\mathrm{SKH}-1$ hairless mice. Toxicology and Applied Pharmacology, v. 186, p. 28-37, 2003.

3 AJJI, Z.; OTHMAN, I.; ROSIAK, J.M. Production of hydrogel wound dressings using gamma radiation. Nuclear Instruments and Methods in Physics Research, Section B, v. 229, p. 375-380, 2005.

4 ALLEN JUNIOR, L. V.; POPOVICH, N. G.; ANSEL, H. C. Formas farmacêuticas e sistemas de liberação de fármacos. Porto Alegre: Artmed, 2007.

5 ALVES, A. O. Presença de trans-resveratrol em geléias de uva e sua relação com a radiação UV. 2006. Dissertação (Mestrado) - Universidade Federal de Santa Maria, Santa Maria, p. 35.

6 AMERICAN SOCIETY FOR TESTING AND MATERIALS - ASTM D 570: Test method of test for water absorption of plastics, 1998.

7 AMERICAN SOCIETY FOR TESTING AND MATERIALS - ASTM D 2765: Standard test methods for determination of gel content and swell ratio of crosslinked ethylene plastics, 2006.

8 AMES, B. N.; SHIGENAGA, M. K.; HAGEN, T. M. Oxidants, antioxidants, and the degenerative diseases of aging. Proceedings of the National Academy of Sciences, v. 90, p. 7915-7922, 1993.

9 ATHAR, M.; BACK, J. H.; TANG, X.; KIM, K. H.; KOPELOVICH, L.; BICKERS, D. R.; KIM, A. L. Resveratrol: A review of preclinical studies for human cancer prevention. Toxicology and Applied Pharmacology, v. 224, p. 274-283, 2007.

10 BADER, Y.; QUINT, R. M.; GETOFF, N. Resveratrol products resulting by free radical attack. Radiation Physics and Chemistry, v. 77, p. 708-712, 2008.

11 BALIGA, M. S.; KATIYAR, S. K. Chemoprevention of photocarcinogenesis by selected dietary botanicals. Photochemistry Photobiology Science, v. 5, p. 243-253, 2006. 
12 BAUMANN, L. Dermatologia cosmética: princípios e prática. Rio de Janeiro: Revinter, 2004.

13 BAUR, J. A.; SINCLAIR, D. A. Therapeutic potential of resveratrol: the in vivo evidence. Nature drug discovery, v. 5, p. 493-506, 2006.

14 BETTERIDGE, D. J. What is oxidative stress? Metabolism, v. 49, n. 2, p. 3-8, 2000.

15 BHAT, K. P. L.; PEZZUTO, J. M. Cancer Chemopreventive activity of resveratrol. Annals of the New York Academy of Science, v. 957, p. 210229, 2002.

16 BLOKHINA, O.; VIROLAINEN, E.; FAGERSTEDT, K.V. Antioxidants, Oxidative damage and oxygen deprivation stress: a review. Annals of Botany Company, v. 91, p. 179-194, 2003.

17 BOOCOCK, D. J.; FAUST, G. E. S.; PATEL, K. R.; SCHINAS, A. M.; BROWN, V. A.; DUCHARME, M. P.; BOOTH, T. D.; CROWELL, J. A.; PERLOFF, M.; GESCHER, A. J.; STEWARS, W. P.; BRENNER, D. E. Phase I dose escalation pharmacokinetic study in healthy volunteers of resveratrol, a potential cancer chemopreventive agent. Cancer Epidemology, Biomarkers \& Prevention, v. 16, n. 6, p. 1246-1252, 2007.

18 BOVEY, F. A. The effects of ionizing radiation on natural and synthetic high polymers. New York, N. Y.: Interscience, 1958.

19 BRAND-WILLIANS, W.; CUVELIER, M. E.; BERSET, C. Use of free radical method to evaluate antioxidant activity. Lebensm-Wiss u Technology, v. 28, p. 25-30, 1995.

20 CAMONT,L.; COTTART, C.H., RHAYEM, Y.; NIVET-ANTOINE, V.; DJELIDI, R.; COLLIN, F.; BEAUDEUX, J. L.; BONNEFONT-ROUSSELOT, D. Simple spectrophotometric assessment of the trans-/cis-resveratrol ratio in aqueous solution. Analytica Chimica Acta, v. 634, p. 121-128, 2009.

21 CUNHA, F. M. Câncer de pele: Melanoma. In: MURAD, A. M.; KATZ, A. (Ed.). Oncologia bases clínicas do tratamento. Rio de Janeiro: Guanabara Koogan, 1996. p. 274-279.

22 COCHRAN, A. J.; GLASPY, J. A.; RIBAS, A.; ECONOMOU, J. E. Malignant melanoma of the skin. In: HASKELL, C. M. (Ed.). Cancer treatment. Estados Unidos, 2001. p. 1158-1161. 
23 D'ERRICO, G.; LELLIS, M. de; MANGIAPIA, G.; TEDESCHI, A.; ORTONA, O.; FUSCO, S.; BORZACCHIELLO, A.; AMBROSIO, L. Structural na mechanical properties of UV-photo-cross-linked poly( $N$-vinyl-2-pyrrolidone) hydrogels. Biomacromolecules, v. 9, p. 231-240, 2008.

24 DONG, Z. Molecular mechanism of the chemopreventive effect of resveratrol. Mutation research, p. 145-150, 2003.

25 DRAGANIC, I. G.; DRAGANIC, Z. D. The radiation chemistry of water. Nova lorque: Academic press, 1971.

26 EL-MOHDY, H. L. A., HEGAZY, E. S. A. Preparation of polyvinyl pirrolidonebased hydrogels by radiation induced crosslinking with potential application as wound dressing. Journal of macromolecular science, Part A: Pure and applied chemistry, v. 45, p. 995-1002, 2008.

27 FARHATAZIZ; RODGERS, M.A.J. Radiation chemistry: principles and applications. New York, N.Y.: VCH Publishers, 1987.

28 FLORY, P.J. Principles of Polymer Chemistry. NewYork, N.Y.: Cornell University Press, 1986.

29 FRÉMONT, L. Biological effects of resveratrol. Life Sciences, v. 66, n. 8, p. 663-673, 2000.

30 GATÉ, L.; PAUL, J.; BA, G. N.; TEW, K. D.; TAPIERO, H. Oxidative stress induced in pathologies: the role of antioxidants. Biomedicine \& Pharmacotherapy, v.53, p.169-180, 1999.

31 GEEVER, L. M.; COONEY, C. C.; LYONS, J. G.; KENNEDY, J. E.; NUGENT, M. J. D.; DEVERY, S.; HIGGINBOTHAM, C. L. Characterization and controlled drug release from novel drug-loaded hydrogels. European Journal of pharmaceutics and biopharmaceutics, v. 69, p. 1147-1159, 2008.

32 GOLDBERG, D. M.; YAN, J.; SOLEAS, G. J. Absorption of three wine-related polyphenols in three different matrices by healthy subjects. Clinical biochemistry, v. 36, p. 79-87, 2003.

33 GONZÁLEZ, S.; FERNÁNDEZ-LORENTE, M.; GILABERTE-CALZADA, Y. The latest on skin photoprotection. Clinics in Dermatology, v. 26, p. 614-626, 2008.

34 HALLIWELL, B. Reactive Species and Antioxidants. Redox Biology Is a Fundamental Theme of Aerobic Life. Plant physiology, v. 141, p. 312-322, 2006. 
35 HALLIWELL, B.; GUTTERIDGE, J. M. C. Free radicals in biology and medicine. 3. ed. New York: Oxford, 1999.

36 HAMID, M.; AZADI, A.; RAFIEI, P. Hydrogel nanoparticles in drug delivery. Advanced drug delivery reviews, v. 60, p. 1638-1649, 2008.

37 HARRIS, M. I. N. C. Pele: estrutura, propriedades e envelhecimento. 2. ed. São Paulo: Senac, 2003.

38 HELLER, J. Drug Delivery Systems. In: RATNER, B. D.; HOFFMAN, A. S.; SCHOEN, F. J.; LEMONS, J. E. (Ed) Biomaterials Science: an introduction to materials in medicine. San Diego: Academic Press, p.346-356, 1996.

39 HIGA, O. Z.; ROGERO, S. O.; MACHADO, L. D. B.; MATHOR, M. B.; LUGÃO, A. B. Biocompatibility study for PVP wound dressing obtained in different conditions. Radiation Physics and Chemistry, v. 55, p. 705-707, 1999.

40 HOFFMAN, A. S. Hydrogels for biomedical applications. Advanced drug delivery reviews, v. 43, p. 3-12, 2002.

41 HOLLER, F. J.; SKOOG, D. A.; CROUCH, S. R. Cromatografia líquida. In: Princípios de análise instrumental. 6. ed. Porto Alegre: Bookman, 2009. p.830841.

42 HUNG, C. F.; LIN, Y. K.; HUANG, Z. R.; FANG, J. Y. Delivery of resveratrol, a red wine polyphenol, from solutions and hydrogels via skin. Biological \& Pharmaceutical Bulletin, v. 31, n.5, p. 955-962, 2008.

43 INCA Instituto Nacional de Câncer. Disponível em: http://www.inca.gov.br/estimativa/2010/estimativa20091124.pdf. Acesso em: 23 nov. 2009.

44 ISO document 10993-5, Biological evaluation of medical devices, Part 5, Tests for cytotoxicity: in vitro methods, 1992.

45 JANG, M.; CAI, L.; UDEANI, G. O.; SLOWING, K. V.; THOMAS, C. F.; BEECHER, C. W. W.; FONG, H. H. S.; FARNSWORTH, N. R.; KINGHORN, A. D.; MEHTA, R. G.; MOON, R. C.; PEZZUTO, J. M. Cancer chemopreventive activity of resveratrol, a natural product derived from grapes. Science, v. 275, n. 5297, p. 218-220, 1997.

46 JUAN, M. E.; VINARDELL, M. P.; PLANAS, J. M. The daily oral administration of high doses of trans-Resveratrol to rats for 28 days is not harmful. The journal of nutrition, v. 132, p. 257-260, 2002. 
47 JUNQUEIRA, L. C.; CARNEIRO, J. Pele e Anexos. In: JUNQUEIRA, L. C.; CARNEIRO, J. Histologia Básica. Rio de Janeiro: Guanabara Koogan, 1999. p. 303-314.

48 KAUR, I. P.; KAPILA, M.; AGRAWAL, R. Role novel delivery systems in developing topical antioxidants as therapeutics to combat photoageing. Ageing research reviews, v. 6, p. 271-288, 2007.

49 KOHEN, R. Skin antioxidants: their role in aging and in oxidative stress - New approaches for their evaluation. Biomedicine \& Pharmacotherapy, v. 53, p. 181-192, 1999.

50 LARSON, R. A. Naturally occurring antioxidants. Boca Raton, FL: Lewis, 1997.

51 LAVERNE, J. A. OH radicals and oxidizing products in the gamma radiolysis of water. Radiation research. v. 153, p. 196-200, 2000.

52 LAZÁR, M.; RYCHLÝ, J.; KLIMO, V.; PELIKÁN, P.; VALKO, L. Free radical in chemistry and biology. Boca Raton, FL: CRC Press, 1989.

53 LEIRO, J.; ÁlVAREZ, E.; ARRANZ, J. A.; LAGUNA, R.; URIARTE, E.; ORALLO, F. Effects of cis-rasveratrol on inflammatory murine macrophages: antioxidant activity and down-regulation of inflammatory genes. Journal of leukocyte biology. v. 75, 2004.

54 LOPÉRGOLO, L. C.; LUGÃO, A. B.; CATALANI, L. H. Direct UV photocrosslinking of poly(N-vinyl-2-pyrrolidone) (PVP) to produce hydrogels. Polymer, v. 44, p. 6217-6222, 2003.

55 MACHADO-PINTO, J. Câncer de pele: epitelial. In: MURAD, A. M.; KATZ, A. (Ed.). Oncologia bases clínicas do tratamento. Rio de Janeiro: Guanabara Koogan, 1996. p. 271-274.

56 MAKRANTONAKI, E.; ZOUBOULIS, C. C. Skin alterations and diseases in advanced age. Drug Discovery Today: Disease Mechanisms, v. 5, n. 2, p. 153-162, 2008.

57 MARSILLAC, J. B.; REZENDE, J. F. N. Câncer da pele. In: MORAES, M. F. (Ed.). Princípios da Cirurgia Oncológica. São Paulo: Atheneu, 1996. p.3549.

58 MARTINEZ, J.; MORENO, J. J. Effect of resveratrol, a natural polyphenolic compound, on reactive oxygen species and prostaglandin production. Biochemical Pharmacology, v. 59, n.7, p. 865-870, 2000. 
59 MENG, X.; MALIAKAL, P.; LU, H.; LEE, M. J.; YANG, C.S. Urinary and plasma levels of resveratrol and quercetin in humans, mice, and rats after ingestion of pure compounds and grape juice. Journal of Agricultural and Food Chemistry, v. 52, n. 4, p. 935-942, 2004.

60 MIQUEL, J.; QUINTANILHA, A. T.; WEBER, H. Handbook of Free radicals and antioxidants in biomedicine. Flórida: $\mathrm{CRC}$, volume 2, editora:CRC press, p. 30-33, 1989.

61 MIRANDA, L. F.; LUGÃO, A. B.; MACHADO, L. D. B.; RAMANATHAN, L. V. Crosslinking and degradation of PVP hydrogels as a function of dose and PVP concentration. Radiation Physics and Chemistry, v. 55, p. 709-712, 1999.

62 MIYACHI, Y. Photoaging from an oxidative standpoint. Journal of Dermatological Science, v. 9, p. 79-86, 1995.

63 OPIE, L.H.; LECOUR, S. The red wine hypothesis: from concepts to protective signalling molecules. European Heart Journal, v. 28, n. 14, p. 1683-1693, 2007.

64 PEPPAS, N. A.; BURES, P.; LEOBANDUNG, W.; ICHIKAWA, H. Hydrogels in pharmaceutical formulations. European journal of pharmaceutics and biopharmaceutics, v. 50, p. 27-46, 2000.

65 PEPPAS, N. A. Hydrogels. In: RATNER, B. D.; HOFFMAN, A. S.; SCHOEN, F. J.; LEMONS, J. E. (Ed.) Biomaterials Science: an introduction to materials in medicine. San Diego: Academic Press, p.60-64, 1996.

66 PINNELL, S. R. Cutaneous photodamage, oxidative stress, and topical antioxidant protection. Journal of the American Academy Dermatology, v. 48, p. 1-19, 2003.

67 PUIZINA-IVIC, N. Skin aging. Acta Dermatoven APA, v. 17, n. 2, 2008.

68 RATNAM, D. V.; ANKOLA, D. D.; BHARDWAJ, V.; SAHANA, D.K.; KUMAR, M.N.V.R. Role of antioxidants in prophylaxis and therapy: A pharmaceutical perspective. Journal of controlled release, v. 113, p. 189-207, 2006.

69 RAZZAK, M.T.; DARWIS, D.; ZAINUDDIN, S. Irradiation of polyvinyl alcohol and polyvinyl pyrrolidone blended hydrogel for wound dressing. Radiation Physics and Chemistry, v. 62, p. 107-113, 2001. 
70 RHAYEM, Y.; THÉROND, P.; CAMONT, L.; COUTURIER, M.; BEAUDEUX, J. L.; LEGRAND, A.; JORE, D.; GARDÉS-ALBERT, M.; BONNEFONTROUSSELOT, B. Chain-breaking activity of resveratrol and piaceatannol in a linoleat micellar model. Chemistry and Physics of Lipids, v. 155, p. 48-56, 2008.

71 REAGAN-SHAW, S.; AFAQ, F.; AZIZ, M. H.; AHMAD, N. Modulations of critical cell cycle regulatory events during chemoprevention of ultraviolet B-mediated responses by resveratrol in $\mathrm{SKH}-1$ hairlessmouse skin. Oncogene, v. 23, p. 5151-5160, 2004.

72 REICHMANIS, E.; O'DONNELL, J.H. The effects of radiation on hightechnology polymers. Washington: American Chemical Society, 1989.

73 ROGERO, S.O.; MALMONGE, S.M.; LUGÃO, A.B.; IKEDA, T.I.; CRUZ, A.S. Biocompatibility study of polymeric biomaterials. Artificial Organs, v. 27, n. 5, p. 424-427, 2003.

74 ROSIAK, J.; RUCINSKA-RYBUS A.; PEKALA W. (1989) Method of Manufacturing of Hydrogel Dressings. Patent U.S.A. No. 4, 871,490.

75 ROSIAK, J. M.; ULANSKI, P.; PAJEWSKI, L. A.; YOSHH, F.; MAKUUCHI, K. Radiation formation of hydrogels for biomedical purposes. Some remarks and comments. Radiation Physics and Chemistry, v. 46, n. 2, p. 161-168, 1995.

76 ROSIAK, J. M.; ULANSKI, P. Synthesis of hydrogels by irradiation of polymers in aqueous solution. Radiation Physics and Chemistry, v. 55, p. 139-151, 1999.

77 ROSIAK, J.M. Hydrogel Dressings. In: CLOUGH, R.C; SHALAB, S.W. Radiation Effects on Polymers. Washington: American Chemical Society, 1991.

78 SATISH, C. S.; SATISH, K. P.; SHIVAKUMAR, H. G. Hydrogels as controlled drug delivery systems: synthesis, crosslinking, water and drug transport mechanism. Indian Journal of Pharmaceutical Sciences, v. 68, n. 2, p. 133140, 2006.

79 SCHNABEL, W. Polymer degradation, principles and practical applications. Munich: Hanser International, 1981.

80 SEM, M., GUVEN, O. Radiation synthesis of poly(N-vinyl-2-pyrrolidone/itaconic acid) hydrogels and their controlled release behaviours. Radiation Physics and Chemistry, v.55, p.113-120, 1999. 
81 SGAMBATO, A.; ARDITO, R.; FARAGLIA, B.; BONINSEGNA, A.; WOLF, F. I.; CITTADINI, A. Resveratrol a natural chemopreventive agent against degenerative diseases. Mutation Research, v. 496, p. 171-180, 2001.

82 SIES, H. Strategies of antioxidant defense. European Journal of Biochemistry, v. 215, p. 213-219, 1993.

83 SINGH, A. Chemical and biochemical aspects of activated oxygen: singlet oxygen, superoxide anion and related species. In: MIQUEL, J.; QUINTANILHA, A. T.; WEBER, H. (Ed.) Handbook of free radicals and antioxidants in biomedicine. Boca Raton, FL: CRC, 1989. v. 1 p. 17-24.

84 SOLEAS, G. J.; GRASS, L.; JOSEPHY, P. D.; GOLDBERG, D. M.; DIAMANDS, E. P. A comparasion of the anticarcinogenic properties of four red wine polyphenols. Clinical biochemistry, v. 35, p. 119-124, 2002.

85 SOUSA, M. A. J.; VARGAS, T. J. S. Anatomia, Fisiologia e Histologia da pele. In: KEDE, M. P. V.; SABATOVICH, O. (Ed.). Dermatologia estética. São Paulo: Atheneu, 2004. p. 3-8.

86 SOUTO, A. A.; CARNEIRO, M. C.; SEFERIN, M.; SENNA, M. J. H.; CONZ, A.; GOBBI, K. Determination of trans-resveratrol concentrations in Brazilian red wines by HPLC. Journal of Food Composition and Analysis, v. 14, p. 441445, 2001.

87 SPINKS, J.W.T.; WOODS, R.J. An introduction to radiation chemistry. 3.ed. New York, N.Y.: John Wiley \& Sons, 1990.

88 STEENVOORDEN, D. P. T.; HENEGOUWEN, G. M. J. B. van The use of endogenous antioxidants to improve photoprotection. Journal of Photochemistry and Photobiology, v. 41, p. 1-10, 1997.

89 STIVALA, L. A.; SAVIO, M.; CARAFOLI, F.; PERUCCA, P.; BIANCHI, L.; MAGA, G.; FORTI, L.; PAGNONI, U. M.; ALBINI, A.; PROSPERI, E.; VANNINI, V. Specific structural determinants are responsible for the antioxidant activity and the cell cycle effects of resveratrol. The journal of biological chemistry, v. 276, n. 25, p. 22586-22594, 2001.

90 STOJANOVIC, S.; SPRINZ, H.; BREDE, O. Efficiency and mechanism of the antioxidant action of trans-resveratrol and its analogues in the radical liposome oxidation. Archives of biochemistry and biophysics, v. 391, n. 1, p. 79-89, 2001. 
91 SUN, A. Y.; SIMONYL, A.; SUN, G. Y. The "French Paradox" and beyond: neuroprotective effects of polyphenols. Free Radical Biology \& Medicine, v. 32, n. 4, p. 314-318, 2002.

92 THOMAS, M. J. The role of free radicals and antioxidants. Nutrition, v. 16, n. 7/8, p. 716-718, 2000.

93 TRELA, B. C.; WATERHOUSE, A. L. Resveratrol: isomeric molar absorptivities and stability. Journal of agricultural and food chemistry, v. 44, p. 12531257, 1996.

94 UDENIGWE, C. C.; RAMPRASATH, V. R.; ALUKO, R. E.; JONES, P. J. H. Potential of resveratrol in anticancer and anti-inflammatory therapy. Nutrition reviews, v. 66, n. 8, p. 445-454, 2008.

95 VALKO, M.; LEIBFRITZ, D.; MONCOL, J.; CRONIN, M.T.D.; MAZUR, M.; TELSER, J. Free radicals and antioxidants in normal physiological functions and human disease. The International Journal of Biochemistry \& Cell Biology, v. 39, p. 44-84, 2007.

96 VITRAC, X.; DESMOULIÈRE, A.; BROUILLAUD, B.; KRISA, S.; DEFFIEUX, G.; BARTHE, N.; ROSENBAUM, J.; MÉRILLON, J. M. Distribution of $\left[{ }^{14} \mathrm{C}\right]-$ trans-resveratrol, a cancer chemopreventive polyphenol, in mouse tissues after oral administration. Life Sciences, v. 72, p. 2219-2233, 2003.

97 ZIANI, K.; OSES, J.; COMA, V.; MATÉ, J. I. Effect of the presence of glycerol and Tween 20 on the chemical and physical properties of films based on chitosan with different degree of deacetylation. Food science and technology, v. 41, p. 2159-2165, 2008.

98 WALLE, T.; HSIEH, F.; DELEGGE, M. H.; OATIS, J. E.; WALLE, U. K. High absorption but very low bioavailability of oral resveratrol in humans. Drug metabolism and disposition, v. 32, n. 12, p. 1377-1382, 2004.

99 WANG, Z.; HUANG, Y.; ZOU, J.; CAO, K.; XU, Y. Effects of red wine polyphenol resveratrol on platelet aggregation in vivo and in vitro. International journal of molecular medicine, v. 9, p. 77-79, 2002.

100 WILLIAMS, D.F. Definitions in biomaterials. In: Progress in Biomedical Enginering. March 3-5, 1986, Chester, England. Proceedings of a Concensus Conference of the European Society for Biomaterials. 
101 WOLFE, J. Nonmelanoma skin cancers: basal cell and squamous cell carcinoma. In: ABELOFF, M. D.; ARMITAGE, J. O.; LICHTER, A. S.; NIEDERHUBER, J. E. (Ed.). Clinical oncology. Philadelphia: Churchill livingstone, 2000. p. 1351-1359.

102 YOUNG, I. S.; WOODSIDE, J.V. Antioxidants in health and disease. Journal of Clinical Patholology, v. 54, p. 176-186, 2001. 